University of Rhode Island

DigitalCommons@URI

Open Access Dissertations

1983

\title{
Three-Dimensional Analysis of Turning Within Airborne Bird Flocks
}

Harold Pomeroy

University of Rhode Island

Follow this and additional works at: https://digitalcommons.uri.edu/oa_diss

Recommended Citation

Pomeroy, Harold, "Three-Dimensional Analysis of Turning Within Airborne Bird Flocks" (1983). Open Access Dissertations. Paper 385.

https://digitalcommons.uri.edu/oa_diss/385

This Dissertation is brought to you for free and open access by DigitalCommons@URI. It has been accepted for inclusion in Open Access Dissertations by an authorized administrator of DigitalCommons@URI. For more information, please contact digitalcommons-group@uri.edu. 


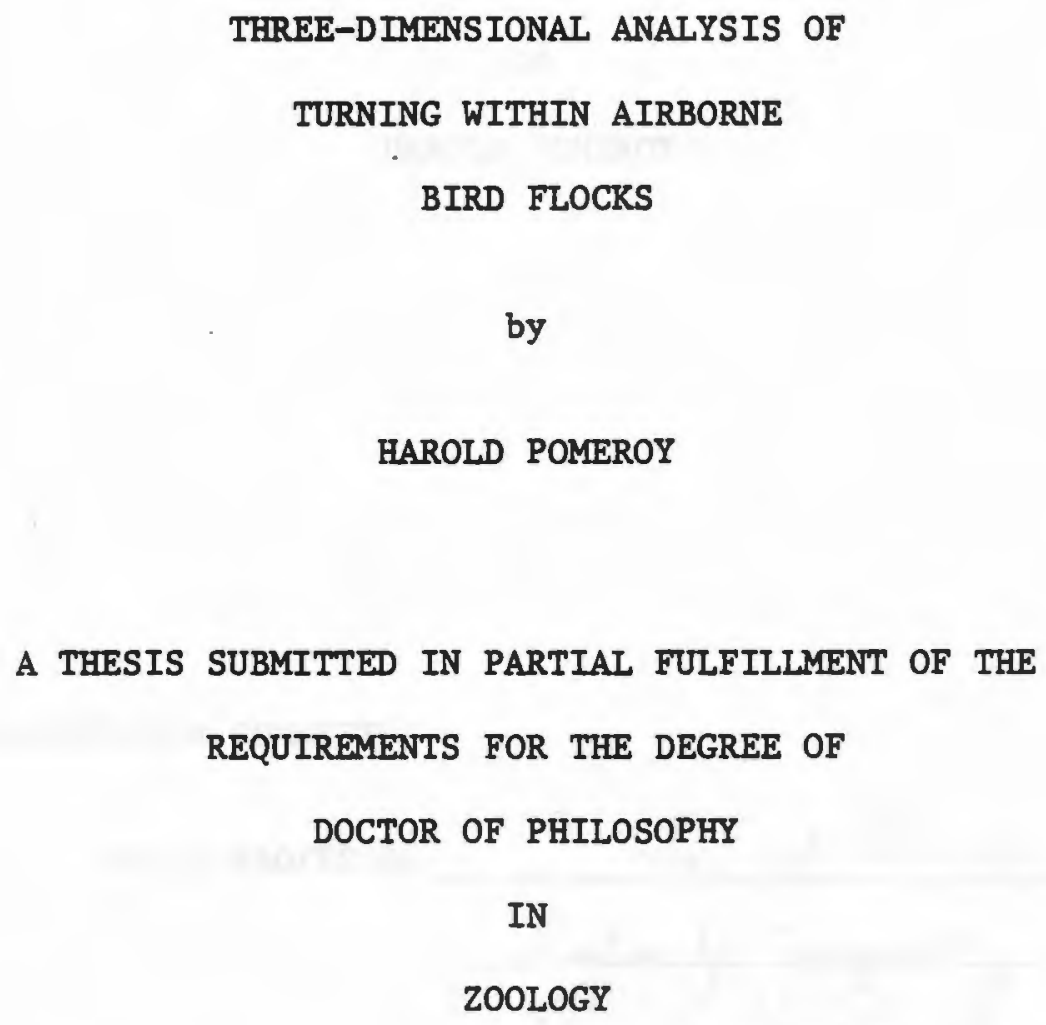

A THESIS SUBMITTED IN PARTIAL FULFILLMENT OF THE REQUIREMENTS FOR THE DEGREE OF DOCTOR OF PHILOSOPHY IN ZOOLOGY 
DOCTOR OF PHILOSOPHY DISSERTATION

OF

HAROLD POMEROY

\section{APPROVED:}

\section{DISSERTATION COMMITTEE}

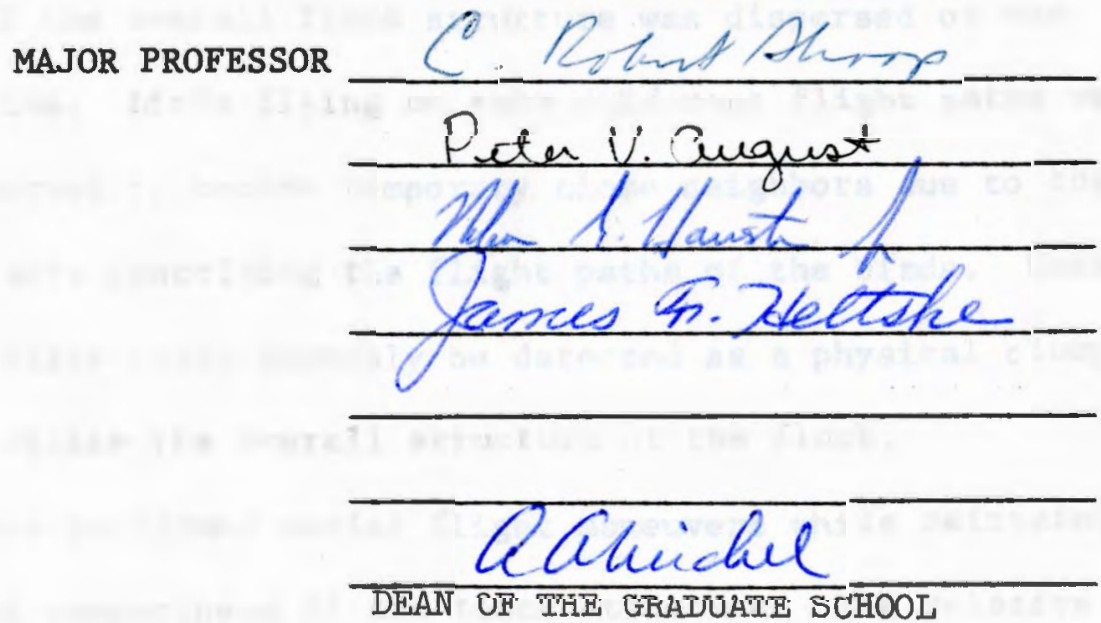

UNIVERSITY OF RHODE ISLAND

1983 


\section{ABSTRACT}

The three-dimensional structure of airborne pigeon flocks was monitored over time. Flocks changed both in overall shape, and in compactness during the execution of turns. Flight speeds of the flocks were sensitive to the vertical rather than the horizontal component of a turn. The compactness of flocks did not seem to change in relation to speed maintained during turns or sharpness of turns.

The cues to which birds responded in adjusting their flight paths may be important in determining flock compactness. Birds within flocks responded to each other's position and maintained positions close to each other. In a flock groups of birds which maintained positions close to each other were observed as a distinct physical clump of nearest neighbors only if the overall flock structure was dispersed or was expanding over time. Birds flying on very different flight paths were occasionally observed to become temporary close neighbors due to the crossing of the arcs describing the flight paths of the birds. Under such conditions birds could possibly be detected as a physical clump of close nelghbors within the overall structure of the flock.

Birds in flock performed aerlal flight maneuvers while maintaining or Increasing the compactness of the flock structure. The relative positions of birds within the flocks were not fixed. The repositioning of birds within the overall structure of turning and wheeling flocks Indicates that adaptive strategies for predator avoldance could be based on a bird's ability to easily reposition within a flock, rather than on the distinctly different advantages of maintaining a peripheral or central location within the flock. 
Behaviorally dominant and subordinate birds did not maintain specific positions within the airborne flocks. There was a tendency for birds of dissimilar dominance rank to be nearest neighbors within the airborne flocks. 


\section{ACKNOWLEDGMENTS}

Many individuals made significant contributions to this project. Dr. Frank Heppner provided financial assistance, technical training, and served as my mentor for the duration of the study. I would like to thank Dr. C. Robert Shoop for graciously taking over as my major professor during the absence of $\mathrm{Dr}$. Heppner. The members of my dissertation committee provided many helpful corments and insights, and worked in many ways to accommodate for the completion of the dissertation.

I would like also to thank the members of the laboratory in which I worked, Randy VanDrah, Geoff LeBaron, and Mary Harris-Tucker, for their assistance in the planning and execution of the experiments. Wilson Lamb and Roger Greenall provided highly technical assistance in the design and construction of experimental apparatus, and in the use of computer graphics for data analysis. My wife Jody worked on all aspects of the study, and provided much of the moral support and energy needed to continue the project. 
Acknowledgements................................ iv

Table of contents.............................. v v

List of figures............................... vi

List of tables............................... vili

Introduction $\ldots \ldots \ldots \ldots \ldots \ldots \ldots \ldots \ldots \ldots \ldots \ldots \ldots \ldots \ldots \ldots \ldots \ldots \ldots \ldots$

Materials and methods............................ 11

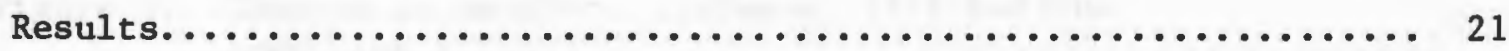

Discussion..................................... 32

Literature cited.............................. 43

Figures $1-22 \ldots \ldots \ldots \ldots \ldots \ldots \ldots \ldots \ldots \ldots \ldots \ldots \ldots \ldots \ldots \ldots \ldots \ldots \ldots \ldots$

Tables $1-2 \ldots \ldots \ldots \ldots \ldots \ldots \ldots \ldots \ldots \ldots \ldots \ldots \ldots \ldots \ldots \ldots \ldots \ldots \ldots \ldots \ldots$ Appendices

A. Bird identification and description............... 72

B. Film exposure synchrony...................... 73

c. Model flock............................... 74

D. Distances between birds....................... 75

E. Headings in horizontal and vertical planes........... 77

F. Dominance matrices......................... 81 


\section{LIST OF FIGURES}

Page

Figure 1. Geometry for position calculations..............48

Figure 2. Effect of flight path of flock on the relative positions of birds.........................49

Figure 3. Calculation of horizontal component

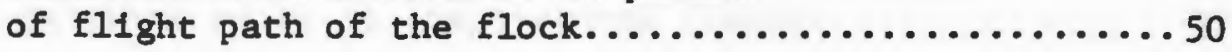

Figure 4. Summary of flock movements over time - Trial 7......51

Figure 5. Distance parameters for between-bird spacing - Trial 7.52

Figure 6. Changes in neighbor distance distributions

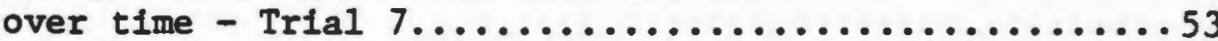

Figure 7. Positions of flock members relative to the direction

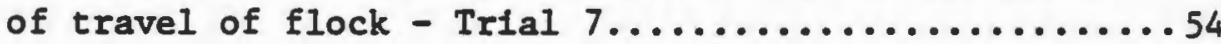

Figure 8. Spearman rank order correlations between front-to back sequence of birds in the flock - Trial 7.......55

Figure 9. Summary of flock movements over time - Trial $8 . \ldots \ldots . .56$

Figure 10. Distance parameters for between-bird spacing - Trial 8.57

Figure 11. Changes in neighbor distance distributions over

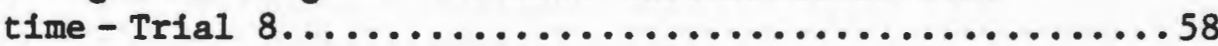

Figure 12. Positions of flock members relative to direction of travel of the flock $-\operatorname{Trlal} 8 \ldots \ldots \ldots \ldots \ldots \ldots . \ldots . \ldots . \ldots 59$

Figure 13. Spearman rank order correlations between front-toback sequence of birds in the flock - Trial 8........60

Figure 14. Summary of flock movements over time - Trial 2......61

Figure 15. Distance parameters for between-bird spacing - Trial 2.62

Figure 16. Changes in neighbor distance distributions over time -

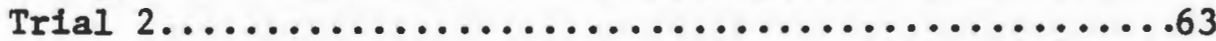

Figure 17. Positions of flock members relative to the direction of travel of the flock - Trial 2................64 
LIST OF FIGURES

Page

Figure 1. Geometry for position calculations..............48

F1gure 2. Effect of flight path of flock on the relative positions of birds............................. 49

Figure 3. Calculation of horizontal component

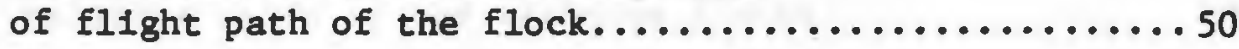

Figure 4. Summary of flock movements over time - Trial 7......51

Figure 5. Distance parameters for between-bird spacing - Trial 7.52

Figure 6. Changes in neighbor distance distributions

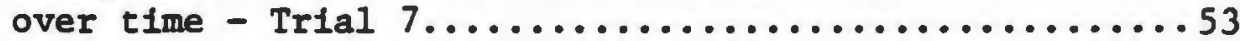

Figure 7. Positions of flock members relative to the direction of travel of flock - Trial 7....................54

Figure 8. Spearman rank order correlations between front-to back sequence of birds in the flock - Trial 7........55

Figure 9. Summary of flock movements over time - Trial 8......56

Figure 10. Distance parameters for between-bird spacing - Trial 8.57

Figure 11. Changes in neighbor distance distributions over

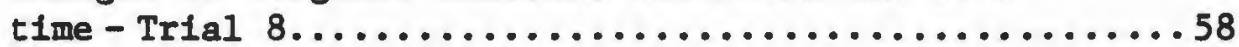

Figure 12. Positions of flock members relative to direction of travel of the flock - Trial $8 \ldots \ldots . . . \ldots . . . \ldots 59$

Figure 13. Spearman rank order correlations between front-toback sequence of birds in the flock - Trial 8.......60

Figure 14. Summary of flock movements over time - Trial 2......61

F1gure 15. Distance parameters for between-bird spacing - Trial 2.62

Figure 16. Changes in neighbor distance distributions over time -

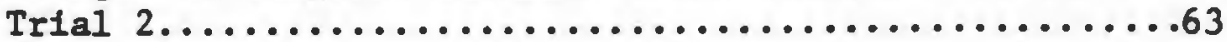

Figure 17. Positions of flock members relative to the direction of travel of the flock - Trial 2................64 
Figure 18. Spearman rank order correlations between front-to-back sequence of birds in the flock -

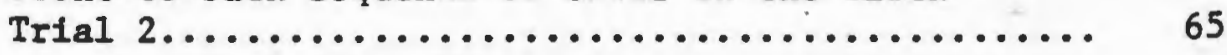

Figure 19. Summary data on turning in flocks - All Trials.... 66

Figure 20. Frequency distributions of first, second, and third nearest neighbor distances - All Trials......

Figure 21. Difference in dominance rank of first nearest neighbor pairs in the alrborne flocks........... 68

Figure 22. Idealized plot showing potentlal cause of redistribution of birds within a tuming flock..... 


\section{LIST OF TABLES}

\section{Page}

Table 1. Composition of the seven flocks................ 70 a

Table 2. Real space positions of birds at each of the

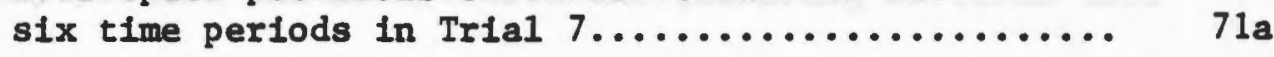


INTRODUCTION

An uneven distribution and relative scarcity of certain essential resources may promote and necessitate the gathering of birds into flocks to exploit resources. Flocking alds in the location and efficient explo1tation of food (Short, 1961; Morse, 1970; Murton, 1968; Hamilton and Gilbert, 1969). Turner (1964) pointed out that imftlative foraging by birds in flocks would facilitate locating and switching to new food sources. Ward and Zahavi (1973) proposed that flocks act as information centers for food finding. Birds may gain from other flock members Information on where (Krebs et al., 1972; Krebs, 1973) and what to eat (Gre1g-Smith, 1978; Murton, 1971).

The ability of individuals in flocks to harvest food sources more radily than an equal number of birds foraging individually has been attributed to the early warning function of flocking (Lazarus, 1978). Pulliam (1973) provided a simple calculation to show that a flock will have a greater chance of detecting an approaching predator than a single bird. The probability that at least one member of the flock w111 detect a predator before it sets within range of attack increases with the slze of the flock. Since knowledge of danger can be rapidly transmitted to other individuals efther passively by orienting and escape movements or actively by alarm signals, all members of the flock can take evasive action sooner than if they were alone or in a smaller flock. Lazarus (1977) termed this the early warning function of flocking to emphasize the importance of early detection in facilitating escape. 
Many predators rely on surprise for their success and abandon an attack once they have been detected by the prey (Rudebeck, 1951; Kenward, 1978). Numerous studies using a measure of the time to take flight in response to an approaching hawk-model have procided empirical support for the early warning hypothes1s. Powell (1974) found response times to a predator shorter for flocks of ten Starlings than for single birds. Siegfried and Underhill (1975) found that response time in flocks of Laughing Doves declined as flock size increased within the range of four to fifteen birds. Kenward (1978) observed that larger flocks of Woodpigeons took flight at a greater distance from an approachIng tame Goshawk.

Lazarus (1977) measured the probability of detection of a predator by different sized flocks using a trained Goshawk and an artificial alarm stimulus. His results and the avallable sensory physlology data were used to develop a model of predator detection in flocks. Based on the model, birds in flocks of various sizes were not taking the fullest possible advantage of their potential collective detection ability. The difference between potential and realized detection ability of the flock may be explained as follows. The formation of groups increases security for each individual in the flock, thus making it possible for the prey to trade some of the security gained for other advantages. This could be done by each individual keeping watch. The latter case would free some members of the flock for alternative behaviors. Reduced predation risk due to flock membership has been demonstrated to result in a reapportionment of flock members time budgets (Murton, 1971; Siegfried and Underhill, 1975; Inglis and Isaacson, 1978; Lazarus, 1978; 
Dlamond and Lazarus, 1974; Lack, 1968).

Powell (1974) found that Starlings share watchfulness while feeding In flocks, while Murton (1968) and Rassa (1977) noted that subordinate Individuals do a disproportionate amount of watching, and thus exhibit a reduced feeding rate. These authors also noted a spatial context to the dominant-subordinate watchfulness relationship, with dominant birds located in the center of the flock. This Idea is consistent with the observation that in colonial nesting birds, dominant individuals occupy the nest sites near the colony center where predation on nests is less than at the periphery (Coulson, 1966; Patterson, 1965).

The arguments developed so far lead to the conclusion that a flock of very large size would be maximally adaptive for detecting danger. However, in a large flock the flock members might physically occulde the visual field of neighbors, and thus negate the benefit of Increased numbers of scanners for detecting a predator. In the case of a threedimensional flock, only peripherally located Inidividuals would be able to detect an approaching predator. If the shape of a typical globular cluster flock is approximated to a sphere (Heppner, 1974), the percentage of the total number of birds in the flock located at the surface changes predictably with flock size. The ratio of the surface area of a sphere to the volume decreases with increasingly larger spheres. Larger flocks would thus consist of a greater number of birds, but a smaller percentage of the total number would be located at the surface of the flock. Increasing the size of a cluster flight formation past some critical number of birds would not result in an Increase in potential for the flock to detect and react to a predator. Rather, there would be a decrease in the relative number of effective 
"watchers" in the flock, and signals from "watchers" would have to travel greater distances and to a larger number of neighbors in order for the warning function of flocks to be effective.

Another problem of large flocks concerns the disrupting effect of a potentlally large number of false alarms (Treisman, 1975). The increase in the number of birds in a flock would result in a greater probability that at least one member of the flock would initlate a group reaction by giving a false alarm, or by inapproprlate response to a neighbor. Davis (1975) studied this problem and showed that the type of response demonstrated by individuals in flocks may be a function of flock size. He noted that the response elfcited by disturbances varied systematically with the size of the flock. As flock size increased, the responses changed from taking wing, to flight intention movements, to orienting responses. This safeguard mechanism may reduce the problem of large flocks belng continually perturbed and distracted.

Superfor ability in detecting predators is only one potential advantage of flocking behavior. Flock members may derive protection from predators by the juxtaposition of neighbor's bodies between themselves and the predator. Williams (1964) first suggested that schooling behavior arose from a kind of defensive hiding in which a threatened fish placed itself among other fish. In doing this a fish could both reduce its conspicuousness, and place other fish between itself and the predator. Hamilton (1971) considered that an animal with near neighbors would have a smaller domain of danger. Thus, the selfish advantage to those Individuals who sought cover by staying close to their neighbors might result in a tendency to aggregate. He considered 
it obvious that predation on individuals outside a flock would select for centripetal behavior.

Pulliam (1973) pointed out that since birds on the periphery of a flock stand a greater risk of predation than solitary prey, it is to their advantage to peel away from the flock exposing a new periphery. Treisman (1975) argued that this would tend to result in the disbandment of the flock, an argument which neglects the fact that there may exist a distinct disadvantage to the first individuals to disband from a flock. The disadvantage could be twofold. Flocks are thought to offer passive structural protection from attack (Mohr, 1960; Tinbersen, 1951; Eib1-Eibesfeldt, 1962; Charnov, 1975). Individuals leaving. the flock would lose this advantage. Birds leaving the flock would also become the odd prey item in the vicinity of the predator, exposing themselves to Increased hazard from predators (Mueller, 1975).

Howland (1974) discussed the relative importance of speed and maneuverability to optimal strategies for predator avoidance. He suggested that zig-zagging evasive maneuvers are important to the prey, and that the timing of each individual in staying with the group is very important. Individuals that do not move with the flock are behaving differently, and in theory will selectively be pressed upon. This concept is expanded in Eshel's (1978) hypothesis concerning the processes operating within groups of evasive prey. He suggested that dominant individuals may lead the group in an evasive path designed to provide themselves with structural protection and to expose the less fit individuals. 
Dominant birds could gain an advantage by being located within the center of the flock structure, or in areas opt1mal for predator avoldance during an attack. If the positions of birds within alrborne cluster flocks remain relatively fixed, a bird in the center of the flock may receive the most consistent benefit. A position on the surface of the flock could result in elther minimum or maximum structural protection, depending upon the direction from which an attack occurred. The direction from which an attack occurred would also have an effect on the ability of birds to detect and respond to an attack. A position on the surface of the flock could result in a bird being the first to detect a predator, or the last bird to recelve an alarm signal which travelled through the flock. Peripheral positions in a flock result in highly variable benefit both in potential for structural protection, and in timely response to predators.

If the positions of birds within a flock were not fixed, birds could place themselves in specific parts of a flock, or at random positions, and attempt to relocate within the structure if the flock was attacked. Some degree of structural reorganization is common to the response of many flocks to a predator (Nichols, 1931; Tinbersen, 1951; Mohr, 1960; Dill and Major, 1978). The effectiveness of a fixed position versus a variable position strategy depends upon the extent to which birds can move about within a turning and wheeling cluster flight formation. The question of mobility of birds within a flight formation has not been addressed, most probably because there exist no studies which have attempted to track the positions of individuals within an airborne flock. 
Symons (1971) has pointed out that almost all studies of fish schooling behavior have depended elther directly or indirectly on the accurate measurement of inter-individual distances within the schools. The photographic techniques used in three-dimensional analyses of fish schools are carried out in the laboratory where boundary conditions are controllable. Bird flocks require an enormous space for the execution of turning and wheeling maneuvers. The technical problems assoclated with field studies of flock geometry have been prohibitive to the point where there extst fewer than six studies relating to airborne flocks, with only one study attempting three-dimensional analyses. As a result there is no information currently avallable to describe fully the activities of birds flying in flocks.

Heppner (1974) summarized the principal characteristics of true flocks. He noted that the activities of flock-members tend to be synchronized such that birds head in the same direction and maintain even spacing. Heppner also differentlated between organized flocks in which birds fly in single file or columns (linear flocks), and flocks which have a three-dimensional structure (cluster flocks). Birds which fly in the cluster configuration include Starlings, many shorebirds, and Pigeons. This study presents the behavior of birds flying In cluster flocks.

Two dimensional analyses of certain structural attributes of flocks have been attempted using both radar (Williams et al., 1976) and photographic techniques (Miller and Stephen, 1966; van Tets, 1966; Nachtisal1, 1970; Gould and Heppner, 1974). 
D111 and Major (1977) made the first analysis of the Internal three-dimensional structure of Starling and Dunlin flocks. Their technique involved single, stereo-photographic samples of many different flocks of the two specles of birds. Data were analyzed to determine statistically the flock geometry of the two species. Although useful for establishing the internal structure of an airborne flock for any one instance in time, their method is not applicable to investigations of flock dynamics.

The computerized, photographic analysis technique introduced here was developed specifically to provide the first quantitative description of the turning process in cluster flocks. I monitored the threedimensional structure of flocks over time, and documented the changes in internal geometry of the flocks. The flight paths of each bird in the airborne flock were tracked so that the behaviors of individuals which resulted in observed changes in flock geometry could be readily identified.

Previous studies have filmed birds in straight and level flight. Such flocks are in the polarized state of group organization (Shaw, 1978), in which individuals in the group face in the same direction, proceed at the same rate of speed, and maintain precise position relative to each other. Birds in the flocks I monitored maintained a compact flock structure, but may not have been in the polarized state.

Breder (1976) presented a detalled model of the optimum geometric relationships between individuals in schools or flocks in the polarized state. He noted that because of the need for some type of locomotion by group members, it is necessary that a certain amount 
of space be maintained by each Individual (Breder, 1965; van 01st and Hunter, 1970). Each Individual, and a spherical shell of space around 1t, is thus considered as a unit sphere. Flocing or schooling can therefore be considered as a packing together of these spheres. Various three-dimensional lattices, and the maximum packing of unit spheres therein are described.

Functionally, the model states that no individual in the group has another individual to either side or directly above or below it. The spatial relationships between individuals in a single layer of such a packed group approximate a diamond shape (Weins, 1973). Threedimensional analyses of the distribution of fish in schools have demonstrated this type of deployment (Cullen et al., 1965; Hunter, 1966; Pitcher, 1973). The applicability of the model to globular flight formation is shown in Dill and Major's (1978) nearest neighbor analysis of Starling and Dunlin flocks.

An interesting aspect of the above model is the restriction on the potential directions of travel available to group members when the formation is turning. Breder (1976) noted that a tighter packing of individuals would require a more precise deployment of group members. With individuals distributed in a precise geometric pattern, certain areas of the flock or school represent forbidden paths of direction of travel. These forbidden sectors would require too close a mutual approach of individuals while turning. The size and position within the group of these critical areas is a function of the density of the group. Functionally stated, a group must expand to make a sharp turn, and as the group compacts the potential for individuals to 
redistribute themselves within the overall structure quickly diminishes. Hunter (1966) demonstrated this phenomenon in fish schools, noting that periods of high angular deviation in the headings of fish always resulted in an expansion of the school structure. Individuals in such a group would be more or less fixed Into place once the structure started to become compact, and for as long as the compact structure was maintained. A bird on the outside of such a structure would not be able to reposition itself to the center or "safe side" of the flock in response to a predator. The present study asked how, or if, the restrictions stated in the model dictate the adaptive strategies that are available to birds within cluster flight formations.

The final aspect of my study focused on the relationship between dominance rank of individual birds and their position in the airborne flocks. I monitored the positions of birds of known dominance rank in order to investigate whether dominant or subordinate individuals were deployed in specific areas within the flocks, or if individuals of specific dominance rank are deployed near individuals of similar or dissimilar rank. 
MATERIALS AND METHODS

A photographic record of the flight flocking behavior of Birmingham Roller pigeons was made over a five week period during the summer of 1980. The flock of 12 birds used in the study was housed in a loft located adjacent a large turf farm. The use of a flock of trained pigeons for filming and analysis provided several advantages. Birmingham Roller pigeons fly in cohesive cluster flight formations. They are large birds, each unique in color and marking pattern, and were thus well suited for any type of photographic analysis (see Appendix A). The time and location of flocking behavior could be controlled. The control of when birds were released from the loft allowed for minlmizing the effects of meteorological conditions on flocking behavior. Filming was done on clear days when wind speeds did not exceed $18 \mathrm{~km} / \mathrm{hr}$.

Although all 21 birds were released for each filming, a subgroup of 12 to 16 birds usually formed a cohesive cluster formation. The flocks remained alrborne in the 1mmediate vicinity of the loft for approximately one hour. Birds not flying with the flock perched on the roof of the loft and could be easily identified. Identification of Individual birds within the airborne flocks was possible.

Simultaneously exposed negatives were taken of the alrborne flocks with two identical fixed-position cameras. The $35 \mathrm{~mm}$, single-lens reflex (Topcon) cameras were equipped with motor drives and factory matched $58 \mathrm{~mm}$ lenses. The motor drives were connected to a common electrical control unit so that both cameras fired simultaneously (single frame rate). 
The deployment of the cameras was orthogonal. The cameras were mounted on tripods, raised to the same elevation, and aligned such that the interaction of their optical axes formed an angle of $90^{\circ}$. When viewed from above, the cameras would be located on opposite ends of a diagonal bisecting a square of dimension $60.8 \mathrm{~m}$ per side. Both cameras pointed at a common third corner of the box. The resulting area of overlap of the visual flelds of view of the cameras approximated a $1000 \mathrm{~m}^{2}$ square. The cameras were activated from a remote position when the investigator determined that the flock was within the field of overlap.

Photographic samples of the flocks were taken at $650(+2)$ msec intervals. A $16 \mathrm{~mm}$ movie camera, used in addition to the still cameras, provided continuous data on the positions of birds. The movie camera was mounted in tandem with one of the $35 \mathrm{~mm}$ cameras so that both yielded similar pictures of the flock. A small lightbulb wired in series with the control mechanism which synchronized the motor drives $11 t$ each time the still cameras were activated. The bulb was in the field of view of the movie camera, making it possible to mark the frames of movie film when the still cameras fired. The movie camera ran at a rate of 24 frames per second, resulting in a sequence of 16 frames of movie film (Kodachrome 25) between each consecutive pair of still camera photographs. The more finely grained information obtained from the movie film was helpful in tracking the paths of specific birds within the flock.

Kodak Panatomic-X film was used in the still cameras. Film was exposed at F1.8 (1/1000) and developed according to manufacturer's 
Instructions. Developed film rolls were viewed at 10X through a modified microfilm reader (Eastman Kodak model C) to check the quality of the negatives. Film pair sequences found usable were printed on $8 \times 10$ RC paper.

As the exact magnification involved in making each print was used In the analytical procedure for calculating the positions of birds, a non-standard printing procedure was required. The negatives were held in place in the enlarger between two thin plates of achromatic glass, rather than by a standard negative holder. This allowed for the entire $24 \mathrm{~mm}$ by $36 \mathrm{~mm}$ area of the exposed negative, and the area around it which included the sprocket holes in the film, to be printed on the RC paper. The actual width of the sprocket holes in $35 \mathrm{~mm}$ film is $1.96 \mathrm{~mm}( \pm 0.05 \mathrm{~mm})$. Measurement of the image of the sprocket hole on prints proved the most convenient method of determining the enlargement involved in making the prints.

Image analysis was done by mounting the prints on a light table and measuring each bird's position on the print with digital readout calipers (Brown \& Sharpe DigiCal). The position of the head of the bird on the print was used in making measurements. The orientation of birds relative to the cameras sometimes necessitated estimating the approximate point of the head of a bird on a print. Cross referencing of photographs taken from the two perspectives alded in such approximations.

ABSOLUTE POSITION: Information derived from the $8 \times 10$ prints was first used to establish where in three-dimensional space each bird 
In the flock was located at each of the points in time at which photographic samples were taken. A Cartesian coordinate system was defined for this point in space analysis. The $X$ and $Y$ axes of the system were perpendicular, and crossed at the point of intersection of the optical axes of the two $35 \mathrm{~mm}$ cameras. The plane of the X-Y axis was level with the ground. The $Z$, or vertical, axis of the system was defined as perpendicular to the X-Y plane. The elevation ( $\mathrm{z}$ axis), and that bird's displacement along the horizontal grid system ( $\mathrm{X}-\mathrm{Y}$ plane) were the real space coordinates of the bird. Real space coordinates were calculated for each bird in the flock for every point in time at which the flock was photographed.

An example of the theory used to develop the computer programs for position calculations is shown graphically in Figure 1. The horizontal and vertical deviations of the image of a bird on a negative from the center of that negative are the base of all calculations.

Data on the position of a bird on the negative from camera $A$ will locate that bird along a line orig-nating and extending from point $T$ (the optical center of the lens) to point $B$ at infinity. The bird could be anywhere along line TB. The trajectory of Iine TB from point $T$ is determined as follows.

The horizontal displacement (distance $D_{1}$ ) of the 1mage of the bird's head from the center of the negative (point R) is measured to yield the length of side QR in triangle QTR. Side RT of the triangle is the focal length of the camera lens when focused at 
infinity $(58 \mathrm{~mm})$. Angle $B$ in triangle QRT can be expressed as tan(QR/RT). Triangle QRT and MET are corresponding right triangles so that angle $B_{1}$ in triangle MET is equal to angle $B$ in triangle QRT. Angle $B_{1}$ in triangle MET defines the horizontal displacement of line $T B$ on the $Y$ axis.

The vertical displacement of the bird's Image from the center of the negative (distance $D_{1}$ ) is measured to yleld side QA of triangle QAT. Side QT can be determined from the previous step in the analysis. Triangle QAT and TFE are corresponding right triangles. The elevation of line TB in the vertical plane (angle 0) can thus be determined in a manner similar to that used to find the horizontal displacement of line TB from the $X$ axis.

The same processes were used on data from camera B to locate that bird along line $C D$. The intersection of lines $T B$ and $C D$ defines point $F$, the position of the bird in three-dimensional space.

The process of establishing the $X, Y$, and $Z$ coordinates of point F varied depending on the position of the bird relative to the optical axes of the cameras. In the present example the bird is located in quadrant II of the horizontal plane. The bird's position at point F is directly above point $E$ on the $X-Y$ plane. Triangle TFC links the bird with the focal points of the two cameras. Distance TC of triangle TFC is the distance between the cameras ( $68 \mathrm{~m})$. Measurement of distance $D_{1}$ on the negative of camera $A$ ylelds angle $B_{1}\left(B_{1}=\right.$ inverse $\tan (D / 58))$. Angle $T$ of $T F C$ can then be expressed as $B_{1}+45$. Measurement of the horizontal displacement of the image of the same bird on the negative of camera B ylelds the angular deviation in the horizontal 
plane of line CF from the $Y$ axis. This value is subtracted from $45^{\circ}$ to obtain angle $C$ of triangle TFC. Angle F of this triangle is easily calculated as 180 minus the sum of angle $T$ and $C$. All internal angles and side TC of triangle TFC are now known. Side TF is then equal to TC*tan (angle C).

The elevation of point $F$ above the horizontal plane can be calculated by determining the length of side EF in triangle TEF. Side TF and angle $0_{1}$ of the triangle are known from previous calculations. Distance EF, the elevation of point F, can be expressed as $\tan (0) * T F$. The remaining side of triangle $\mathrm{TEF}$, side $\mathrm{TE}$, is easily calculated as $\mathrm{TE}=\cos (0) * \mathrm{TF}$.

The position of the bird along the $Y$ axis (side ME of trlangle MET) is given by TE*sin(B). The displacement of the bird along the $X$ axis is determined as follows. The distance from the optical center of the camera lens to point $S$ is constant (TS=68 m). Side TM of triangle MET can be calculated as TM=ME*tan(B). Distance TM must be subtracted from 68 m (f $T M>68 \mathrm{~m}$ ), or 68 m must be subtracted from distance TM (if $T M<68 \mathrm{~m}$ ), depending upon where point $M$ lies on the $X$ axis.

The $X, Y$, and $Z$ Cartesian coordinates of all birds in the flock were determined for every point in time at which the flock was photographed. Coordinate posttions of each possible palring of birds were used to calculate distances between flock members using the formula:

$$
D=\quad\left(X_{R}-X^{2}+\left(Y_{R}-Y_{N}+\left(Z_{R}-Z_{N}^{2}\right.\right.\right.
$$


Subscripts $R$ and $N$ in the formula refer to the reference (R) and neighbor (N) bird. Each bird in the flock was analyzed in turn as the refernce bird for every point in time. Distances between each reference bird and all other birds in the flock were calculated to yield a series of values for first nearest neighbor, second nearest neighbor, through $\mathrm{N}^{\text {th }}$ nearest neighbor. Data for each of the neighbor distances categories, and the associated mean values, were plotted over time to graphically represent the structure of the flock.

Mean separation distance between all flock members was calculated for all times at which the flock was photographed. This distance is the average of all unique combinations of between-bird distances within the flock. Nearest neighbor distance is not sensitive to fragmentation of a flock into subgroups. Mean separation distance is sensitive to such changes in structure, and is thus a true measure of flock compactness (Hunter, 1966). Plots of changes in the relative values of these two parameters over time were used to study internal flock structure.

RELATIVE POSITION: The real space positions of birds were used in a second step of the analysis which assigned positional relationship to birds in the flocks. The terms right, left, above, and below are a function of the flight direction of the flock. The difference between birds' absolute positions in three-dimensional space and their positions relative to each other with reference to the flight direction of the flock is illustrated in Figure 2.

The absolute positions of birds A and $B$ on the Cartesian coordinate system is the same in Figures $2 a$ and $2 b$. The birds are at the same 
elevation above the $X-Y$ plane. If the direction of travel of the birds corresponds to flight path 1 (Level flight in $F 1 g .2 a$ ) bird B is located directly behind bird A. If however, the direction of travel of the birds is as represented by flight path 2 (a dive in Fig. 2b), the position of birds $A$ and $B$ relative to each other is very different than that seen in Figure 2a. In the latter case bird A is in front of (distance Q) and above (distance T) bird B.

Changes in the positions of birds over time were used in the second step of computer analysis to continually determine the direction of travel of the flock. The three-dimensional coordinates of birds at two successive time periods were used to determine the birds' displacement along the $X, Y$, and $Z$ axes. The horizontal and vertical components of the mean flight path of the flock were then determined using methods described by Batschelet (1965).

The original Cartesian coordinate system was shifted in several steps to obtain relative positions of birds within the flock (Fig. 3). The first shift of the axes adjusted for the horizontal component of the direction of travel of the flock. The $X-Y$ plane was rotated on the $\mathrm{Z}$ axis so that a heading of zero degrees corresponded to the horizontal component of the flight direction of the flock. The axes were then adjusted to the vertical component of the flock's flight path. The axis system was rotated on the $Y$ axis so the $X-Y$ plane was Included or declined to correspond with the vertical component of the flight path of the flock. The last step of adjustement involved placing the rotated axis sytem at the geometric center of the flock. 
A rotated and adjusted system of axes was made for each but the first.time perlod in the series of photographic samples. The positions of blrds at time $\mathrm{N}+1$ were recalculated in reference to a coordinate system defined by the flight path of the flock from time $\mathbf{N}$ to tIme $\mathrm{N}+1$. The resulting serles of plots of birds' relative positions on the $X-Y$ (flock as viewed from above) and $X-Z$ (flock was viewed from the side) planes ylelded information on left, right, above, and below. These plots were used to ascertain whether the integrity of the positional relationships between birds was maintained as the flock flew through the alr.

A premise basic to the study was that the negatives produced by the two cameras were exposed at exactly the same t1me. To test for synchrony of film exposure the cameras were mounted in tendem such that they both faced the screen of a high speed digital readout timing device (Berkeley model 500B). Shutter speeds of both cameras were set at $1 / 1000$. The cameras were electrically activated from the common control unit at $500 \mathrm{msec}$ intervals until the ends of the 36 exposure rolls of film were reached. Analysis of the exposed negatives Indicated that the two cameras consi-tently fired at exactly the same time ( $\pm \mathrm{msec}$ ), and the time perlod between firing remained $500 \mathrm{msec}(+1.5 \mathrm{msec}$ ) for the ent1re 36 frames (Appendix B).

A fleld simulation was conducted to determine empirically the accuracy and precision of the photographic and digitizing methods employed in the study. A three-dimenslonal test "flock" In which the distances and angular relationships between "birds" were known was constructed from wood dowels and styrofoam "birds". The test flock was suspended from a helium-filled balloon. Two 
assistants on the ground used tether lines to "fly" the apparatus through the filming area. Analyses of the sequence of photograph pairs taken of the model provlded an estimate of the error term for the experimental method. The calculated distances between "birds" and angular relationships between "birds" differed from the actual measured distances and angles by $\pm 2.6 \%$. In addition, each of the series of photographic samples of the model flock provided essentially the same estimate of the true flock geometry (Appendix C).

DOMINANCE: A group observation method rather than staged, paired encounters was used to study dominance in the flock. The activities of the entire flock were observed in the loft and selected indicators of dominance recorded. Observations of interactions between birds in the flock were made on alternate days for the duration of the study. Each observation period lasted 90 minutes, with 45 minutes spent at each end of the loft. Two observation areas were used to minimize site-dependent dominance (Brown, 1975).

Agonistic encounters between birds and the act of supplanting were used to establish a win/loss matrix for each observation perfod. Three summary matrices, each representing six observation periods, were formulated and used to establish dominant and subordinate birds in each of the alrborne flocks analyzed. As Pigeons do not form linear dominance hierarchies (Brown, 1965), data from the dominance matrices were used to investigate whether individuals of elther extreme rank behaved differently than other birds in the flock. 
RESULTS

The turning and wheeling maneuvers of flocks descending to low flight around their loft were photographed. Seven film trials representing a varlety of flock flight behaviors were analyzed. All birds housed in the loft did not fly with the airborne flocks during. the filming of each trial. Each trial therefore varled in the relative composition of individuals and the total number of birds present in the flock.

Table 1 shows the composition of the flocks for each of the seven trials. Three types of Information are given for each trial. Assigned numbers were trial specific labels used to distinguish birds in the serles of photographs for a trial. Identification numbers were given to each bird and used throughout the duration of the study to Identify specific individuals (Appendix A). All members of alrborne flocks which could be identifled have entries in Table I for the associated dominance rank of that individual.

A complete analysis will be presented for three trials representative of the different behaviors observed within the alrborne flocks. The first trial presented (trial 7) demonstrates the types of information avallable from the study. Summary data for five trials are shown for flock speeds, compatness, and turning arc, as well as for distributions of distances to first, second, and third nelghbors. Dominance data are summarlzed for all seven trials.

Table II shows the three-space Cartesian coordinate positions of the 11 birds in trial seven. This information is shown graphically in Figure 4. Figure 4a shows the positions, as seen from above, of all birds in the flock at each of the six instances in time at which 
the flock was photographed. The horizontal spread of the flock at each point in time is readily seen. As the time period between photographic samples of the flocks remained constant at $650 \mathrm{msec}$, the relative distances traveled by birds between photographic samples of the flocks remained constant at $650 \mathrm{msec}$, the relative distances traveled by birds between points in time can also be seen. Figure $4 \mathrm{~b}$ shows the elevation of the geometric center of the flock at each of the six time periods. Inspection of Figure 4 shows that the flock was executing a right turn of approximately $90^{\circ}$, was losing altitude and was possibly accelerating.

Nearest neighbor palrings and assoclated separation distances, as well as distances to all neighbors of each bird, were calcualted for the six time perlods (Appendix D). The average distance to first nearest neighbor, and the mean separation distance between flock members are plotted for each time period in Figure 5. Mean separation distance reflects distance between all combinations of individuals in a group and is thus a good measure of the compactness of the group (Hunter, 1966). Figure 5 shows that the flock became more compact from time one to time two, and then expanded. If both parameters in Figure 5 changed over time such that the curves were parallel, the information derived from the plot would indicate only that one flock was expanding or compacting. For example, from time two to time four to time five the flock structure continued to expand, while at the same time average distance to first nearest neighbor decreased. This combination of changes in the two parameters is an indication of the formation of nearest neighbor pairs or subgroups within the expanding 
flock.

More complete information on flock structure at each point in time of trial seven may be obtalned from plots of all neighbor distances within the flock. Interpretation of neighbor distance plots with reference to: (1) the helght and slope of the line connecting mean neighbor distance, (2) step versus smooth linear increase in distance to nelghbors, and (3) distribution of distance values within the neighbor classes, can be used to establish flock structure.

Nelghbor distance plots for each point in time of trial seven are shown in Figure 6. Figure $6 a$ shows the distributions and associated mean values for distances to increasingly remote neighbors within the flock at the first time perlod at which the flock was photographed. There is a near linear increase in nearest neighbor distances $\left(R^{2}=0.78\right)$, indicating no subgroups of clumps. The distribution of values within each neighbor class suggest that no stragglers existed at this time.

Figure 5 indicates that the flock compacted from time one to time two, and then expanded. Flgure 6 allows a quick description of how the flock expanded. The dotted lines in Figures $6 \mathrm{~b}$ through $6 f$ are a trace of the solid line connecting the mean neighbor distances at times one. This dotted line appears as a reference so that changes in the distribution of nelghbors can be more readily seen.

The changes over time in the line connecting mean distance to neighbors could take several forms representing elther an expanding or compacting flock structure. The Iine could remain inear, with a change in slope. An increase or decrease in all neighbor distances 
could occur, resulting in a line which was parallel to the solid line of time one, but representative of difference distance values. The third alternative is for the original line to exhibit one or more large changes in slope, indicating a step increase in distance to neighbors characteristic of subgroups or clumps.

Figure $6 \mathrm{~b}$ shows that the flock became more compact from time one to time two due to a decrease in distances to all neighbors. The occurrence of high values in the distributions for third through tenth nelghbor in Figure $6 c$ indicates a group of three birds broke away from the main body of the flock. The only distribution of birds in a flock which dould result in the plot of Figure $6 \mathrm{c}$ would consist of three birds that were close to each other so that the distances to first and second nelghbors had no high values, but were relatively distant from the rest of the flock so that their distances to third through tenth neighbors appear as the high values in the classes. Figure 6d shows that the flock had become dispersed at time four, with no clear indication of stragglers or clumps.

The clumped distribution of the birds indicated at time five in Figure 5 is confirmed in Figure 6e. A Scheffe multiple comparison test of the distance distribution of values to nearest nelghbors was performed to check if the linear relationship at time one had become stepped at time five. The test confirmed that the line connecting mean values of nearest neighbor distances has two distinct segments. The first segment describes the distributions of neighbors one through five, and the other segment describes the distribution of neighbors six through ten $(F=3.22, d f=9.90, P<0.05)$. This 
Those birds, such as individuals six, two, and eleven, whose flight paths were the same, maintained positions close to each other over time. Birds five and eight flew together on a flight path which described a different arc than that of birds two, six and eleven. The redistribution of birds within the flock as seen in Figure 7 is thus due to the fact that different birds, or groups of birds, had flight paths whose arcs were elther of different radius, or of similar radius but which originated at different centers. The latter situation would result in arcs which crossed, and in the rotation of relative positions of birds.

Birds which continued to Ely on a course such that they maintained positions close to each other will be said to be part of a closelyflying subgroup subgroup (CFS). One must monitor the positions of birds over a period of time to establish CFSs, and thus no previous analyses of bird flocks have detected such associations. If one considers birds two, six, and eleven as a CFS during the six time periods in trial seven, it is of interest that the previous graph analyses which established clumped distributions of birds within the flock indicated these three birds as a physical clump only at time periods two and five.

Flgure 8 gives a quantitative confirmation of the shuffing of birds' positions within the flock. For each of the five points in time of trial seven at which relative positions could be determined, the birds were ranked in order of distance from the front of the flock. A Spearman rank order correlation could then be used to 
Indicate the degree of association between the front-to-back sequence of birds at any two sequential periods in time. Four correlations were calculated to Indicate the measure of assocaition between all rankings involving a time gap of one (sequential ranking tested). High correlations for all tests involving a gap of one time period would indicate short-term stabllity. I was also interested in the assoclation between rankings made at the beginning and end of the trial. If the positions of birds within the flock remained constant over time, the correlation between front to back ranking of birds Involving two sequential time periods would be the same as the correlation between the first and last time periods. A series of correlations between front to back rankings of birds was made, controlling for an increasingly longer time interval between the two perfods at which the rankings were established. Figure 8 shows a decrease in the association between front to back sequence of birds with increasing time sap between sample periods, Indicating that the internal flock structure was not stable over time.

TRIAL 8: Trial elght consisted of eight photographic samples of a flock of 16 birds. The flock executed a roller-coaster type turn. Figure 9 indicates that there was a slowing down and climbing during the middle portion of the turn. The latter stages of the turn were characterized by an acceleration and diving of the flock. Flock compactness and distance to first nearest nelghbor at the elght periods in time of trial eight are shown in Figure 10. The flock became more compact during the beginning of the turn, dispersed during the middle of the turn (time 5), and then became 
compact.

The distributions of distances to all nelghbors are seen in Figure 11. The inftial compacting of the flock was due to a residtribution of birds so there was a decrease in distances to more remote neighbors. At times four and five there was an increase in distance to nearer neighbors, indicating a breakup of the flock structure. A large decrease in distances to all neighbors occurred by time six. The close nelghbor distances indicative of a compact flock were maintained throughout the rest of the trial. A single straggler was seen at times five and six.

Figure 12 shows the flock as viewed from above, and from the side at seven of the time periods for trial eight. The overall shape of the flock changed from a front echelon with little vertical spread (time 2), to a sphere. Changes in the relative positions of individuals were evident. The positions of many birds rotated around the $\mathrm{Z}$ axis in a counter-clockwise direction over the period of time during the flock was photographed.

The repositioning of birds within the flock over time is shown in Figure 13. Correlations between front to back rankings of birds decreased with increasing time gap between the periods at which birds were ranked. Although the flock was not stable in terms of constant relative positions of flock members, the shifting of positions within the flock did not result in an expanding flock structure.

TRIAL 2: Trial two shows a flock of dispersed individuals and subgroups which merged to form a single, core group. Figure 14 shows the flock of 14 birds vlewed from above at six instants in time. 
The flock turned appromately $90^{\circ}$ to the right, while maintaining level flight. Figure 15 shows that the flock expanded slightly, and then continued to become more compact over time. Distance to first nearest neighbor decreased from time one to time two, while during the same time overall flock structure loosened. This indicates clumps or nearest neighbor pairs at time two.

Nearest neighbor distance increased from time two to time three, while flock structure became more compact, Indicating that the nearest neighbor pairs of time two separated to form a dispersed flock. Mean separation distance and distance to nearest neighbor decreased over the next three time periods.

The distributions of distances to all nelghbors are shown in Figure 16. The high values in all the distributions of distance to neighbor Indicate one bird was separated from the flock. The large difference in values of first versus second neighbor distance suggest that nearest neighbor pairs may have existed at time two. Figure 16c shows that at time three the Iine connecting the mean values of the distributions had separated into two segments, one describing the distributions of first through fifth neighbor distances and the other discribing distance values for sixth through eleventh neighbors. A Scheffe multiple comparison test of the distributions confirmed that the line connecting mean values consists of two segments $(F=2.4, \mathrm{df}=12.143, \mathrm{P}<0.05)$. Step increases in distances to neighbors, a situation suggesting the existence of clumped distribution of birds, exist at times three and four. The step distribution is not seen at 
times five or six, indicating that the subgroups have merged into a single, core flock. Note the decrease in distance to all neighbors at times five and six, which also suggests the merging of subgroups to form a single flock.

The processes described above are apparent in Figure 17. Nearest neighbor pairs do exist at time two. Figure 17 (frame 2) shows neighbor pairs 6 and 3, 4 and 5, and pair 8 and 7. All birds except 2 and 14 have a close nearest neighbor. Groups 1, 9, 10, 11, 2 and 3, $4,5,7,8$ at time three, and groups $1,9,10,12$ and $3,4,7,8$ at times four, merged into a single flock by time five. Bird 14 was the single straggler at time six. The relative positions of birds changed over time. The shifting of positions is seen in Figure 18 as a decrease in correlation between front to back rankings of birds as the time period between rankings increases.

SUMMARY DATA: Summary data relating to sharpness of turn, flight speed, and elevation changes of flocks are given for each trial in Figure 19. These data were used to establish which parameters influence the flight speed of a turning flock. Figure 19a shows that birds in trial two executed a $95^{\circ}$ turn. The turn was made while the flock was in level flight and maintalning a flight speed of approximately $21 \mathrm{~km} / \mathrm{hr}$. There was no relationship between sharpness of a segment of the turn and flight speed maintalned during that segment. Flgure 19b shows that birds in trial six made a $180^{\circ}$ turn while maintaining a slightly slower speed than the flock in trial two. Two of the sharpest turn segments in the horizontal plane were associated with the highest flight speeds. The flock in trial elght (Figure 19c) also made a 
$180^{\circ}$ turn, and slowed down in the middle of the turn. The flight speed of the flock may have been Influenced by the vertical rather than the horizontal component of the flight path. The flock was climbing during the period of time in which flight speed dropped. During the second half of the turn the flock started to dive and accelerate. The fastest speed attalned by the flock was during this period of drop in altitude, a time also including the sharpest horizontal components of the turn. This trend is also seen in trial seven (Figure 19d) In which the flock accelerated and dove as it negotlater a sharp turn. The flock in trial nine (Figure 19e) accelerated as it dove, making the sharpest horizontal component of 1ts turn while travelling the fastest. The data in Figure 19 indicate that the vertical component of a turn may be most influentlal in determining flock speed.

To facillate comparisons between flocks in this study, frequency distributions of first, second, and third nearest neighbors for each trial were assembled (F1gure 20). Note the difference in shape of the distribution between the loosely organized flock in trial six (Figure 20b) and the consistently compact flock in trlal elght (Figure 20d). There is a tendency for flocks which changed in degree of compactness over time to have second and third nelghbor distances distributed more normally than a consistently compact flock. The former trend can be seen in trials seven and nine. The latter trend is seen in trial elght, In which the distributions of second and third neighbors are skewed to the left. 
DOMINANCE: Data collected during each trial were analyzed to establish whether dominance rank had an effect on behavior or position of birds within the airborne flocks. The observation sessions showing interactions between individuals in the flock are summarized in three dominance matrices (Appendix F). Each matrix consists of data from six 90 minute observation sessions. The matrices were used to establish a dominance rank order of birds for each of the three time periods during which filming took place. The ratio of the number of wins to the number of losses that each bird had as a result of its interactions with other flock members was used to establish the two most dominant and two most subordinate birds in each of the airborne flocks. Tests for an effect of dominant or subordinate status on position within the flocks thus involved only birds a: elther end of the dominance rank order. The mean distance from the center of the flock for all time periods in all trials was not different for the dominant group and the subordinate group $(t=1.71, d f=174, P>0.05)$, or from the average distance to nearest neighbor for the entire flock $(t=1.18, d f=519, P>0.05)$.

A final analysis utilized the rank order of birds established in the matrices to determine whether birds of high or low rank tended to assoclate with birds of similar or different rank. Figure 21 is a plot showing the summary pattern of association of dominance rank between nearest neighbors in the airborne flocks. The plot indicates a trend for association of birds of dissimllar rank. 


\section{DISCUSSION}

A type of compact cluster flock commonly observed is the spherical ball reaction of some species of birds to predators (Mohr, 1960; Tinbersen, 1951; Dill and Major, 1977). The flight behavior of Birmingham Roller Pigeons is characterized by a continuously compact flock during the performance of turning and wheeling maneuvers. The first training flock of pigeons in my study was attacked by a Cooper's hawk on several occasions prior to the beginning of filming. The pigeons responded by performing evasive maneuvers. while maintaining a compact cluster structure. Several birds which did not stay with the flock were selectively preyed upon. To discuss the present study in relation to adaptive strategies in alrborne flocks I needed to first determine if I was really observing compact cluster flight formations. If this could be established, it would then be useful to document how the movement of individuals within the flocks either conformed to or differed from predictions of models which describe the deployment and movement of birds within threedimensional flocks.

The mean distance to first nearest nelghbor for the flocks in this study $(153.8 \mathrm{~cm})$ is similar to those reported by Dill and Major (1978) for Dunlin $(70.0 \mathrm{~cm})$ and Starling $(145.0 \mathrm{~cm})$ flocks. Absolute 
distances to nearest neighbor as a measure of the density or compactness of a flock is not sensitive to the size of the birds which are spacing themselves apart in the flock. One can take into account the size of the birds in a flock by computing the ratio of distance to first nearest neighbor to the average size of flock members. The range of values for the ratio in the present study go from approximately 4:1 which is close to the $3.25: 1$ ratio of tightly packed Dunlin flocks, to $8.5: 1$ which is slightly higher than the $71 .: 1$ ratio reported for Starling flocks (D111 and Major, 1978).

The distance distributions for first, second, and third nelghbors In the seven flocks of this study also resemble those reported by Dill and Major (1977) for Starling and Dunlin flocks. These types of distributions have been attributed to birds that fly in tight, relatively closely spaced flocks.

The polarlzed Dunlin and Starling flocks exhlbited the internal geometric construct predicted by Breder's (1976) model of optimm packing. This construct has been observed in virtually all fish schools studied to date. The pigeon flocks of my study did not maintain a precise geometric construct, and did not seem to be affected by the limitations of movement of individuals within the structure which Breder's (1976) model suggested. The flocks did in many cases maintain a compact structure while performing a turning maneuver. The following suggestlons may explain the observed results.

The distances between fish in schools relative to the size of fish indicates that there is much less internal or empty space in 
schools than in bird cluster flocks. Hunter (1966, 1969) and van Olst and Hunter (1970) demonstrated that spacing between fish in four species of fack mackeral was approximately equal to one-half the body lengths of Individual fish. Pitcher (1973) and Cullen et al. (1965) also found nearest nelghbors were about one-half body length apart.

The greater amount of relative empty space in the cluster flocks may be necessitated in part by the medium in which birds travel, and their speed. The empty space made it possible for birds to be in transit through the flock structure during the time the flock was turning. High angular devlation in headings of fish in schools Indicated a decrease in compactness, and breakup of the structure to allow fish to negotiate a turn. A peak value in angular deviation In headings of birds in the flocks of this study did not necessartly signify a breakup of the flock structure. The potential for birds to travel through the flock resulted in many cases in a more compact flock at times of highest angular deviation of headings.

An understanding of the simultaneous occurrence of great internal change, and malntained overall cohesive structure is best obtained through an analysis of the turning process in the cluster flocks. The redistribution of birds within the flocks always involved the apparent rotation of individuals' relative positions within the flock always involved the apparent rotation of individuals' relative positions within the flock structure. Analyses of the flight paths of birds revealed that individuals were not flying parallel arcs as would be expected with a column type turn. A column turn involves 
a situation in which birds maintain the same relative positions throughout the turn. The individuals remain parallel to one another such that samples of the flock taken at any point in time would yield a similar geometric construct and deployment of individuals wthin the flock.

Turns in this study were all sharp and seemed to involve a breakdown in any structure which may have existed prior to the turns. In contrast to a column turn, the flight paths of many birds approached or crossed during a turn. This particular aspect to the pattern of change in the deployment of birds would have implication to studies of leadership strategies and the propagation of information throughout the flock.

A simple model of turning consistent with the data would involve all birds in a flock starting to turn at approximately the same time, and each bird describing an arc of similar radius originating at its position at the onset of the turn. An example of the resulting change in positions of birds within the flock over time is shown in Figure 22. The plot shows that the crossing of flight paths of birds results in the counter-clockwise rotation of their relative positions within the flock. Such a pattern of repositioning of birds within the flock was observed in all the flocks in my study. Not shown in the figure is the fact that the crossing of flight paths of unequal radius could bring birds together in physical clumps for a short time. This type of temporary assoclation between birds was seen in trial seven, in which birds three and ten travelled different arcs that approached at time five. 
There is probably less behavioral significance to the temporary spatial association of birds whose flight paths cross at one point in time than would extst for birds that tended to stay together throughout the entire course of a turn. In all trials some groups of birds continued to maintain positions close to each other as the flock traveled through the turn. If individuals were adjusting their flight paths to a few nearest neighbors rather than the central mass of the flock, a breakup of the flock into subgroups as seen in trial seven could occur. Pairs or groups of birds within a flock which describe simflar paths through space may be considered CFSs. In trial seven the CFSs were also distinct physical clumps because the flock was breaking apart. CFSs in a flock which is compact and not expanding may not appear as distinct physical units within the overall flock structure. This situation existed in trial two. A group of birds originally on the outside edge of the flock relative to the turn, cut short. Another subgroup did not seem to respond to the turn as quickly, and turned later and on a different arc than the first group. As a result, the flight paths of the subgroups crossed. There was a breakup of these into two distinct CFSs. The crossing of the flight paths of the CFSs resulted in birds switching relative positions within the flock. Because the two CFSs were passing through each other the flock at no time separated into distinct physical clumps.

The maintained spatial association in CFSs could be the result of random paths, or it could result from pairs or groups of birds within a flock which respond to each other over time in adjusting their flight paths. The concept of Individual response to specific neighbors 
has basis in both fish schools and bird flocks. Hunter (1966) studied the communication of velocity changes in schools of jack mackeral. He demonstrated that responding fish may be quicker to sense alteration in a nelghbor's behavior if the neighbor occupies a particular area of the visual field. Gould and Heppner (1974) suggested that the Vee formation of geese is such that neighbors are In the center of the visual field of following birds. It is very common for pairs or small groups of birds to break away from and then rejoin cluster flocks, a situation which would occur if birds followed specific neighbors within the flock resulting in pockets of response. Localized pockets of response have been observed to form within schools of fish that are turning (Shaw, 1978).

Two aspects of turning in cluster flocks have been discussed. The first involves the potential for birds to change relative position within an airborne flock. A spherical flock structure involving relatively fixed positions of individuals would offer distinctively different advantages to peripherally and centrally located birds. My study indicates that turning and wheeling cluster flocks are in a constant state of structural reorganization, and that adaptive strategies for reducing the risk of predation could be based on the phenomena of relocation rather than maintaining a fixed position in the flock. A bird would not necessarily have to peel off from the surface of the flock (Pulliam, 1973) to become separated from the flock. An individual located in the center area of a flock could easily become a straggler, due to positional rotation of individuals in a turn. 
The second aspect of turning relates to the cues to which birds respond in altering their flight paths. The position in space at which a bird is located in relation to other birds in the flock may be a function of which bird or birds the individual attempted to follow and respond to in making adjustments to its flight path. This effect is compounded by the fact that with birds traveling at $25 \mathrm{~km} / \mathrm{hr}$ and making a sudden, sharp turn, a slight delay in response could result In a very different arc of turning and cause the responding bird to elther leave the flock or end up in an area of the flock distant from the bird to which it had responded.

These two aspects of turning in cluster flocks may act to influence how the potential for flocks to offer passive structural protection (Mohr, 1960; Charnov, 1975) and the selection of odd prey by predators (Mueller, 1975) interact in dictating adaptive strategles within alrborne flocks.

Eshel (1978) proposed a strategy in which passive structural protection, selection of odd prey, mobility of individuals, and dominance are all important factors within groups of evasive prey. The behavior of the escaping group is described as consisting of a serles of Interactions between the prey and the predator, and among the prey. Dominant individuals in the group gain an advantage as a result of the interactions by initiating maneuvers which eventually expose weaker individuals. The results of my study indicated that there was a tendency for birds of dissimilar rank to take positions close to each other while in the alrborne flocks. The selection could have been on the part of dominant birds, subordinate birds, or 
mutual attraction. One possible explanation for the association is that dominant birds are maintaining positions near subordinate Individuals in order to 1) Insure potential use of the subordinate Individuals as structural protection in the event of attack, or 2) be in a position where they could most effectively perform evasive maneuvers which would result in a subordinate bird being singled out from the flock structure.

The continual redistribution of birds within turning flocks has bearing also on several current hypotheses of the aerodynamics of flocking behavior. It has been proposed that birds in flight formations could theoretically achleve an aerodynamic advantage by flying in the updrafts created by their nelghbors (Lissaman and Shollenbeger, 1979; Higdon and Carrson, 1978; May, 1979). Models which relate various three-dimensional flock structures to Increased aerodynamic lift to all members of the flock may not apply to flocks when flock members are turning in a manner described in this study. The aerodynamic models assumed maintained and spectfic geometric construct within flocks. The observed crossing of flight paths, and changes in flock compactness in this study indicate that birds could not long remain in the updraft segments of winstip vortices from leading birds.

The birds within the flocks of Dill and Major's (1978) study were deployed in a manner which would result in an aerodynamic advantage to flock members. It is interesting to note that the flocks filmed in their study were in the process of traveling between roosting and feeding areas, or migrating through the study area. Birds of the same species respond to predators by flying in compact, turning and 
wheeling cluster flocks (D1II and Major, 1977). Under the latter conditions the adaptive strategies of flocking relate to each individual's ability to protect itself rather than aerodynamic advantages. Some of. the benefits of each type of flock configuration and behavior are exclusive to one type of flock. It would seem very likely however, that birds can easily and rapidly switch from an aerodynamic flock formation to a flock configuration in which evalsive maneuvers, staying with the group, and structural protection from nelghbors minimize the threat of predation. Probably the turning and wheeling flocks observed in my study represent only one of the types of flocking behavior exhibited by birds which normally fly in a cluster formation.

Several results from this study may have bearing on future investigations of three-dimensional flocks. Two potential problems exist with the present dominance study. The first concerns the fact that pigeons do not form linear dominance hlerarchles (Brown, 1975) so that dominance rank may be useful for establishing two distinct classes of Individuals at elther end of the hierarchy, but not for Iinear analyses. The second problem is that of site dependent dominance (Brown, 1975). A dominance relationship established under certain circumstances or areas may not be absolute. The problem in this study was that a pigeon's dominance rank as observed at the loft may only apply in the loft. Dominance rank established in the loft may not carry over to interaction within the alrborne flocks. 
The difference between physical clumps and CFSs suggested by this study provides the following guldeline for requirements of sampling. A single sample of a flock can establish the geometric construct that exists at a particular time, but is insensitive to CFSs in a flock. The movement and redistribution of birds within a turning flock render analyses based solely on detecting physical clumps, or analyses based on nearest neighbor data from a single sample of a flock, of questionable value for establishing the processes responsible for maintenance of flock stability and structure. The above type of nearest nelghbor analyses may establish artitrary associtions such as temporary neighbor pairs resulting from birds whose flight paths approach or cross at a point in time. Spatial analyses for clumped versus uniform or random distribution of birds based on single samples of the flock may be insensitive to CFSs or truely functional relationships which exist within the flock.

An important aspect of this study is the establishment of a method for obtaining a quantitative description of the structural changes and reorganization in airborne flocks. The plots of first nearest neighbor and mean separation distance were effective in establishing general trends in the changes in flock geometry over time. The plots of distribution of distances to all neighbors for each period in time provided more specific information. For example, the plots allowed me to establish whether changes in flock compactness were due to uniform response of all birds in assuming closer or more distant positions from nelghbors, to the formation or merging of subgroups, or to the existence of stragglers. 
This study provided the method of analysis, and descriptions of flock geometry which suggest what types of strategies are available to birds flying within cluster flocks. The next logical step in analysis of three-dimensional flocks would be to use either this method or some type of structural analysis method to study responses of birds in cluster flocks to a trained hawk, and to quantify the responses of flock members. 


\section{LITERATURE CITED}

Batschelet, E. 1965. Statistical methods for the analysis of problems in animal orientation and certain biological rhythms. 57pp. Washington, D.C., Am. Inst. Biol. Sci.

Beer, J.R. 1958. The composition of bird flocks. Flicker, 30: 78-83. Breder, C.M. 1965. Vortices and fish schools. Zoologica, 50: 97-114. 1976. Fish schools as operational structures. Fishery Bul1., $74(3): 471-502$.

Brown, J.L. 1975. The evolution of behavior. W.W. Norton and Co., New York. 761pp.

Charnov, E.L. and J.R. Krebs. 1975. The evolution of alarm calls: altruism or manipulation? Am. Nat., 109: 107-112.

Coulson, J.C. 1966. The influence of the pair-bond and age on the breeding blology of the Kittiwake gull Rissa tridactyla. J. of Anim. Ecol., 35(2): 269-279.

Crook, J.H. 1961. The basis of flock organization in birds. In W.H. Thorpe and O:L. Zangw 111 eds., Current problems in animal behavior. Camb. Univ. Press, London. 424pp.

Cullen et al. 1965. Methods for measuring the three-dimensional structure of fish schools. Anim. Behav., 13(4): 534-545.

Davis, J.M. 1975. Soclally induced flight in pigeons. Anim. Behav., 23(3): 597-601.

Diamond, S. and J. Lazarus. 1974. The problem of vigilance in animal life. Brain, Behav. and Ecol., 9: 60-79.

Dill, L.M. and P.F. Major. 1977. Spatial structure of bird flocks. Nat. Res. Counl. Canada Fleld Note No. 76.

1978. The three-dimensional structure of alrborne bird flocks. Behav. Ecol. Socioblol., 4: 111-122.

Eibl-Eibesfeldt, I. 1962. Frelwasserbeobachtunsen zur Deutung des Schwarmverhaltens verschiedener Fische. Z. fur Tierpsychol., $19(2)$ : 163-182.

Emlen, J.T. Jr. 1952. Flocking behavior in birds. Auk, 69: 160-170. 
Eshe1, I. 1978. On a prey-predator nonzero-sum game and the evolution of gregarious behavior of evasive prey. Am. Nat., 112: 787-795.

Gould, L.L. and F.H. Heppner. 1974. The Vee formation of Canada geese. Auk, 91: 494-506.

Goss-Custard, J.D. 1970. Feeding dispersion in some overwintering wading birds. In J.H. Crook, eds., Soclal behavior in birds and mammals: essays on the social ethology of animals and man. pp. 3-35.

Greigh-Smith, P.W. 1978. Imitative foraging in mixed-species flocks of Seychelles birds. Ib1s, 120: 233-235.

Hamilton, W.D. 1971. Geometry for the selfish herd. Journ. Theor. B101., 31: 295-311.

Hamilton, W.J. III. and W.M. Gilbert. 1969. Starling dispersal from a winter roost. Ecol., 50(5): 886-898.

Heppner, F.H. 1974. Avian flight formations. Bird Banding, 45(2): 160-169.

and J.D. Haffner, 1972. Communication in bird flocks: an electromagnetic model. In J.G. Laurado, A. Sances Jr., and J.H. Battocletti eds., Blological and clinical effects of low intensity magnetic fields. Thomas, Springfield. 287pp.

Higdon, J.L. and S. Carrson. 1978. Induced drag in a bird flock. Am. Nat., 112: 727-744.

Howland, H.C. 1974. Optimal strategles for predator avoldance: the relative importance of speed and maneuverability. J. Theor. B1o1., 47: 333-350.

Hunter, J.R. 1966. Procedure for analysis of schooling behavior. J. Fish. Res. Bd. Canada, 23: 547-562.

1969. Communcation of velocity changes in jack mackeral (Trachorus symmertricus) schools. Anfm. Behav., 17: 507-514.

Inglis, I.R. and A.J. Isaacson. 1978. The resposnes of Dark-bellied Brant geese to models of geese in various postures. Anim. Behav., 26: 953-958,

Kenward, R.E. 1978. Hawks and doves: factors affecting success and selection in Goshawk attacks on Wood-pigeons. J. Anim. Ecol., 47: 449-460. 
Krebs, J.R. 1973. Social learning and the significance of mixedspecles flocks of Chickadees (Parus spp). Can. J. Zool., 51: $1257-1288$.

MacRoberts, M.H. and J.M. Cullen. 1972. Flocking in the Great Tit, Parus Major: an experimental study. Ibis, 114: 507-539.

Lack, D. 1968. Ecological adaptations for breeding in birds. Methuen, London, 409 pp.

Lazarus, J. 1977. Natural selection and the function of flocking in birds. Ib1s, 114: 556-558.

1978. Vigilance, flock size, and domain of danger in the White-fronted goose. Wildfowl, 29: 135-145.

Lissaman, P.B.S. and C.A. Shollenberger. 1970. Formation flight in b1rds. Sc1., 168: 1003-1004.

May, R.M. 1979. Flight formations in geese and other birds. Nature, 282 : $778-780$.

Miller, R.S. and W.D. Stephen. 1966. Spatial relationships in flocks of Sandhill Cranes (Crus canadensis). Ecol., 47: 323-327.

Mohr, H. 1960. Zum Erkennen von Raubvoseln, Insbesondere von Sperber und Baumbalk, durch Kleinvoseln. Z. fur Tlerpsychol., 17(6): 686-699.

Morse, D.H. 1970. Ecological aspects of some mixed-species foraging flocks of birds. Ecol. Mongr., 40: 119-168.

Mueller, H.C. 1971. Odd1ty and specific search Image more important than conspicuousness in prey selection. Nature (Lond.), 233: 345346.

1975. Hawks select odd prey. Sc1., 188: 953-954.

Murton, R.K. 1968. Some predator-prey relationships in bird damage and population control. In R.K. Murton and E.N. Wright, eds.; The problems of birds as pests. Academic Press, New York. 231pp.

1971. The significance of a specific search image in the feeding behavior of the Wood-pigeon. Behavior, 40: 10-42.

Nachtigall, W. 1970. Verbandflus der Ganse. Z. Vers1. Physiol., 67: 414-422.

Nichols, J.J. 1931. Notes on the flocking of shore birds. Auk, 48: 181-185. 
Patterson, I.J. 1965. Timing and spacing of broods in the Black-headed sull Larus ridibundus. Ib1s, 107(4): 433-459.

Pitcher, T.J. 1973. The three-dimensional structure of schools in the minnow, Proximum phoximus(L.). Anim. Behav., 21: 673-686.

Powell G.V.N. 1974. Experimental analysis of the social value of flocking by Starling (Sturnus vulgaris) in relation to predation and foraging. Anim. Behav., 22: 501-505.

Pulliam, H.R. 1973. On the advantages of flocking. J. Theor. Biol., 38: 419-422.

Rasa, O.A.E. 1977. The ethology and sociology of the Dward Mongoose (Helosale undulata rufula). 2. Teirphyschol., 43: 337-406.

Rudebeck, G. 1951. The cholce of prey and modes of nunting of predatory birds with special reference to their selective effect. Oikos, 2: $65-88$.

Shaw, E. 1978. Schooling fishes. Am. Scientist, 66(2): 166-175.

Short, I. 1961. Interspecies flocking of birds on montane forst in Oaxaca, Mexico. Wilson Bul1., 73(4): 341-347.

Slegfried, W.R. and L.G. Underhill. 1975. Flocking as an ant1-predator strategy in Doves. Anim. Behav., 23: 504-508.

Symond, P.F.K. 1971. Spacing and density in schooling threespined sticklebacks (Gasterosteus aculeatus) and mummichogs (Fundulus heteroclitus). J. Fish. Res. Bd. Canada, 28: 999-1004.

Thompson, W.A. and I. Vertinsk. 1974. The survival value of flocking in birds. J. Anim. Ecol., 43: 785-820.

Tinbersen, N. 1951. The study of instinct. Claredon Press of Oxford Univ. Press, Oxford. 228 pp.

Treisman, M. 1975. Predation and the evolution of gregariousness I: models for concealment and evasion. Anim. Behav., 23: 779-800.

Turner, E.R.A. 1964. Soclal feeding in birds. Behavior, 24(2): 1-46.

van 01st, J.C. and J.R. Hunter. 1970. Some aspects of the organization of fish schools. J. Fish. Res. Bd. Canada, 27: 1225-1238.

van Tets, G.F. 1966. A photographic method of estimating densites of bird flocks in flight. CSIRO Wild1. Res., 11: 103-110. 
Vine, I. 1971. Risk of visual detection and pursuit by a predator, and the selective advantage of flocking behavior. J. Theor. B1o1., 30: 405-442.

Ward, P. and Z. Zahav1. 1973. The importance of certain assemblages of birds as information centers for food finding. Ibis, 115: 517-534.

Weins, D. 1973. Hydromechanics of fish schooling. Nature (Lond.), 241: 290-291.

Williams, T.C., Klonowsk1, T.J. and P. Berkeley. 1976. Angle of

Canada goose V flight formation measured by radar. Auk. 93: 554-559.

Williams, G.C. 1964. Measurements of consociation among fishes and comments on the evolution of schooling. Publ. Mus. Mich. State Univ., Biol. Ser., 2(7): 351-383. 
Figure 1. Calculation of the positions of birds in three-dimensional space. The image of the bird at point $F$ forms on the negative of camera $A$ to yield distances $D_{1}$ and $D_{2}$. These distances are used in a series of geometric calculations to locate point F (see text for full explanation of calculations). 


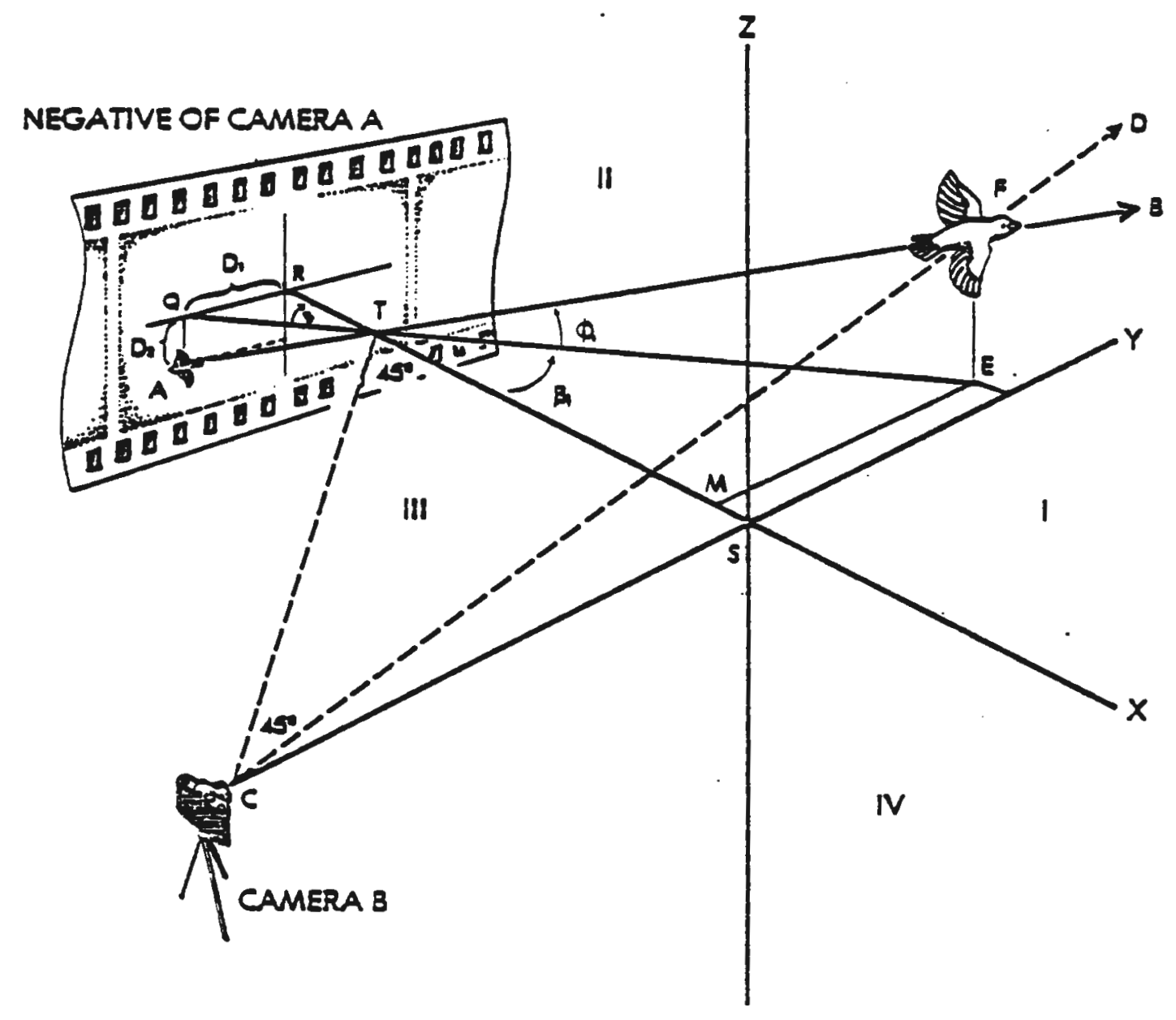


Figure 2. Effect of flight path upon relative positions of birds within the flock structure. Fig. 2a shows a level flight path in which bird $A$ is directly in front of bird $B$.

Fig. 2b shows a flight path involving a dive. In this case bird $A$ is in front of and above bird $B$. 


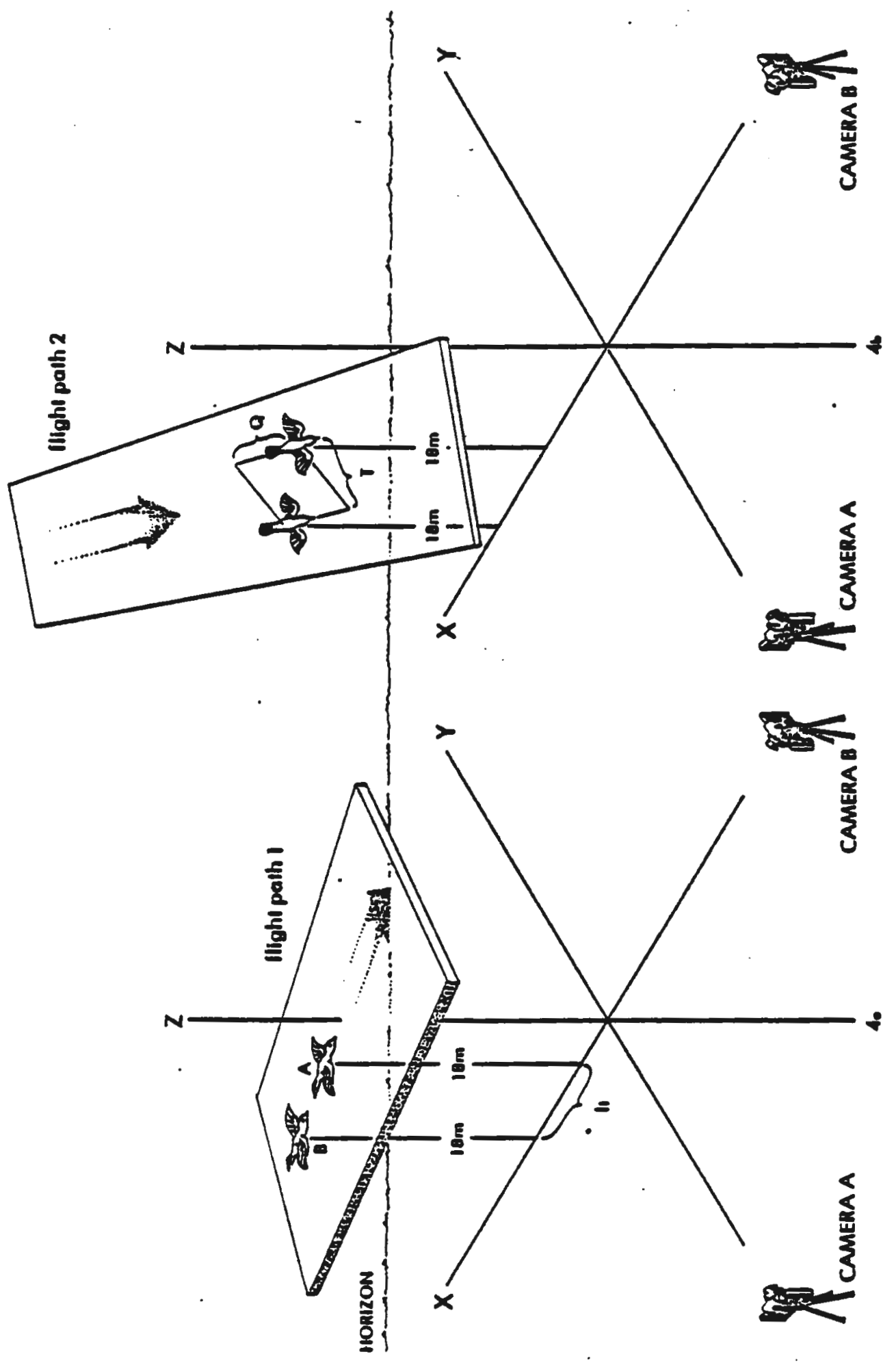


Figure 3. Calculation of the horizontal component of the flight path of the flock.

Bird $A$ as viewed from above at two points in time is shown to have turned to the right. Displacement along the $X-\operatorname{axis}(\Delta X)$, and the $Y-\operatorname{axis}(\Delta Y)$ is used to determine angle $\theta$, and thus the flight vector of bird $A$. The sum of all $X_{s}$ and $Y_{s}$ were used to find angle $\theta$ for the flock as a whole. 
$50 a$

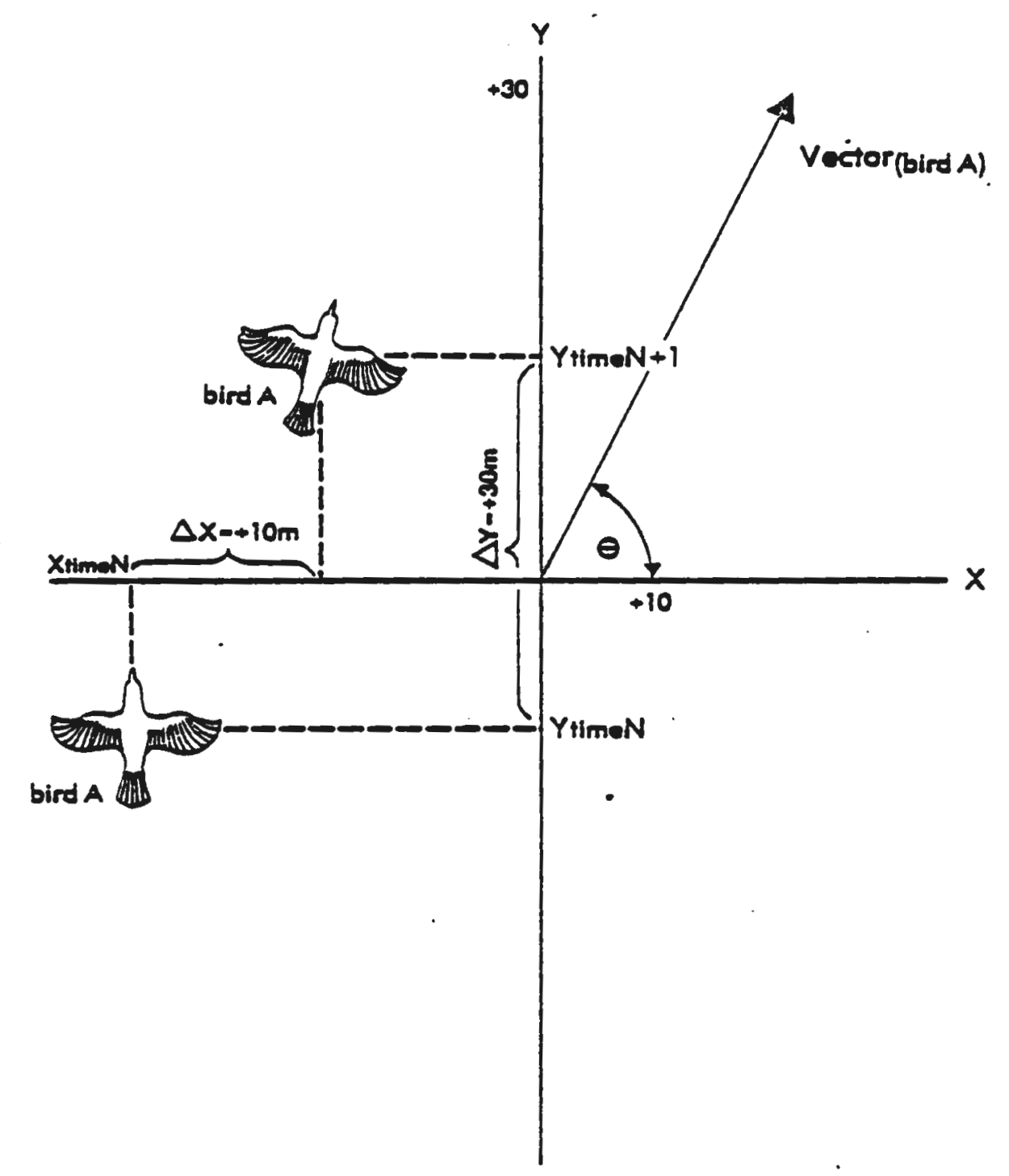


Figure 4. Summary information on flock movements over time. Figure $4 \mathrm{a}$ shows the flock in trial seven as seen from above for each point in time at which photographic samples were taken. The deployment of birds in the horizontal plane is readily seen. Arrows indicate the mean direction of travel of the flock. Figure 4b shows the changes in elevation of the geometric center of the flock. Note that the $X-Y$ plane was elevated approximately $150 \mathrm{~cm}$ above ground level. 

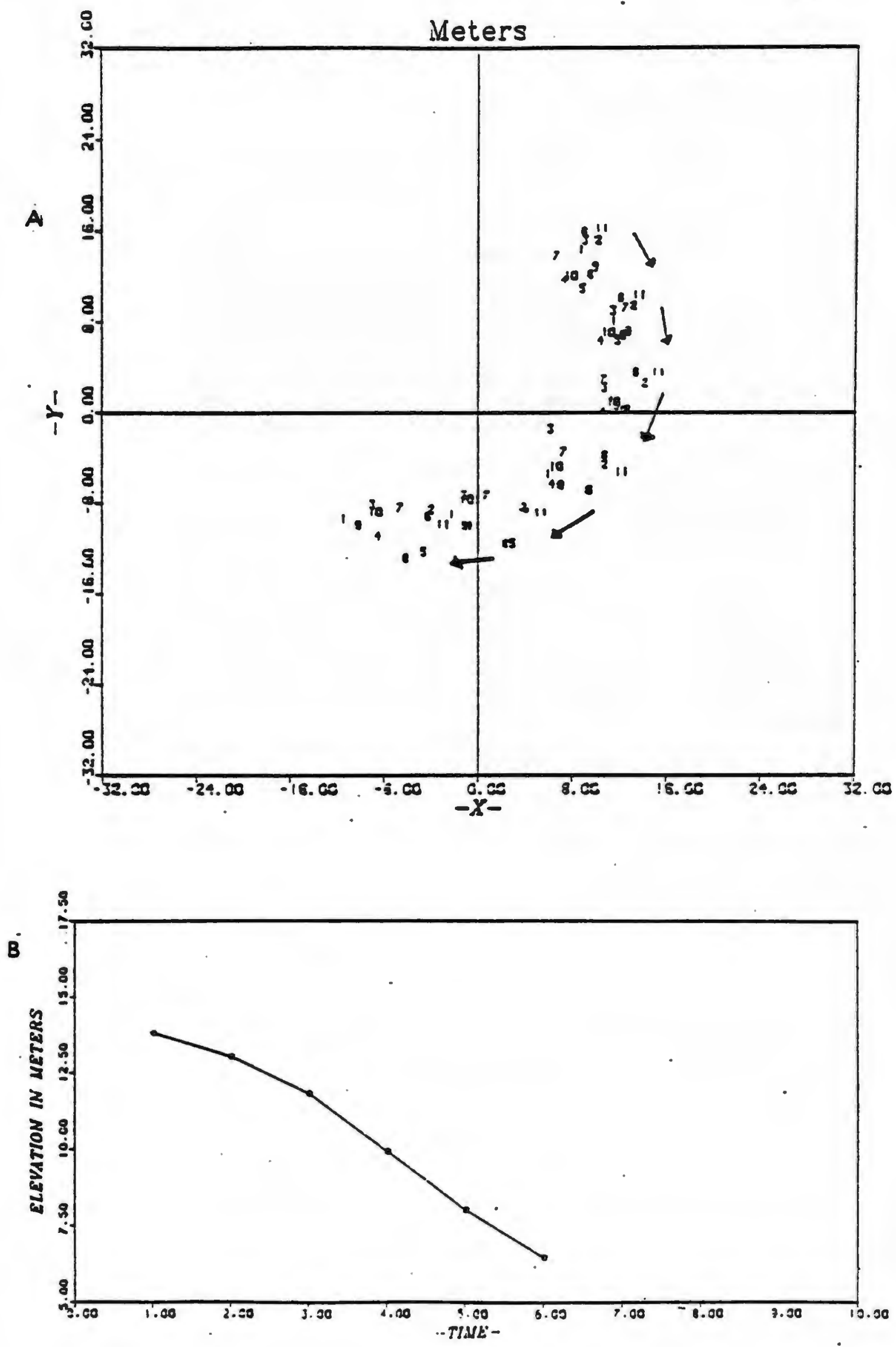
Figure 5. Changes in values for mean separation distance and mean distance to first nearest nelghbor for the six time perlods in trial seven. Various types of combinations of change in the two parameters are indicative of specific types of deployment of flock members (see text for full explanation). 


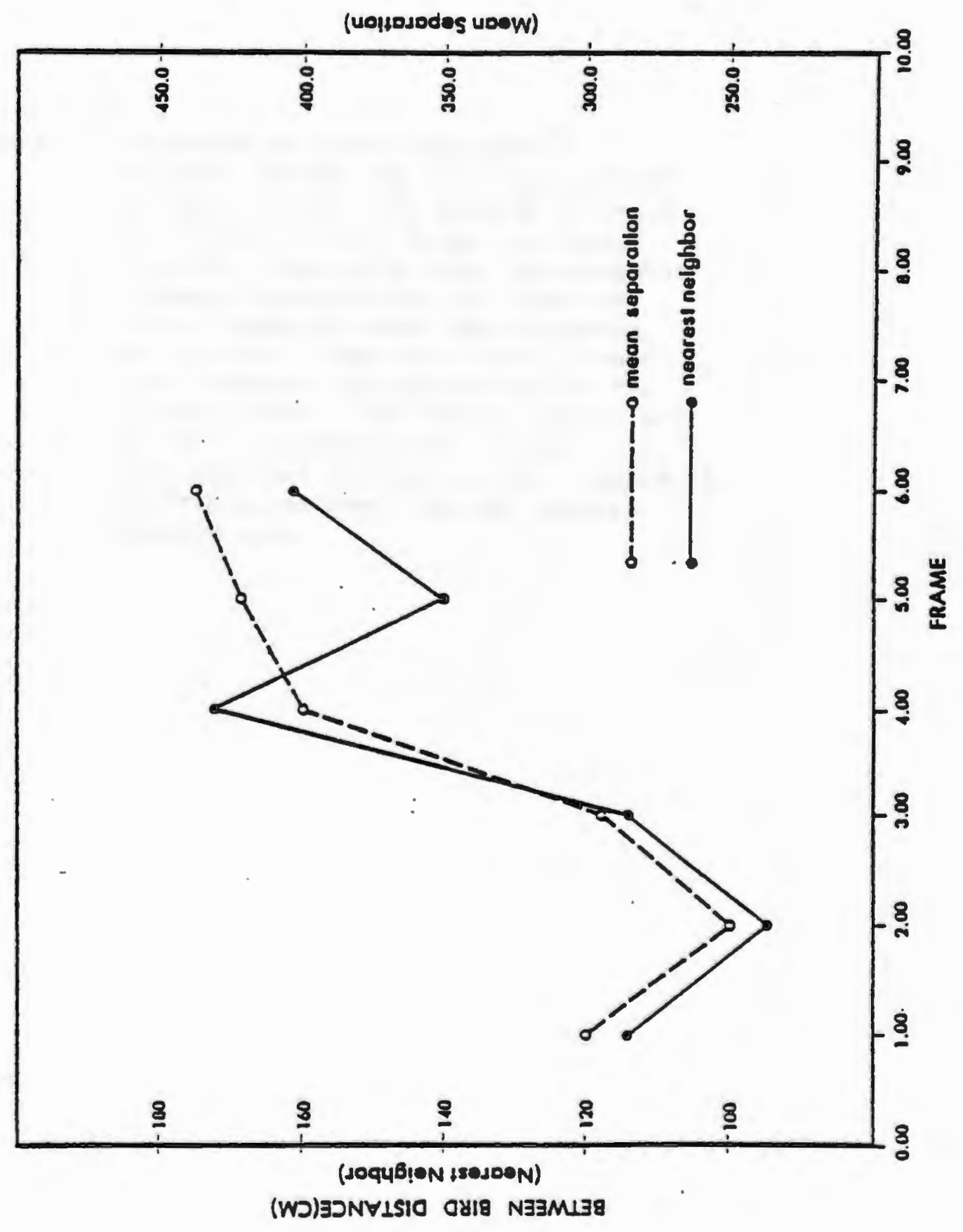




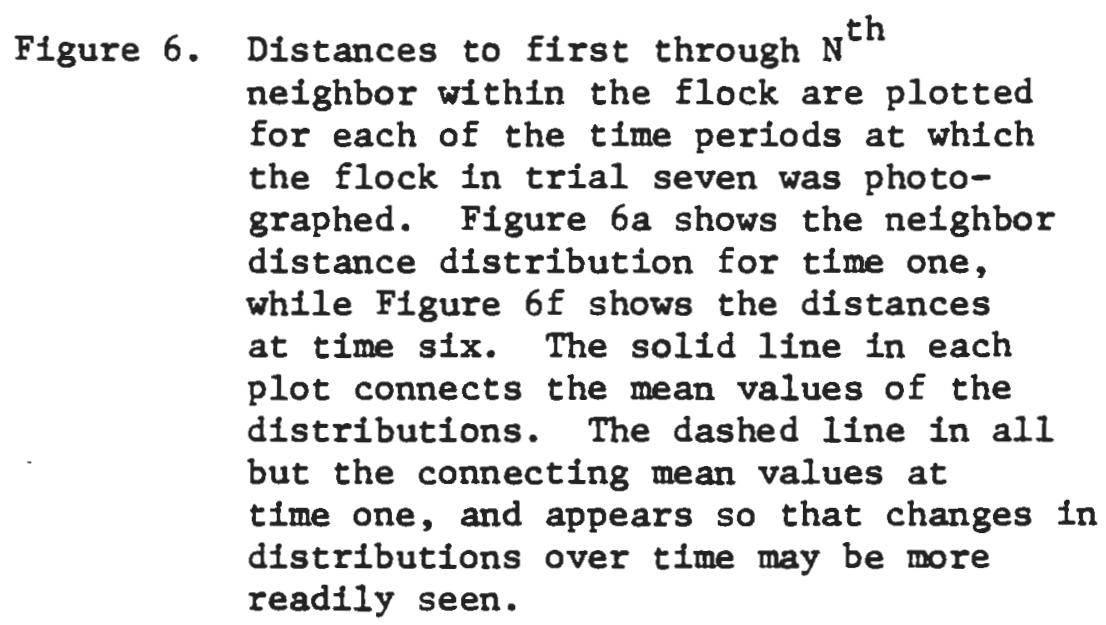



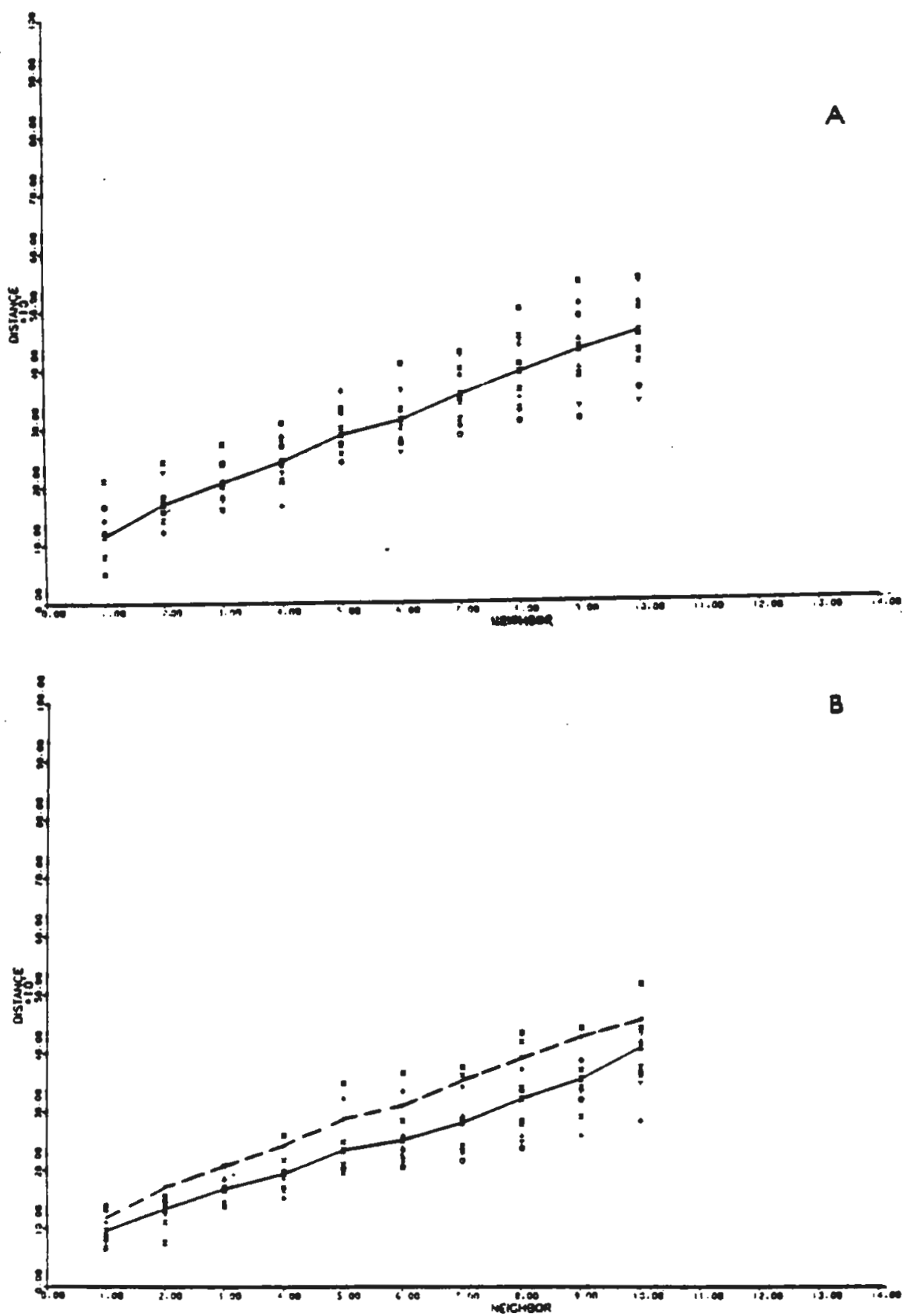


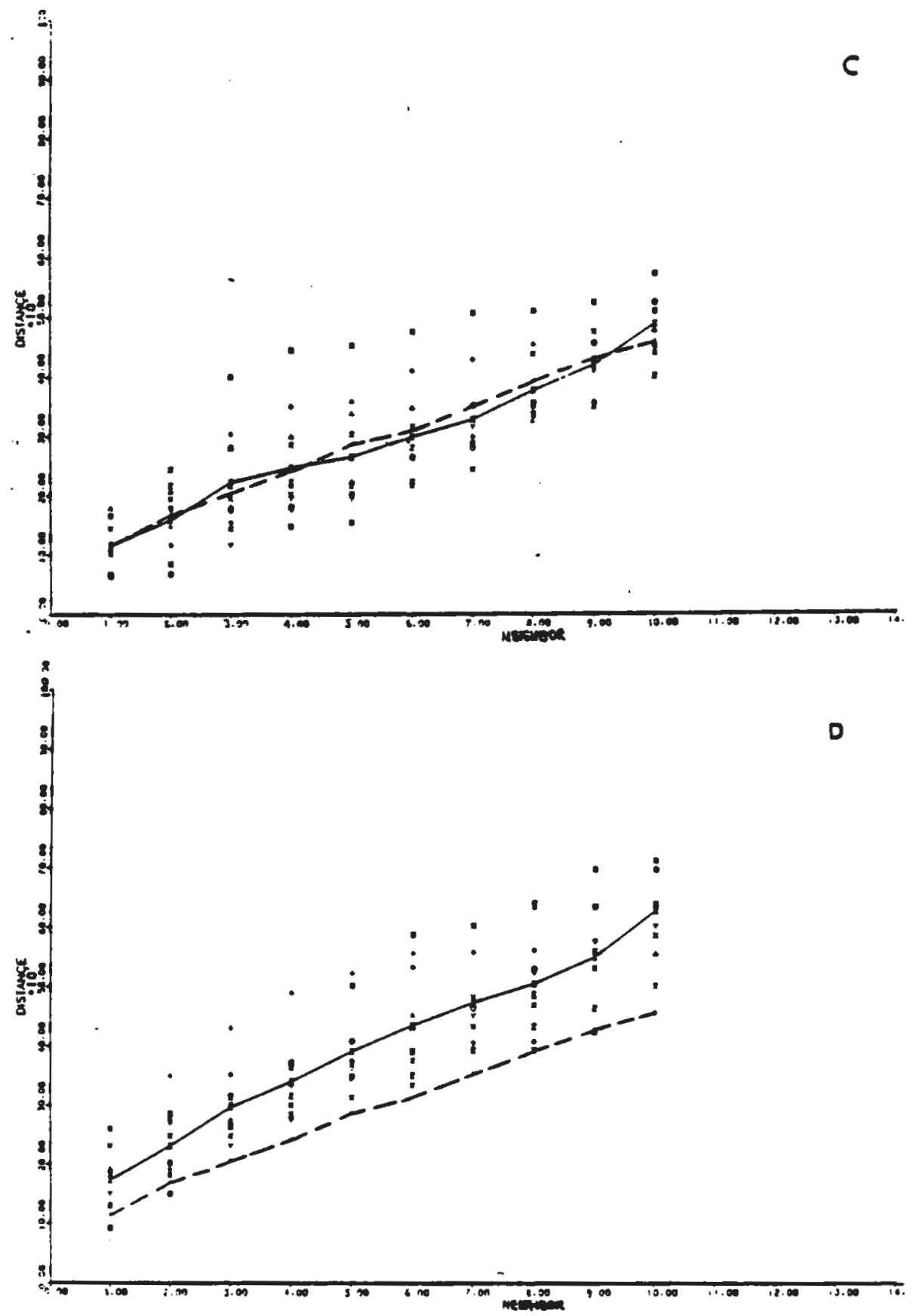



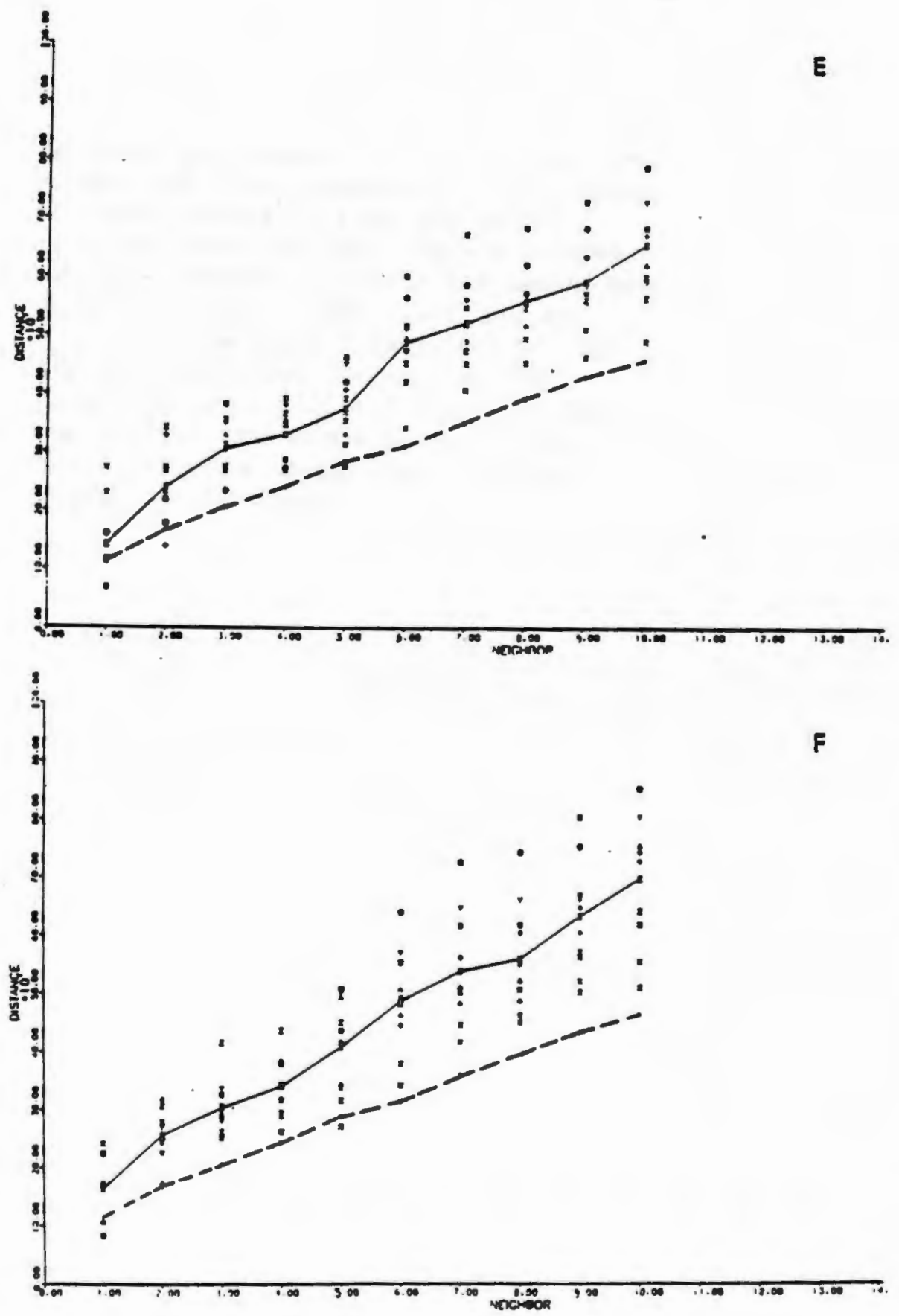
Figure 7. Relative positions, shown from two viewpoints, of flock members in trial seven at five perlods in time for which relative position could be calculated. Assigned numbers of birds are shown as seen from above (left plot) and as seen from the side (right plot). The $X-Y$ axis has been centered at the geometric center of the flock in each of the plots. The arrow at the right of the $\mathrm{X}$ axis indicates the direction of travel of the flock. 
FRAME 2
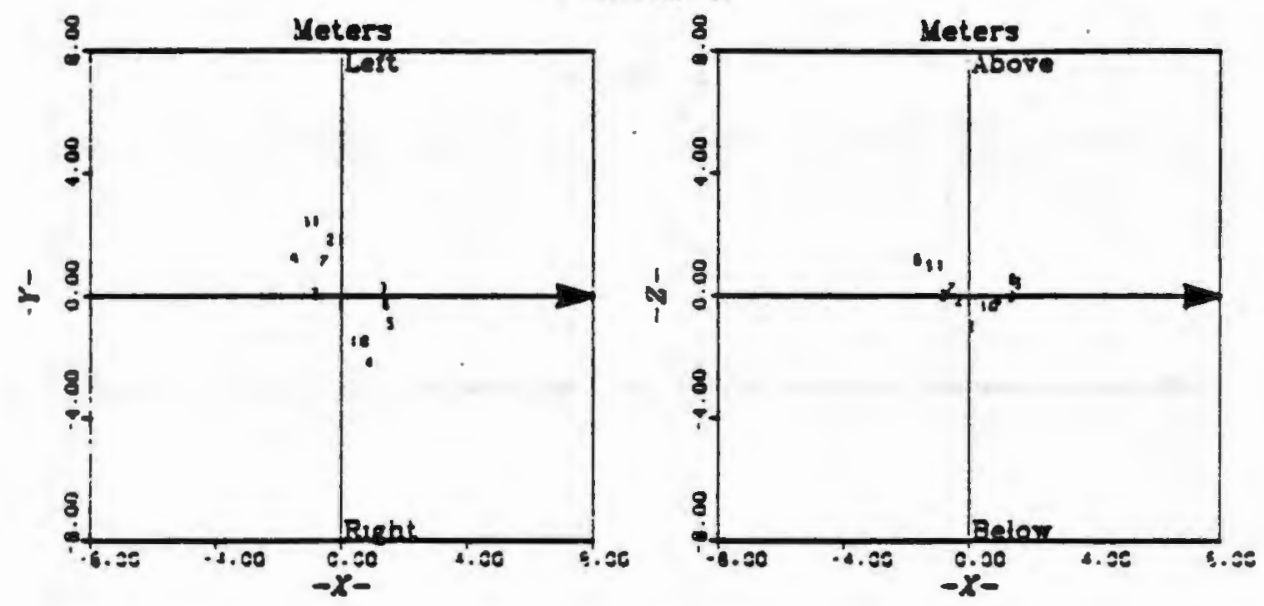

FRAME 3
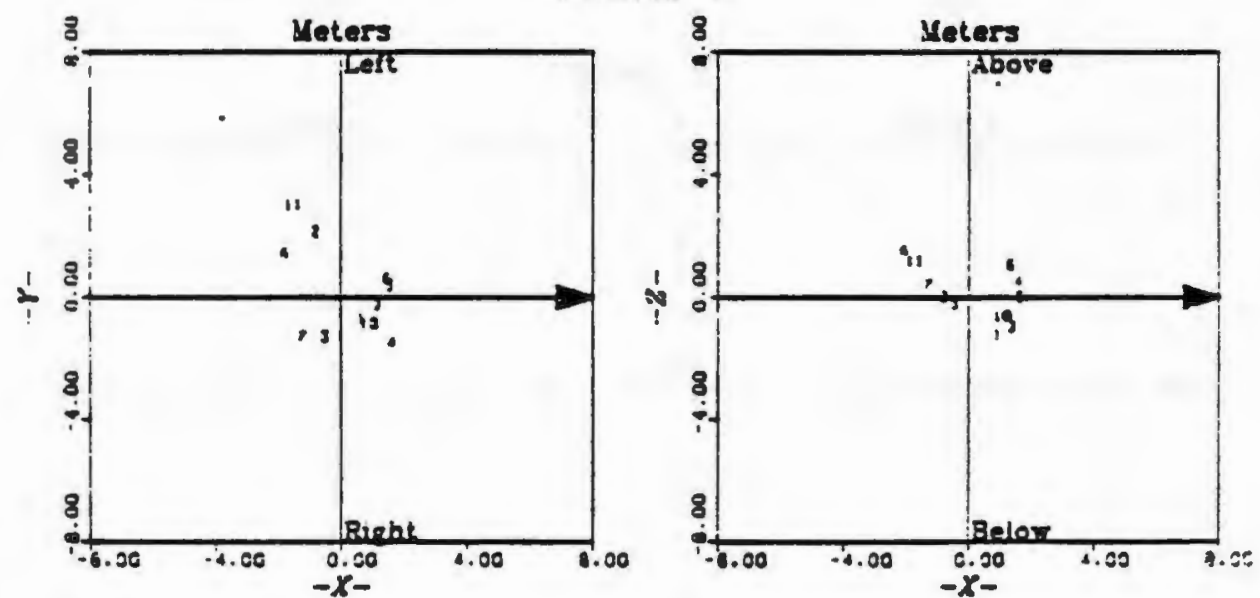
FRAIE 4
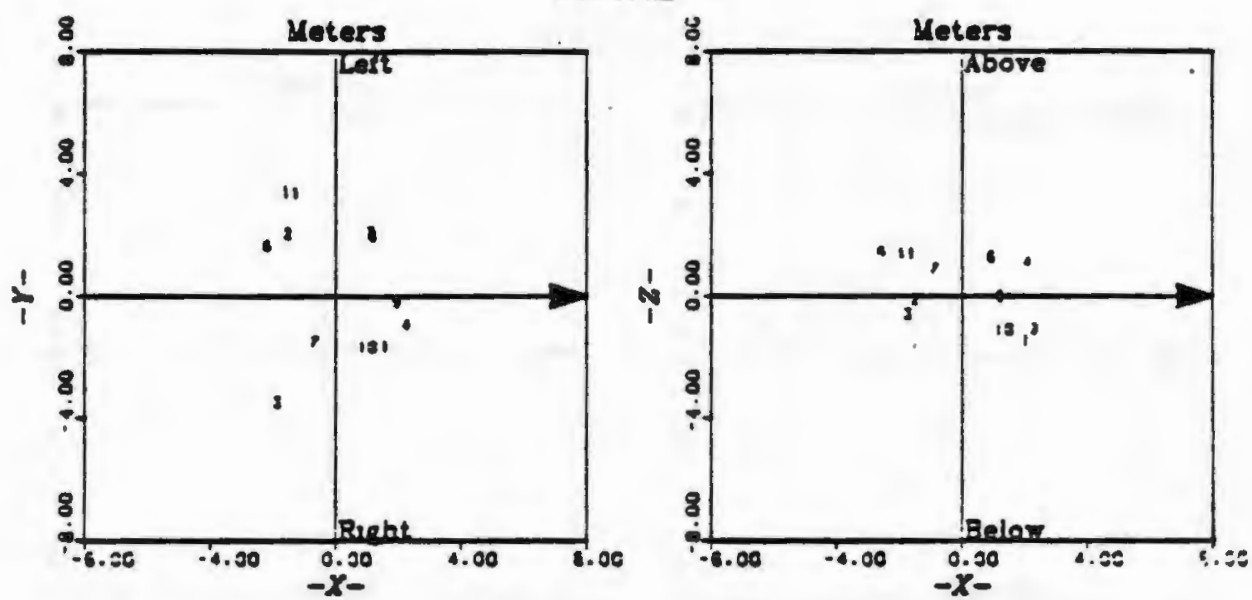

FRAME 5
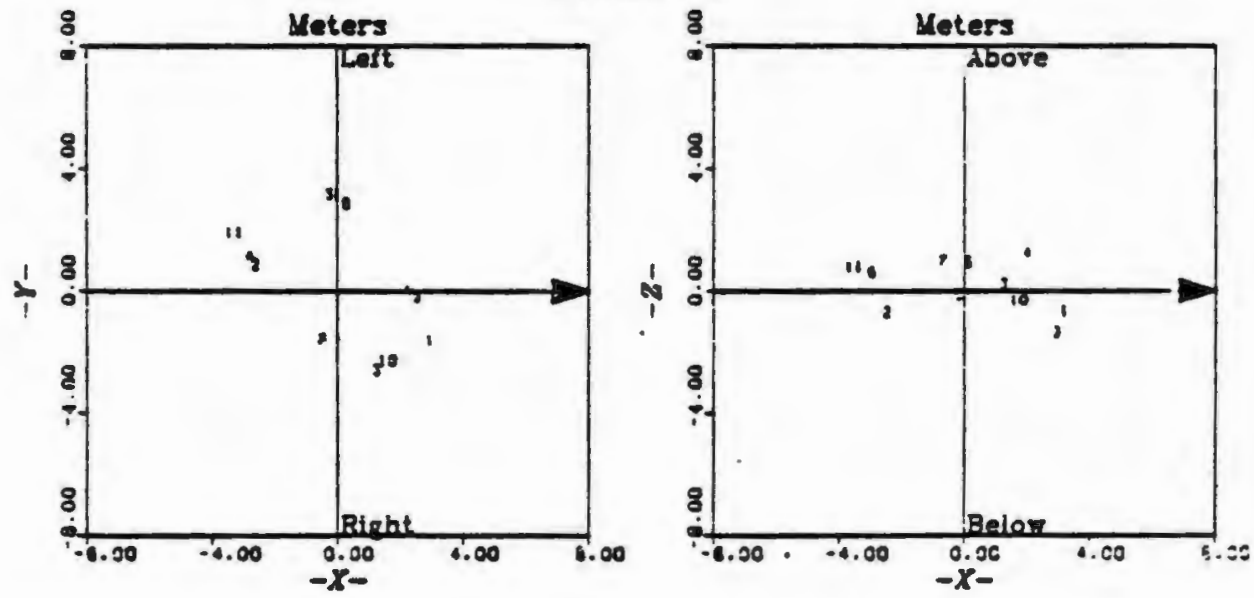
$54 c$
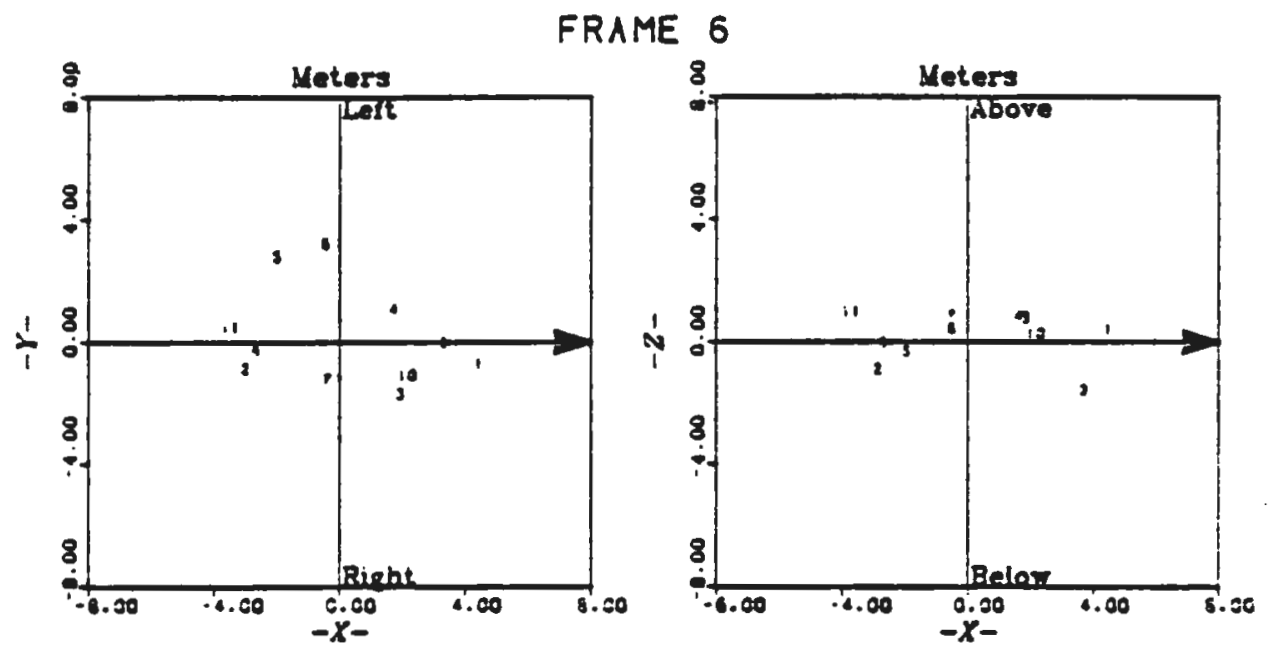
Figure 8. Spearman rank order correlations between front to back sequence of birds in the flock. Correlation coefficients (ordinate) are plotted for each of the increasingly longer time periods separating when the two rankings of birds used in the correlation were established (abscissa). 


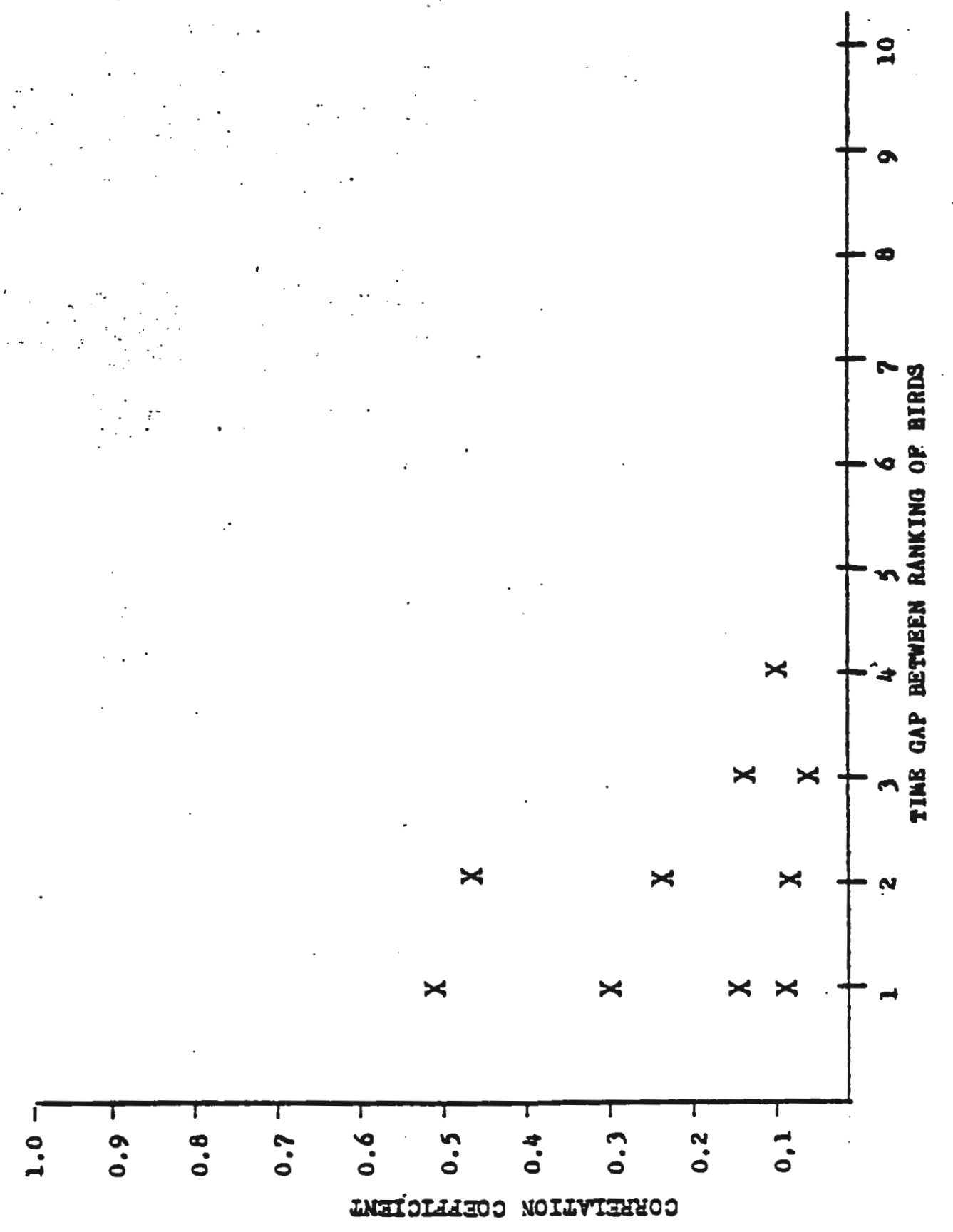


Figure 9. Summary information on flock movements over time. Figure 9a shows the flock in trial elght as seen from above for the eight points in time at which the flock was photographed. Arrows indicate the direction of travel of the flock. Figure $9 \mathrm{~b}$ shows the changes in elevation of the geometric center of the flock over time. Note that the $X-Y$ plane was elevated approximately $150 \mathrm{~cm}$ above ground level. 

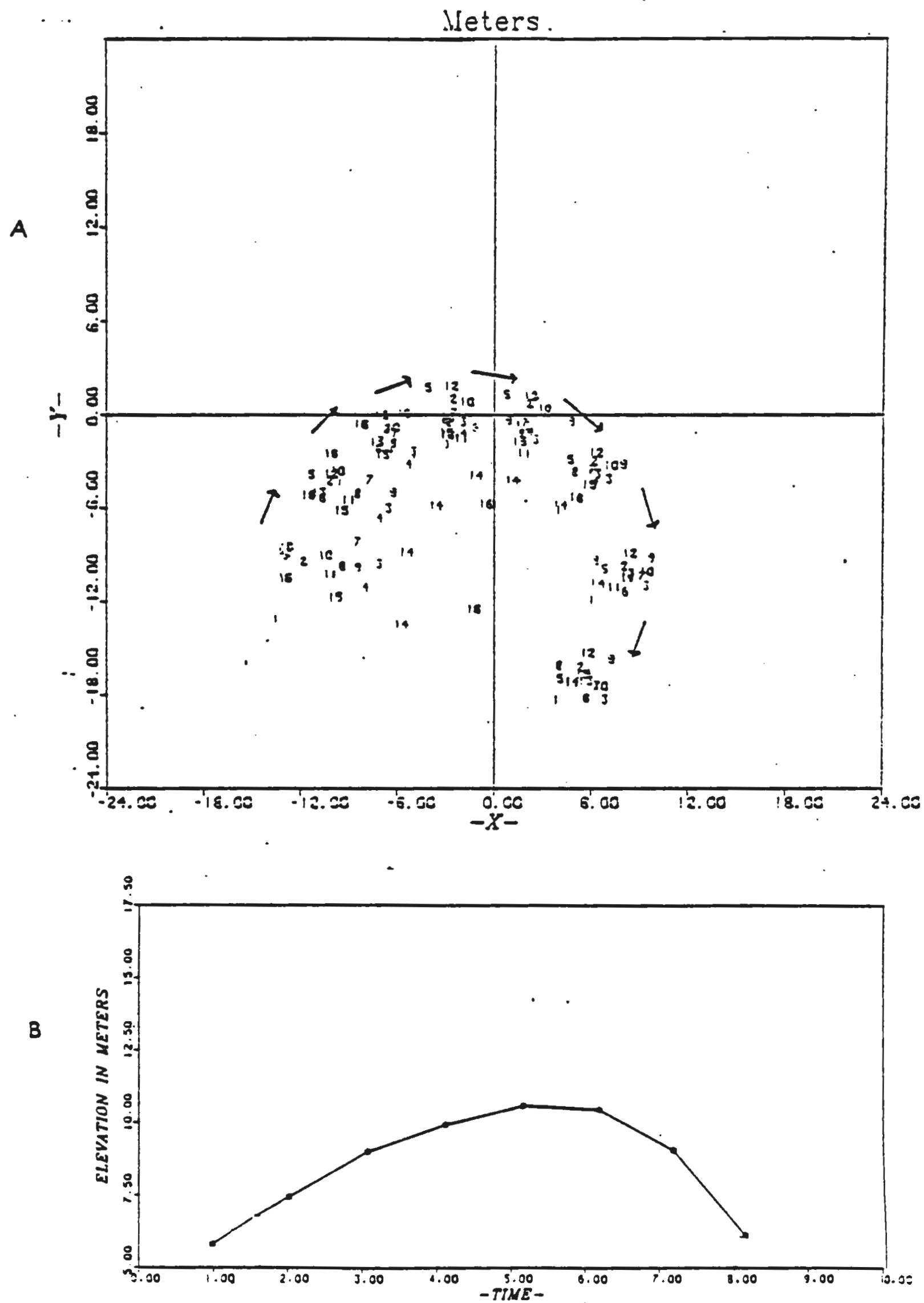
Figure 10. Changes in values for mean distance to nearest neighbor and mean separation distance within the flock for the eight time periods in trial eight. Specific types of combinations of changes in the two parameters may indicate different types of deployment of birds within the flock (see text for full explanation). 


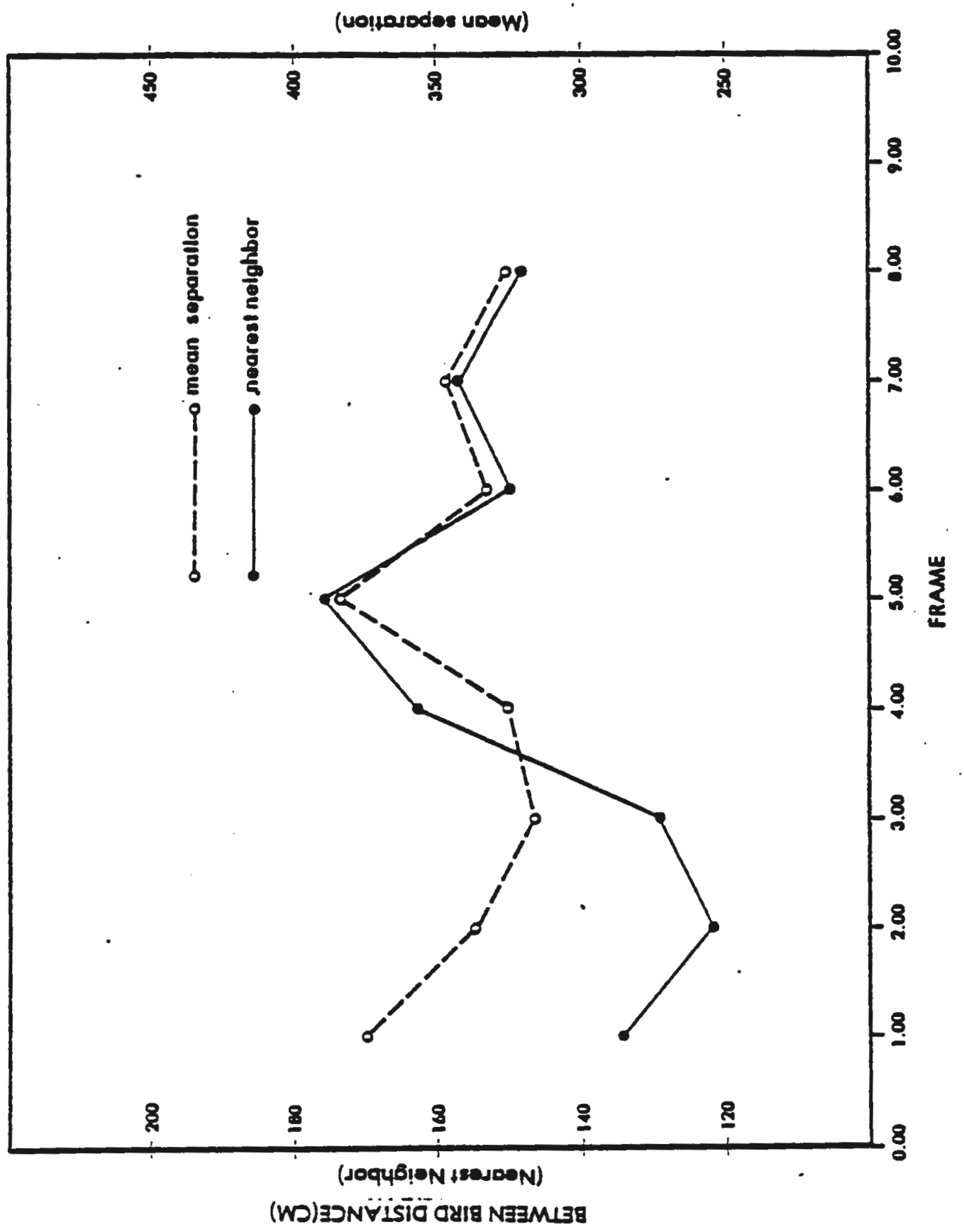


Figure 11. Distances to first through $\mathrm{N}^{\text {th }}$ neighbor within the flock are plotted for each of the time periods at which the flock in trial elght was photographed. Figure lla shows the nelghbor distance distribution for time one, while Figure $11 \mathrm{~b}$ shows the distances for time eight. The solid line in each plot connects the mean values of the distributions. The dashed line in all but the first plot is a trace of the Iine which connects mean values at time one, and appears so that changes in distributions over time may be more readily seen. 
$58 a$

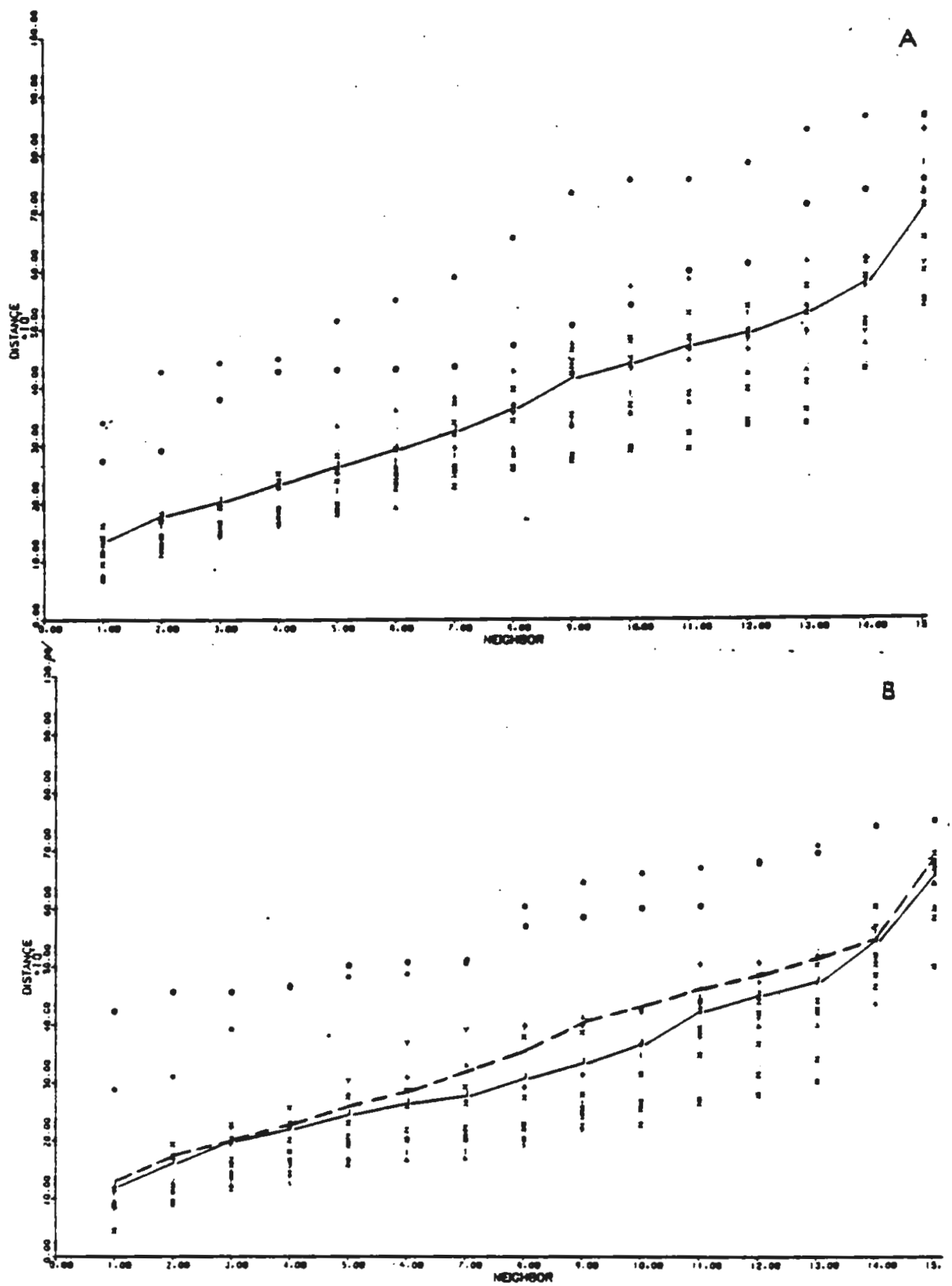



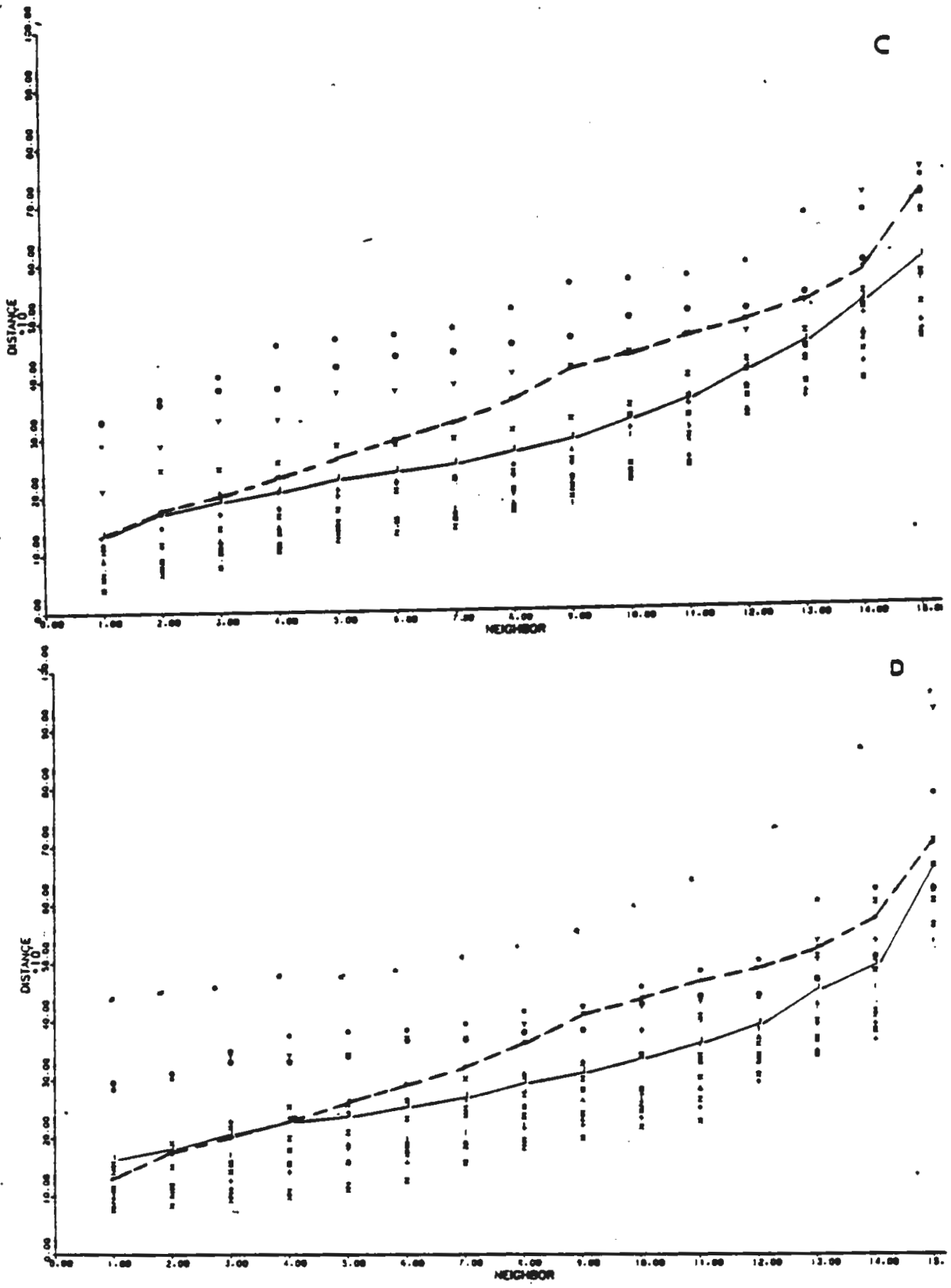
$58 d$

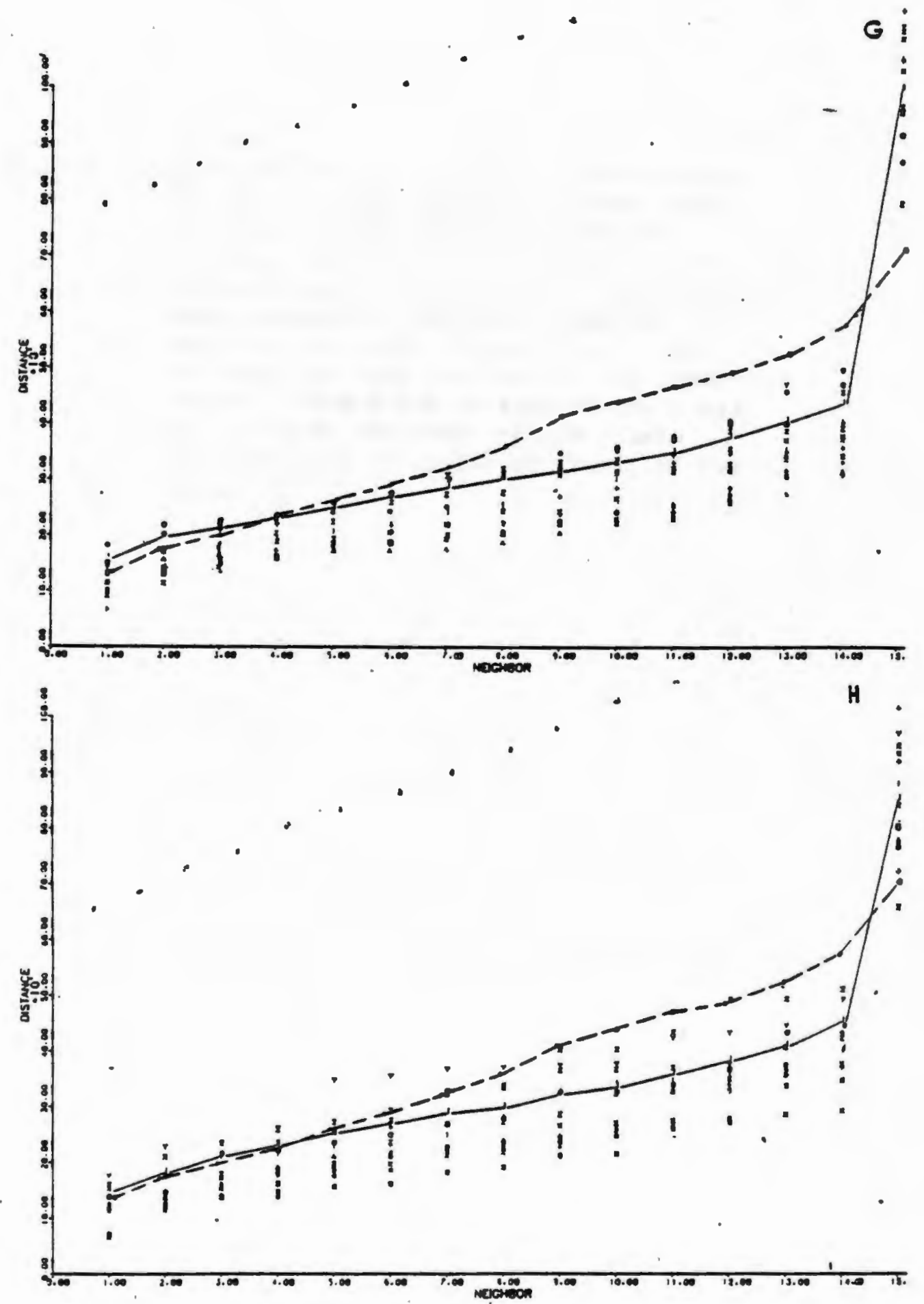


Figure 12. Relative positions, shown from two viewpoints, of flock members in trial elght at seven periods in time for which relative positions could be calculated. Assigned numbers of birds are shown as seen from above (left plot) and as seen from the side (right plot). The $X-Y$ axis has been centered at the geometric center of the flock in each of the plots. The arrow at the right of the $X$ axis indicates the direction of travel of the flock. 
FRAME 2
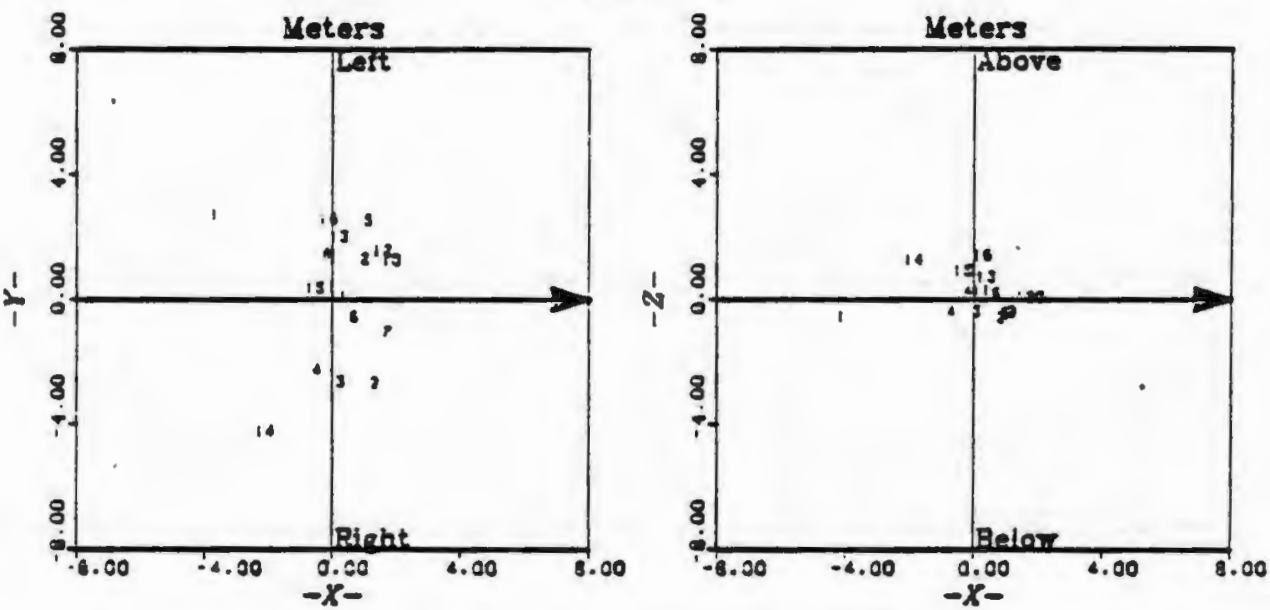

FRAME 3
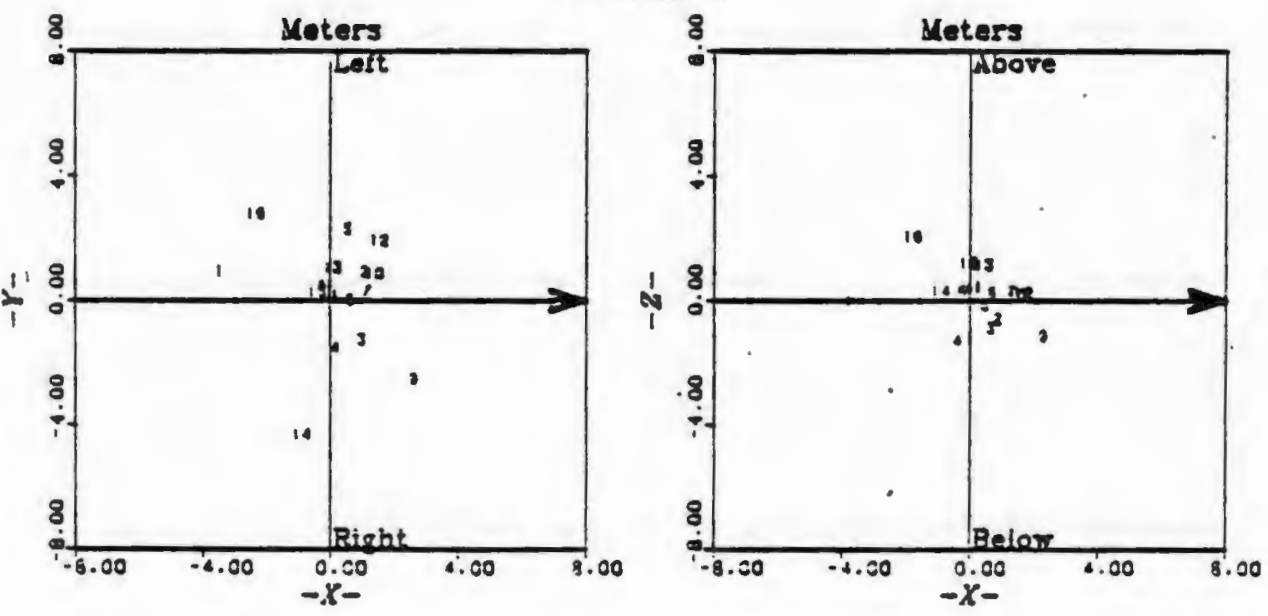
FRAME 4
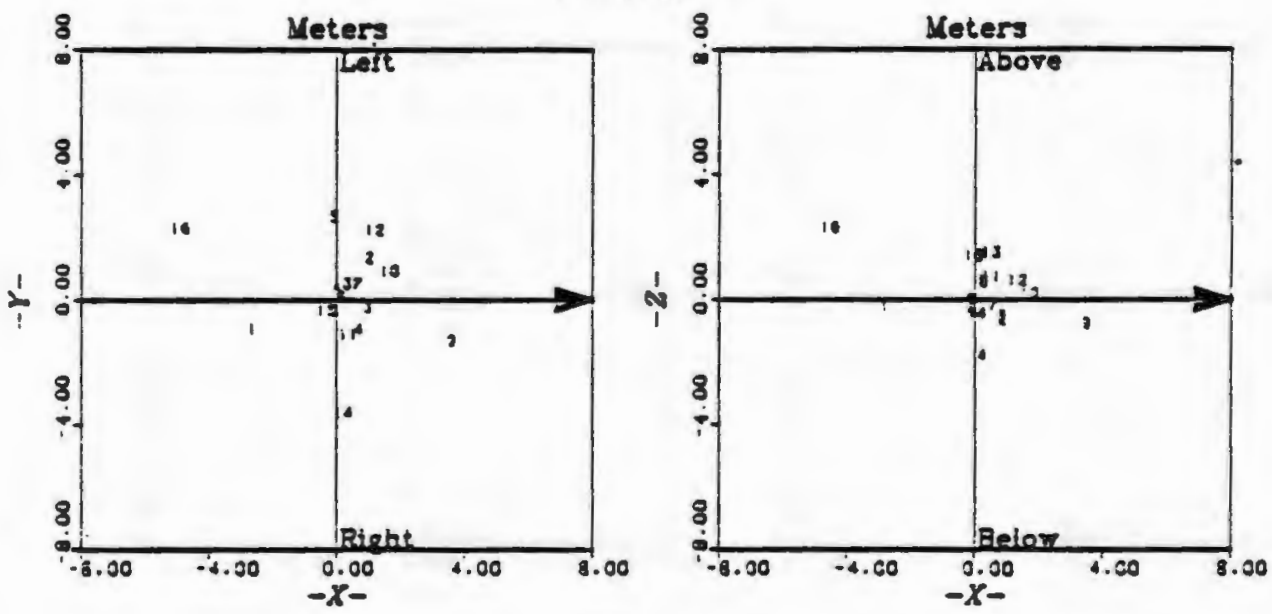

FRAME 5
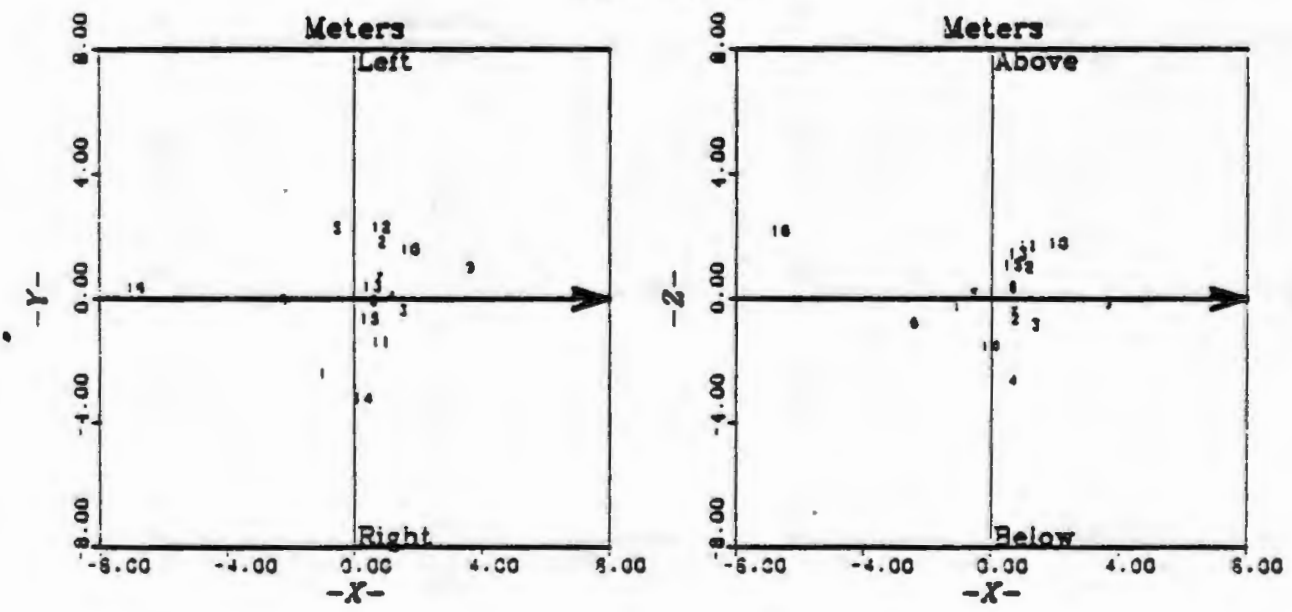

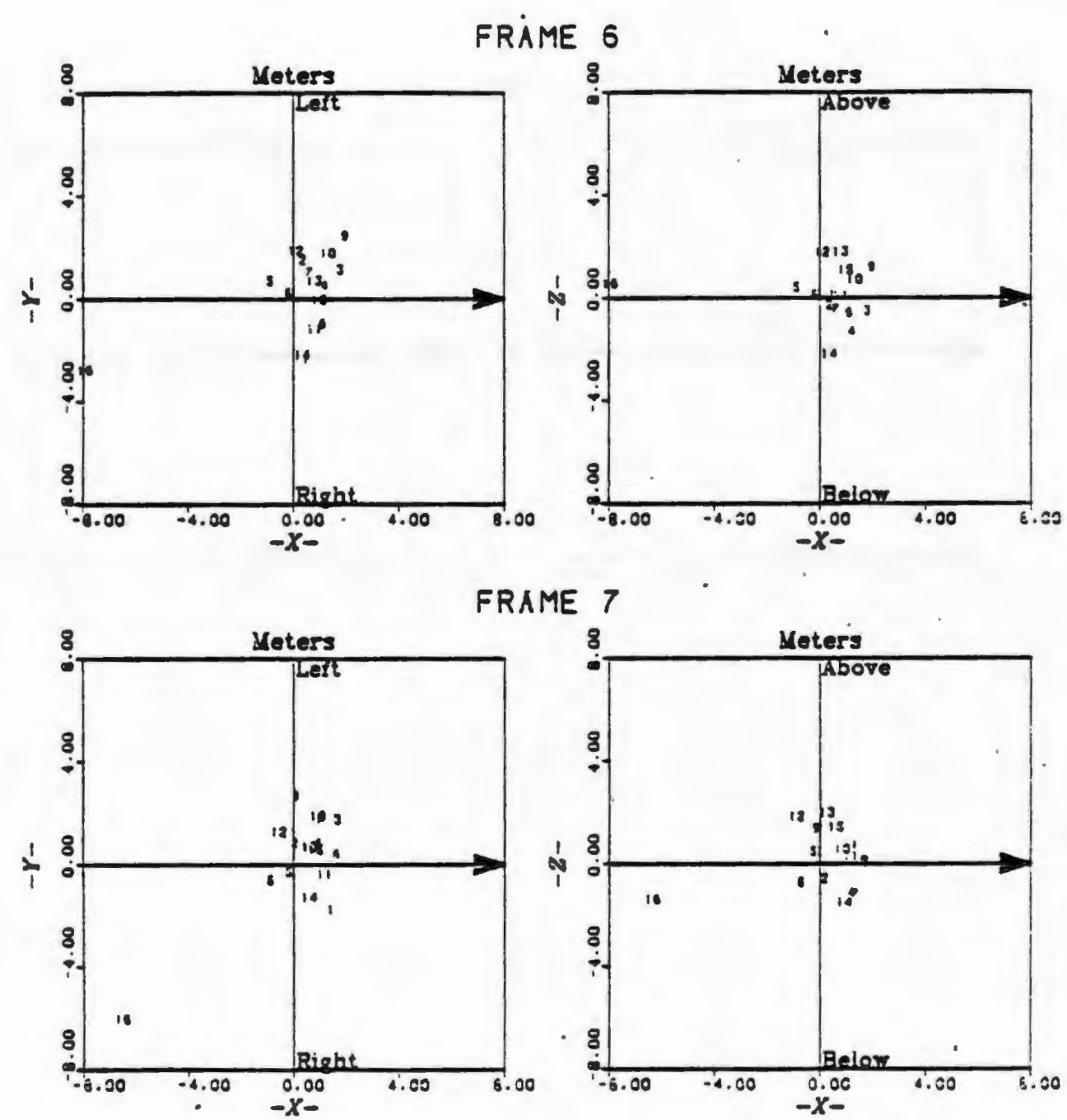
FRAME 8
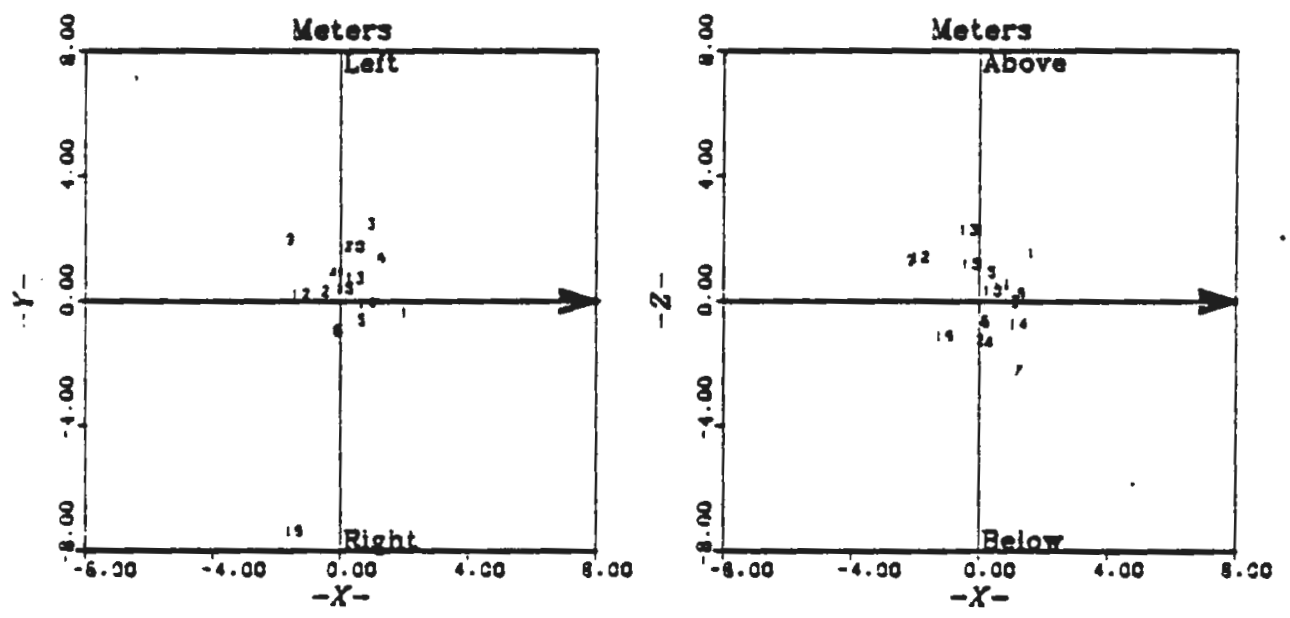
Figure 13. Spearman rank order correlations between front to back sequence of birds in the flock. Correlation coefficients (ordinate) are plotted for each of the increasingly longer time pertods separating when the two rankings of birds used in the correlation was established (abscissa). 


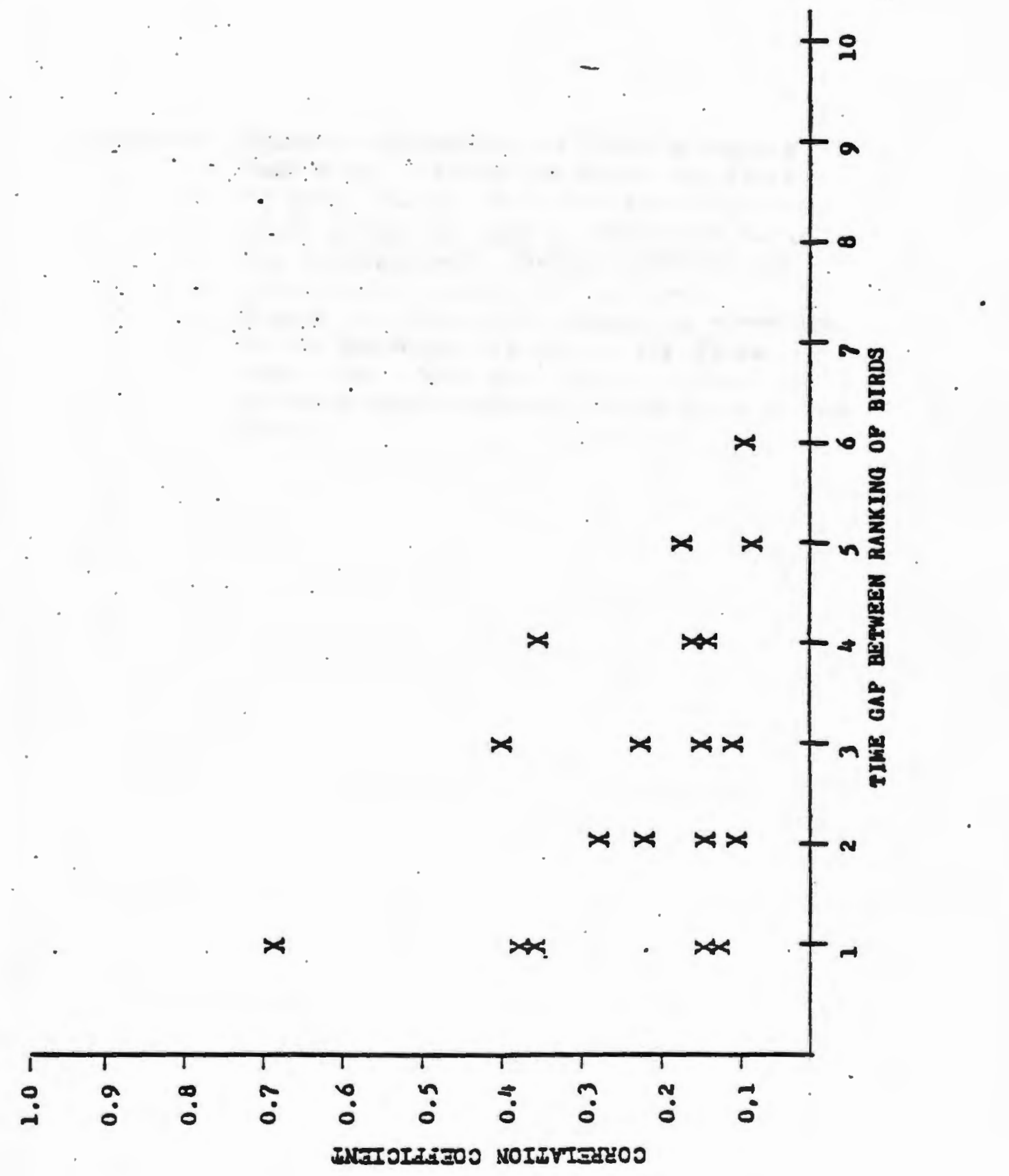


F1gure 14. Summary information on flock movements over time. Figure 14a shows the flock in trial two as seen from above for the seven points in time at which the flock was photographed. Arrows indicate the direction of travel of the flock. Figure $14 \mathrm{~b}$ shows the changes in elevation of the geometric center of the flock over time. Note that the $X-Y$ plane was elevated approximately $150 \mathrm{~cm}$ above ground level. 

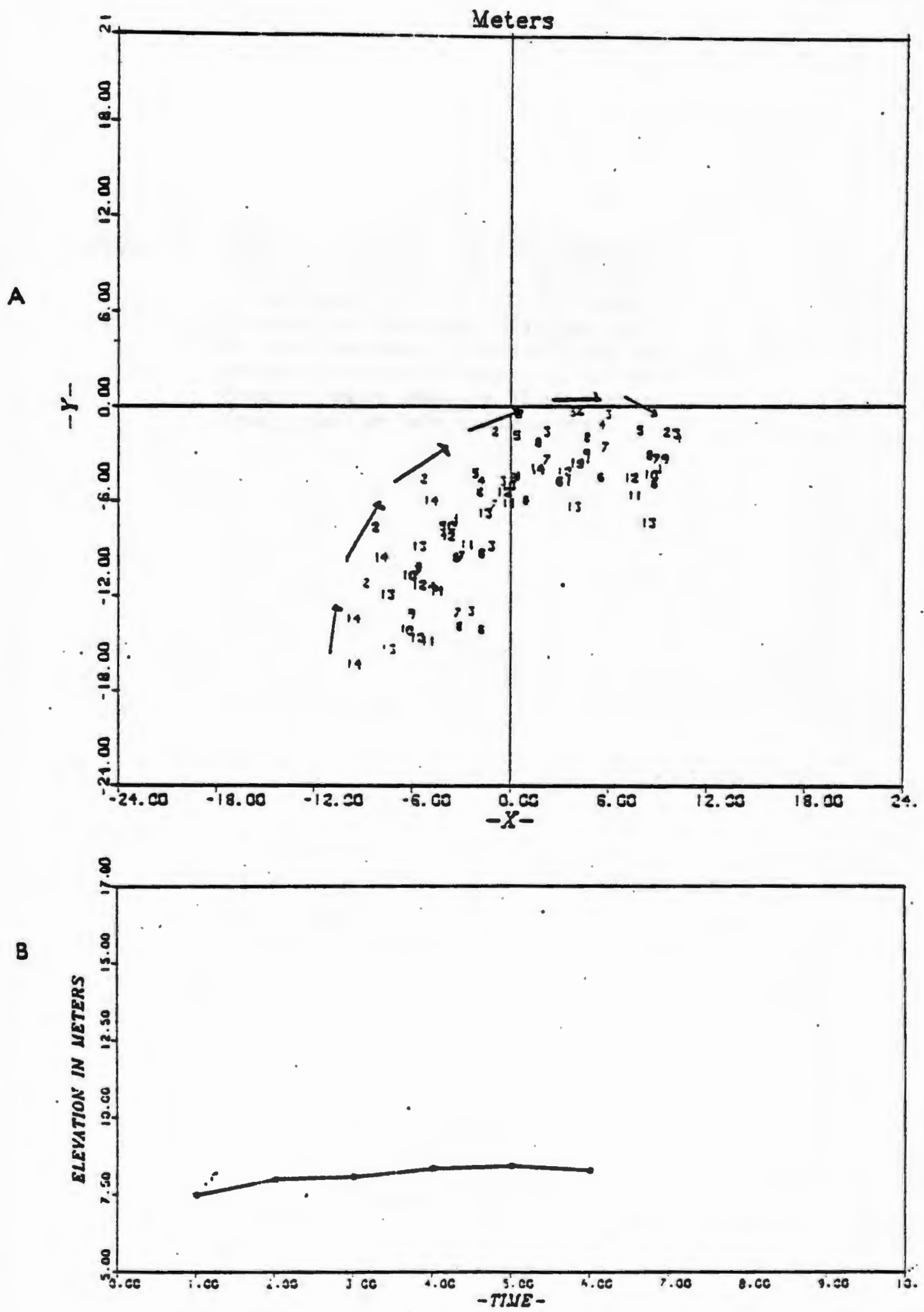
Flgure 15. Changes in values for mean separation distance and mean distance to first nearest nelghbor for the six time perlods in trial two. Varfous types of combinations of change in the two parameters are indicative of specific types of deployment of flock members (see text for full explanation). 


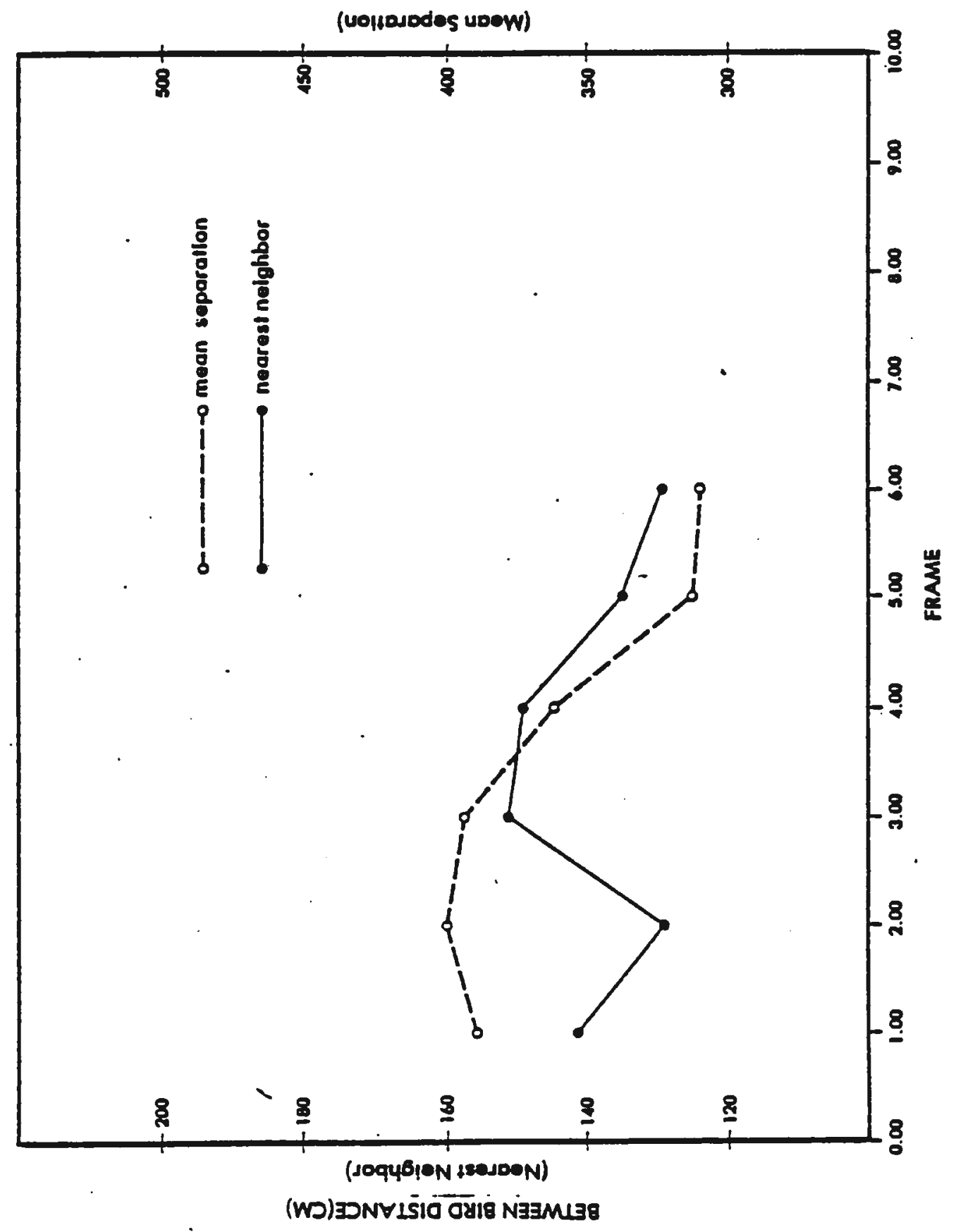


Figure 16. Distances to first through $\mathrm{N}^{\text {th }}$ neighbor within the flock are plotted for each of the time periods at which the flock in trial two was photographed. Figure 16a shows the neighbor distance distribution for time one, while Figure $16 f$ shows the distances at time six. The solid line in each plot connects the mean values of the distributions. The dashed line in all but the first plot is a trace of the line which connects mean values at time one, and appears so that changes in distributions over time may be more readily seen. 


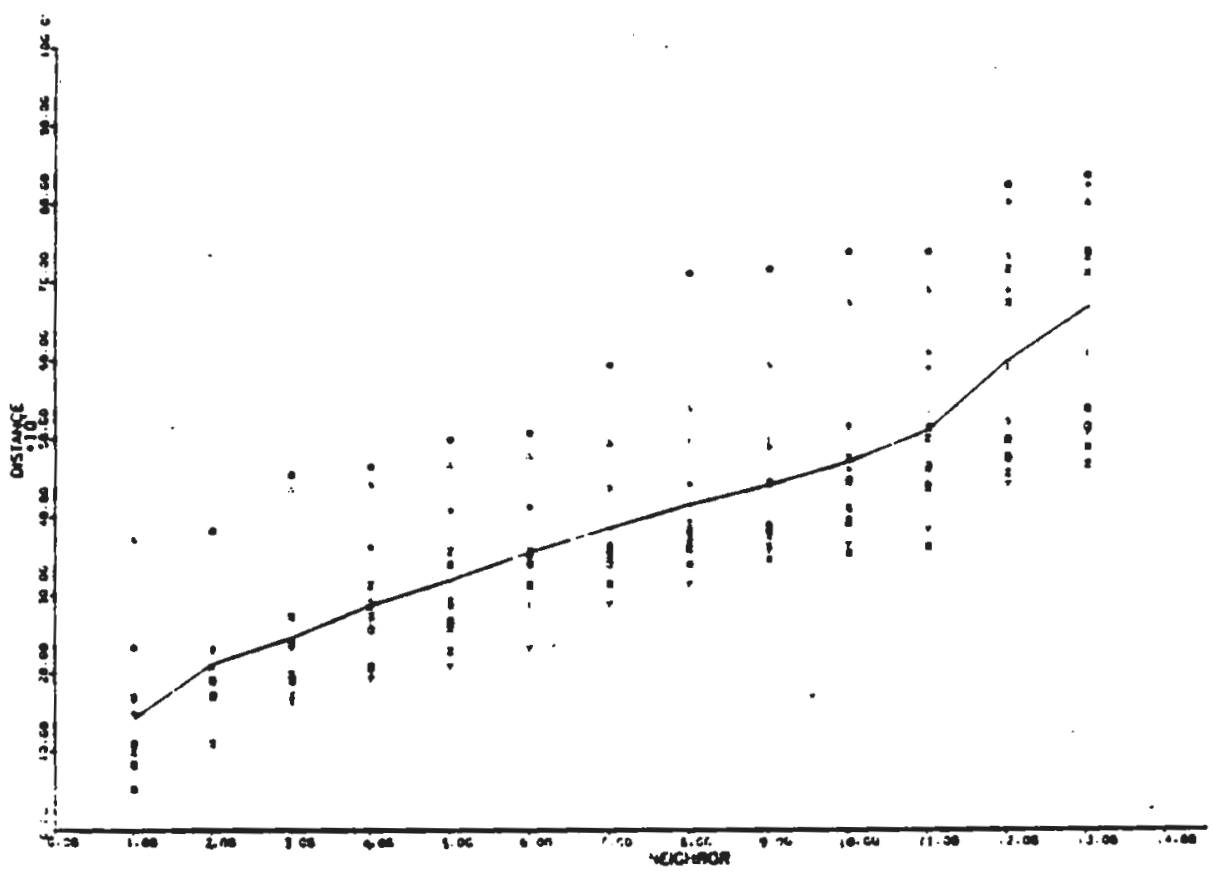

A

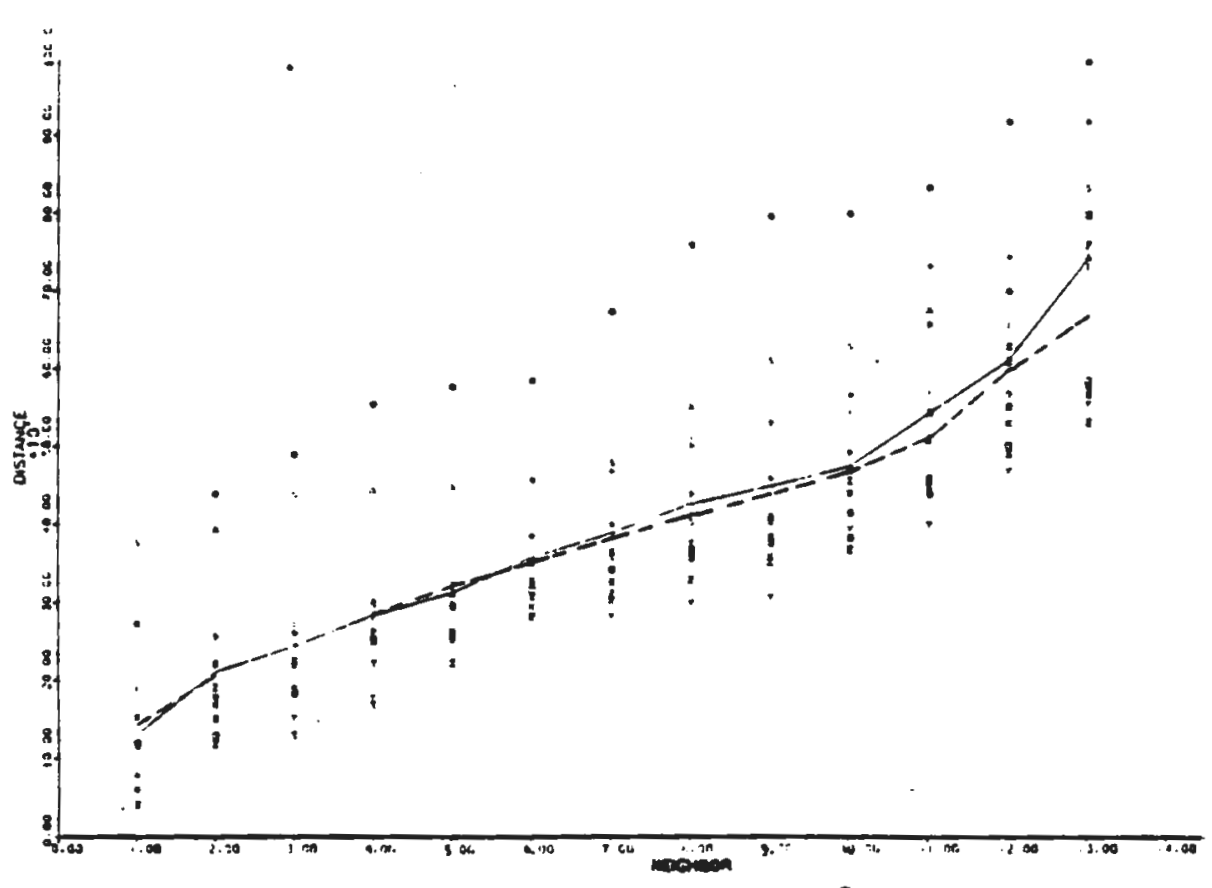




$$
\underline{m}
$$


$63 c$

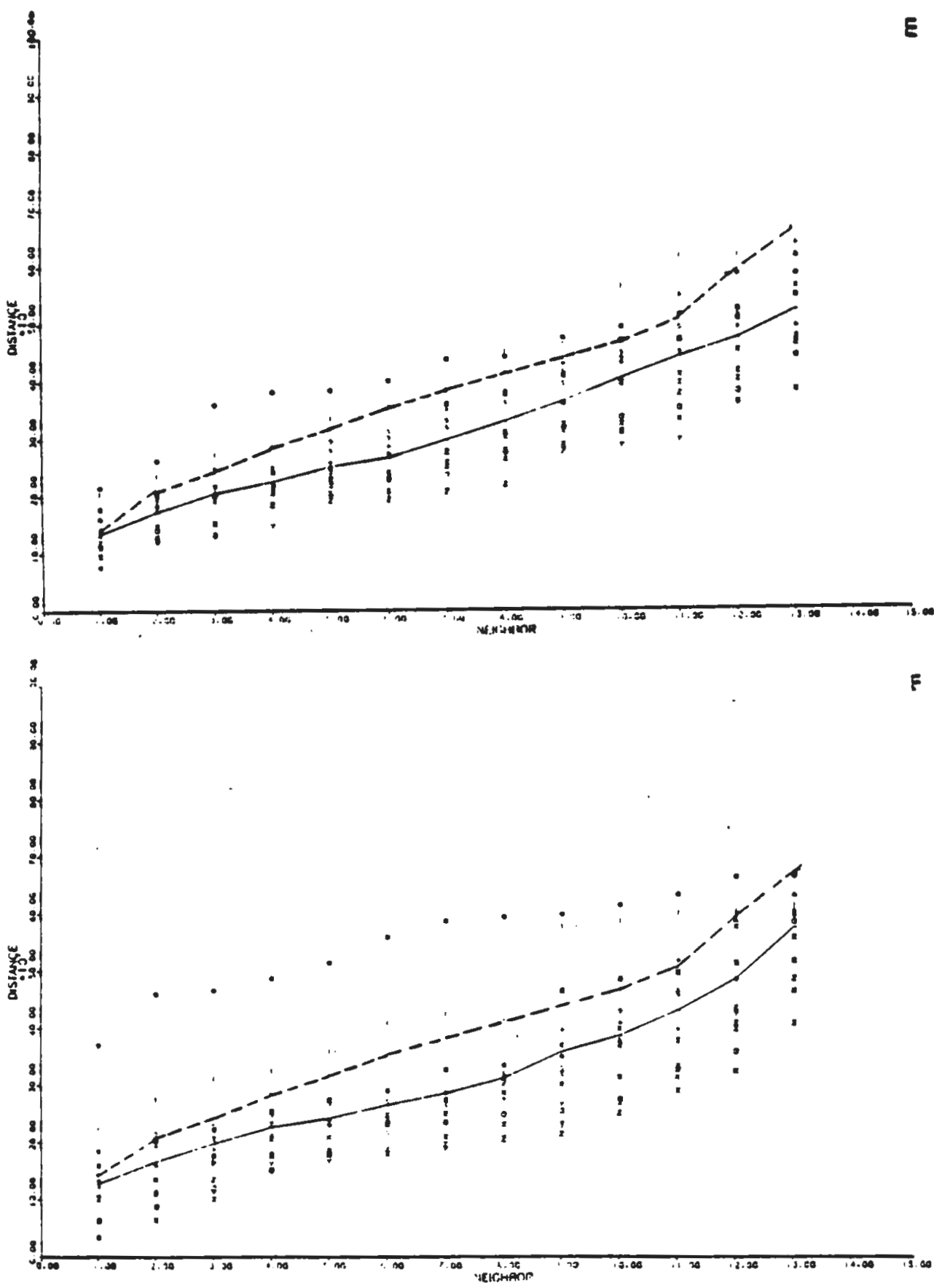


Figure 17. Relative positions, shown from two viewpoints, of flock members in trial two at five periods in time for which relative positions could be calculated.

Assigned numbers of birds are shown as seen from above (left plot) and as seen

from the side (right plot). The $X-Y$ axis

has been centered at the geometric center of the flock in each of the plots. The arrow the right of the $X$ axis indicates the direction of travel of the flock. 
FRAME 2
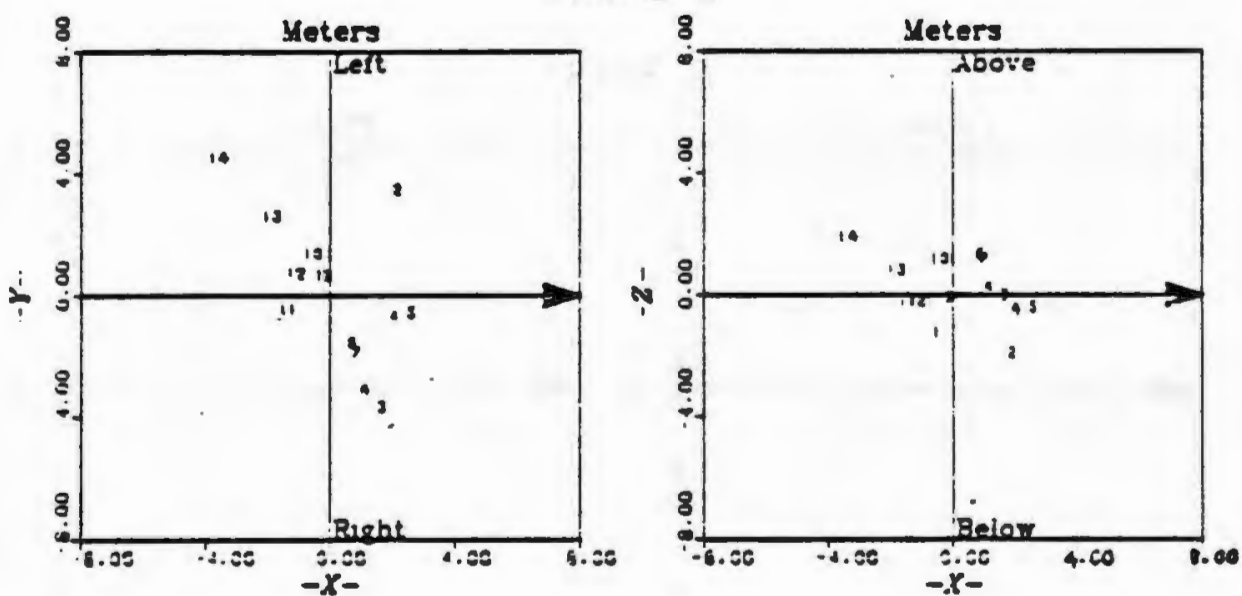

FRAME 3
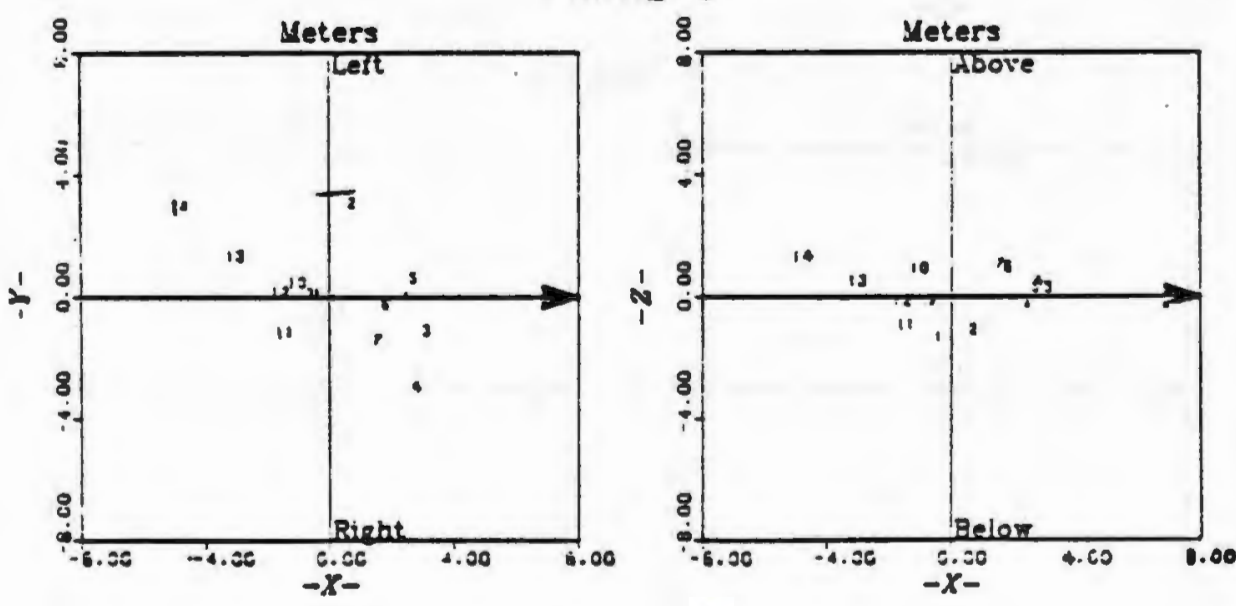
FRAME 4
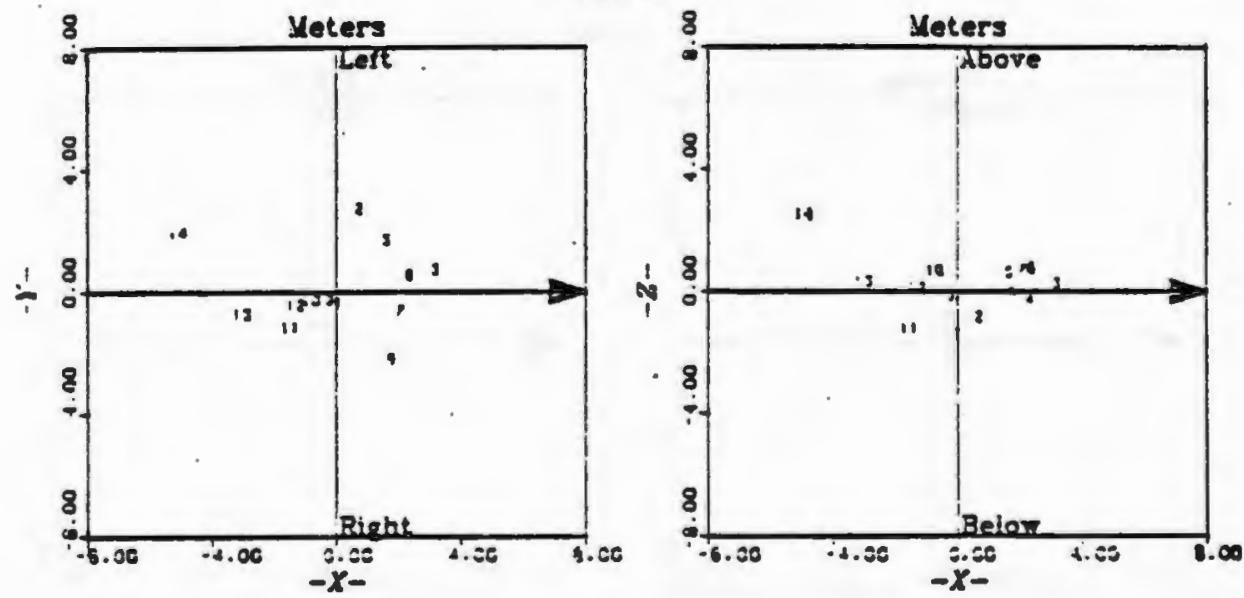

\section{FRAME 5}
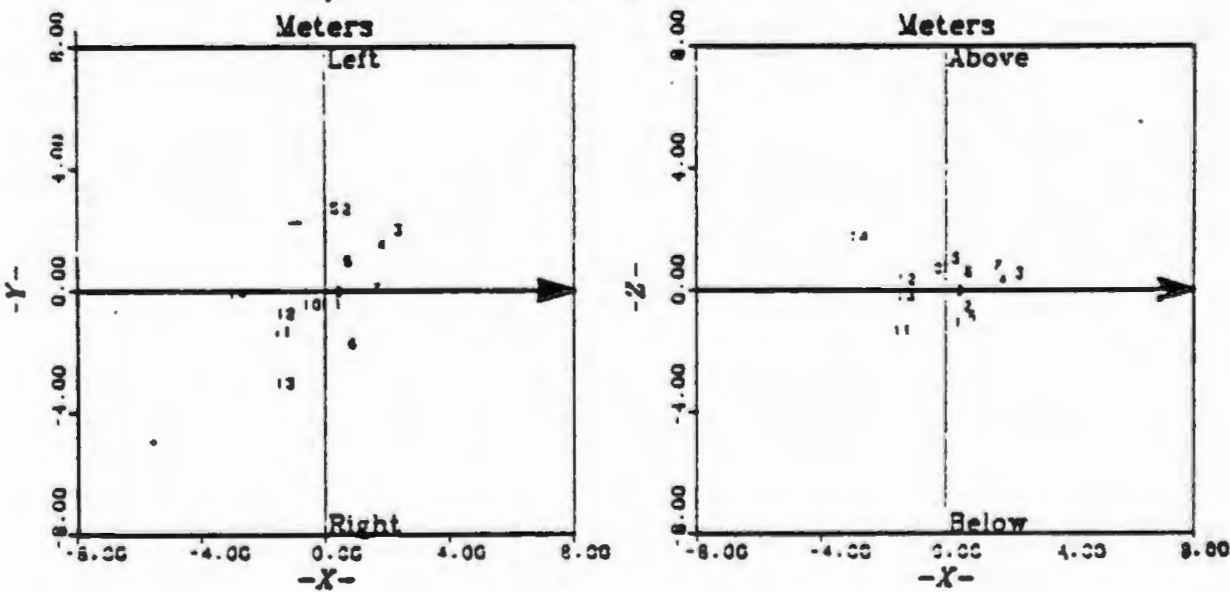
FRAME 6
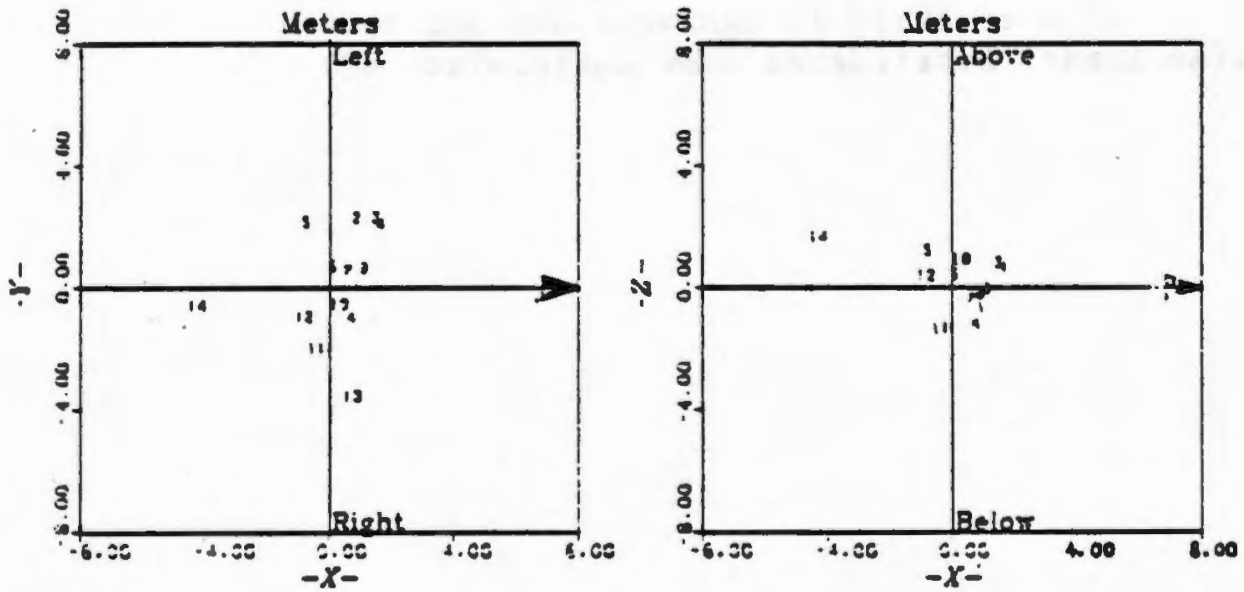
Figure 18. Spearman rank order correlations between front to back sequence of birds in the flock. Correlation coefficients (ordinate) are plotted for each of the increasingly longer time periods separating when the two rankings of birds used in the correlation were established (abscissa). 


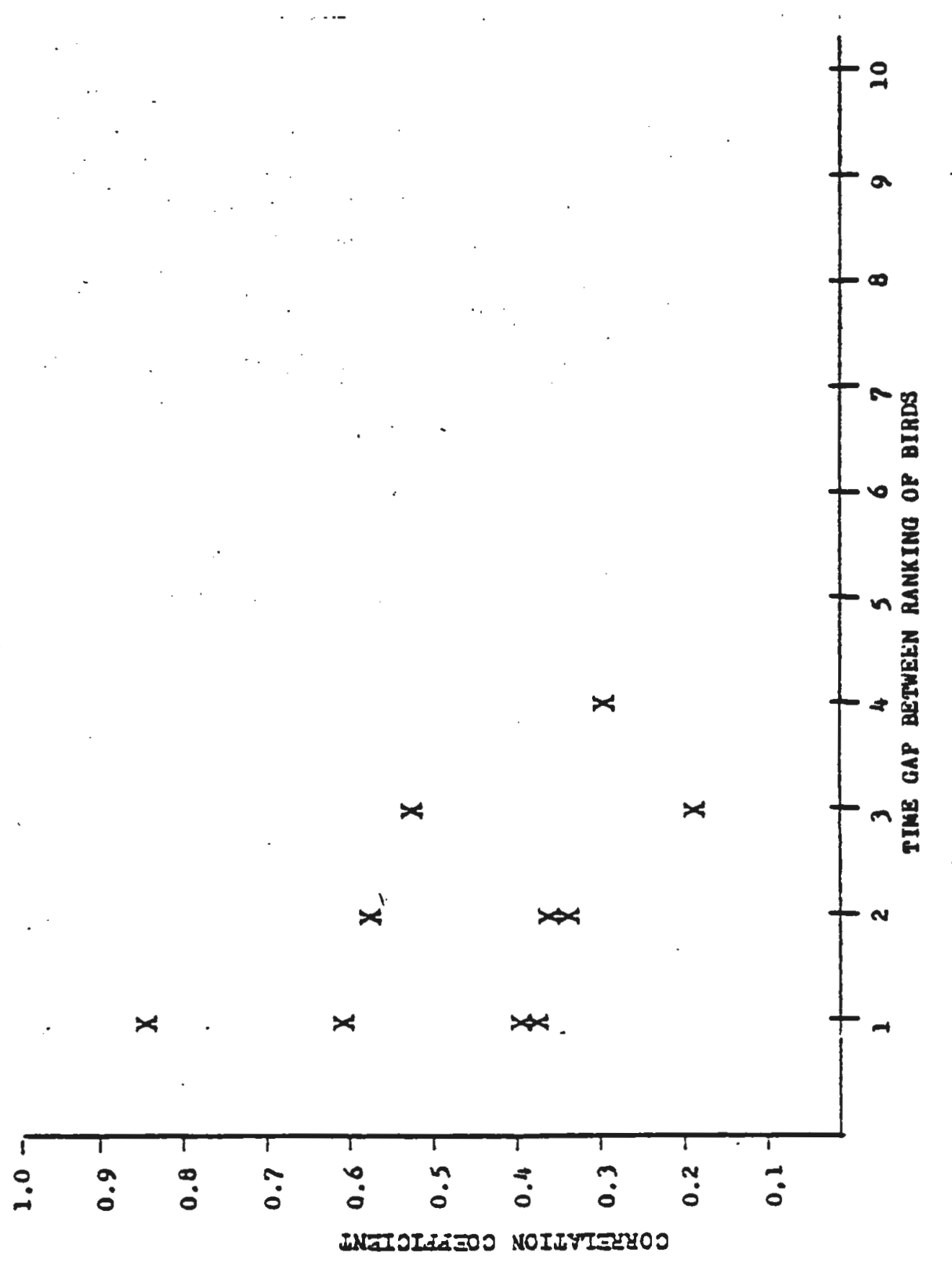


Figure 19. Summary data on turning in flocks. A table is Ilsted for each trial which shows the mean flight speed maintained by birds in the flock between sequential time perfods, and the angle of turn described by the flock during the same time period. Two plots are shown for each trial, which show the average flight speed and changes in elevation of the geometric center of the flock over time. F1gures 19a. through $19 \mathrm{e}$ show tables and plots for trials two, six, elght, seven, and nine respectively. 


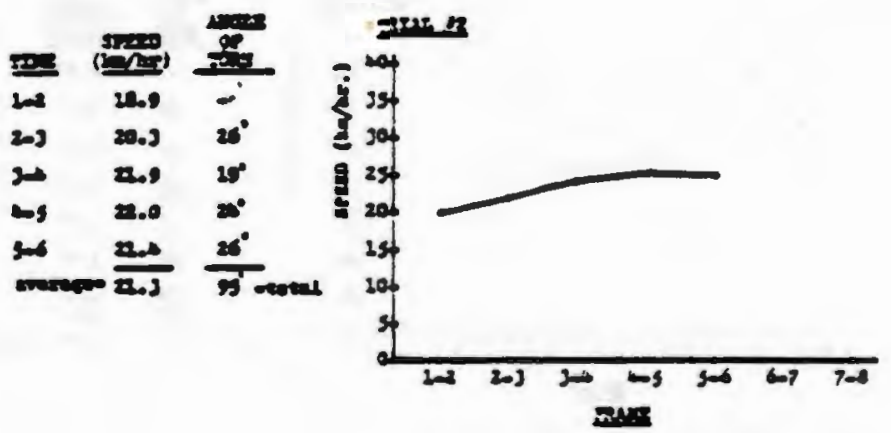

a
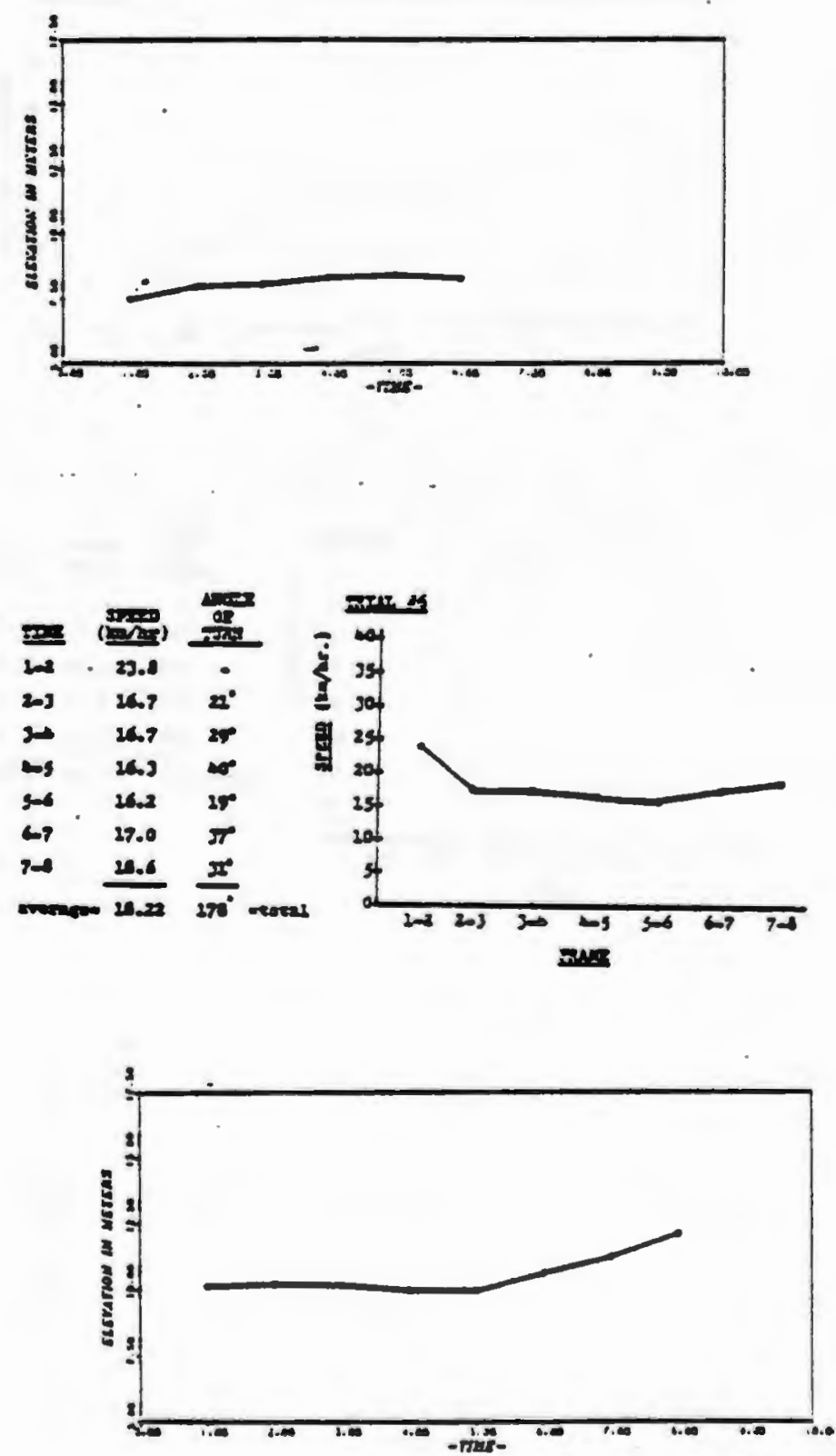


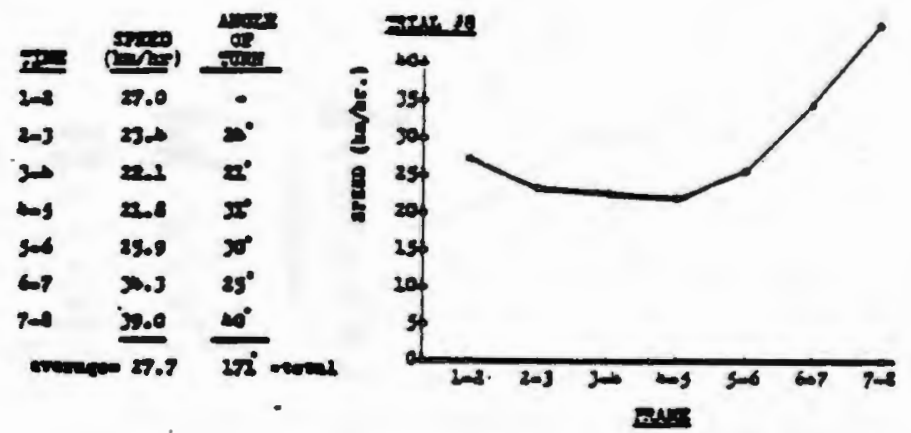

C
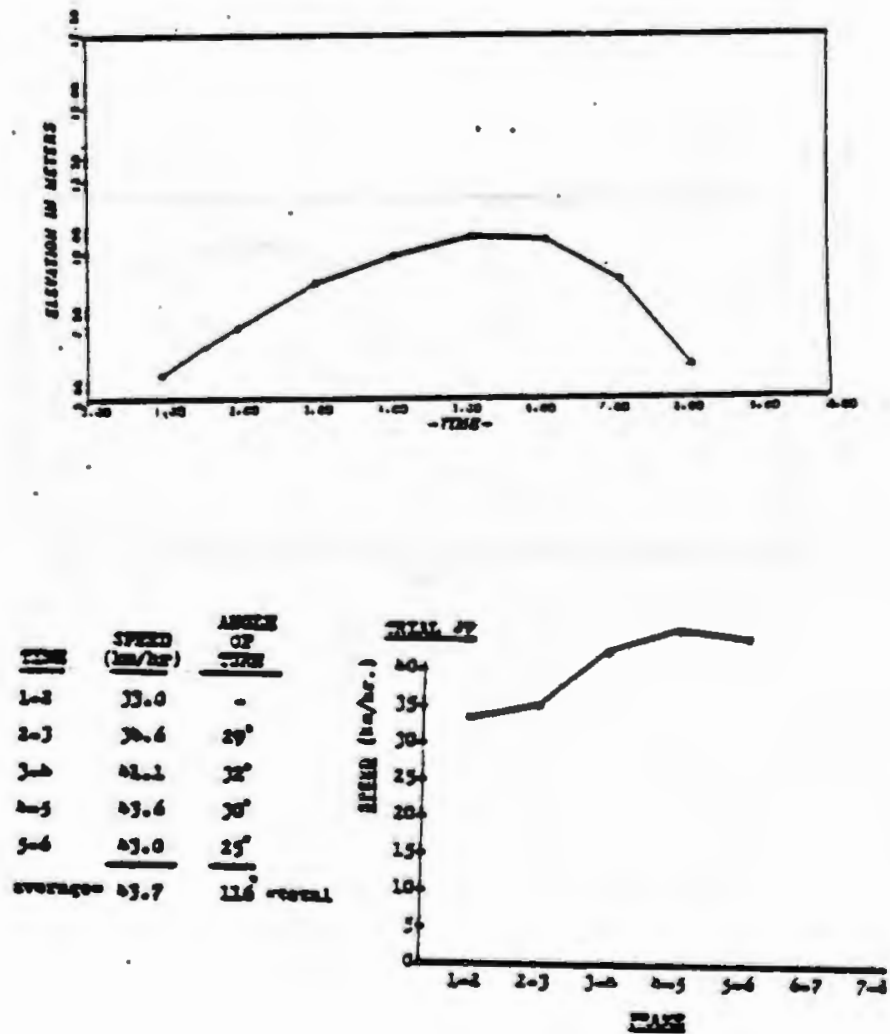

d

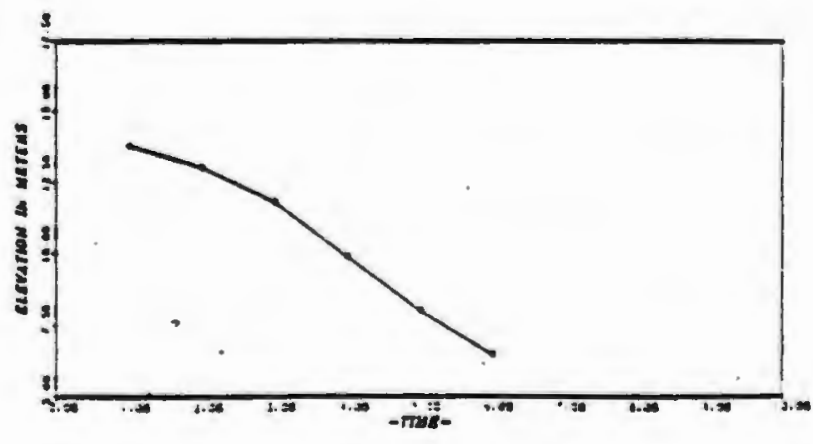




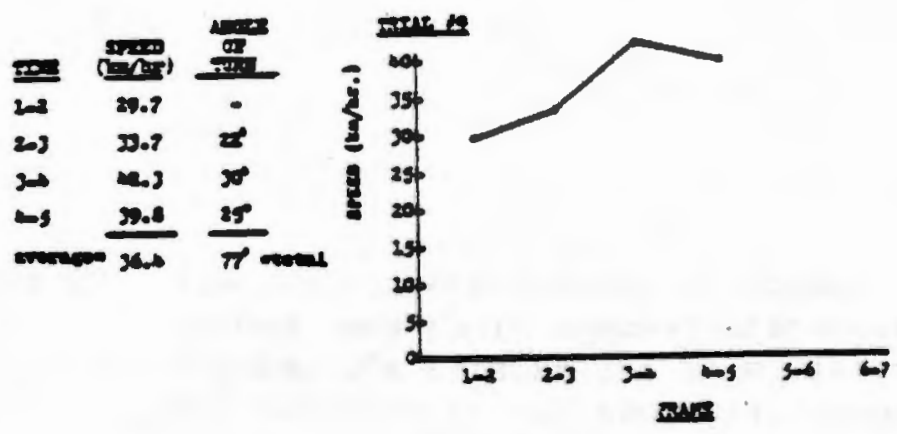

e

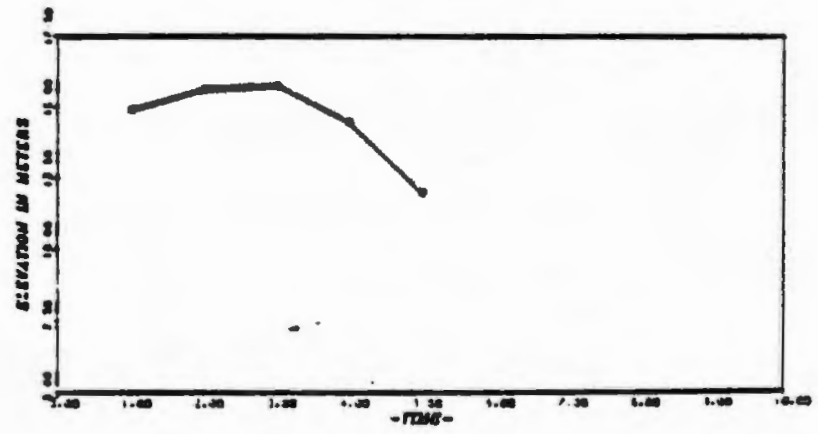


Figure 20. Frequency distributions of pigeon first, second, and third nearest distances. Figures 20a through 20e show distributions for birds in trials two, six, seven, eight, and nine respectively. 
$67 a$

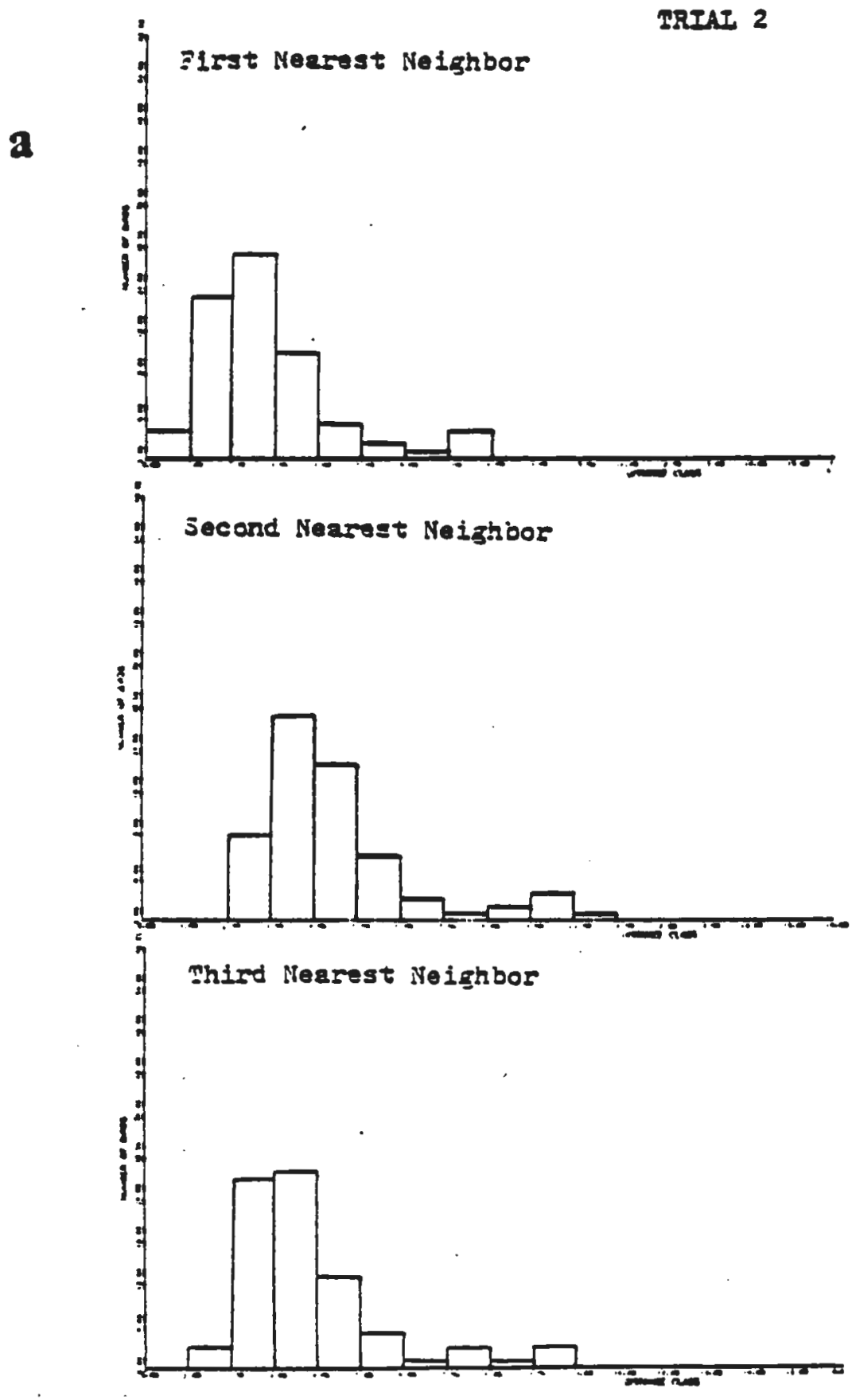


$67 b$

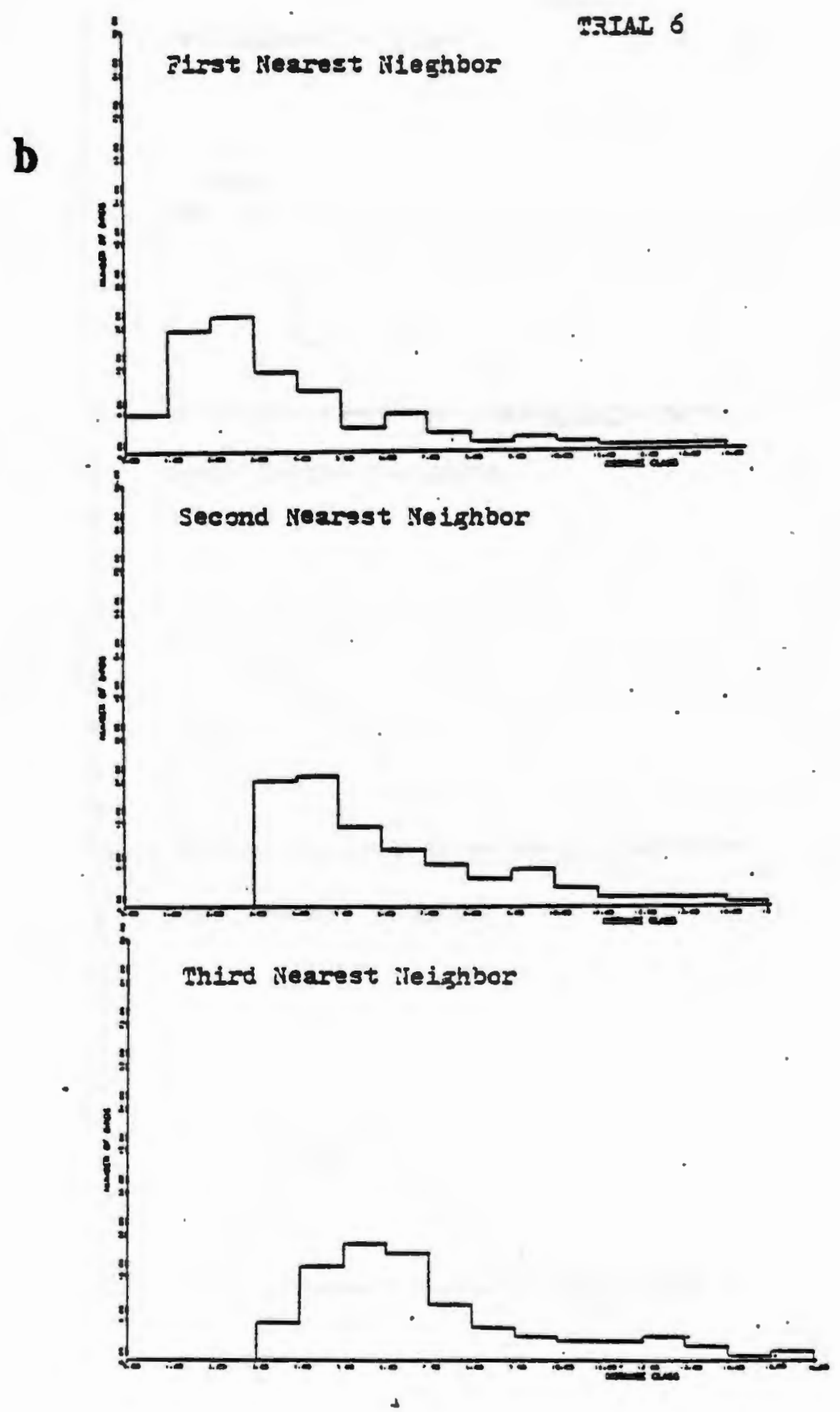


$67 c$

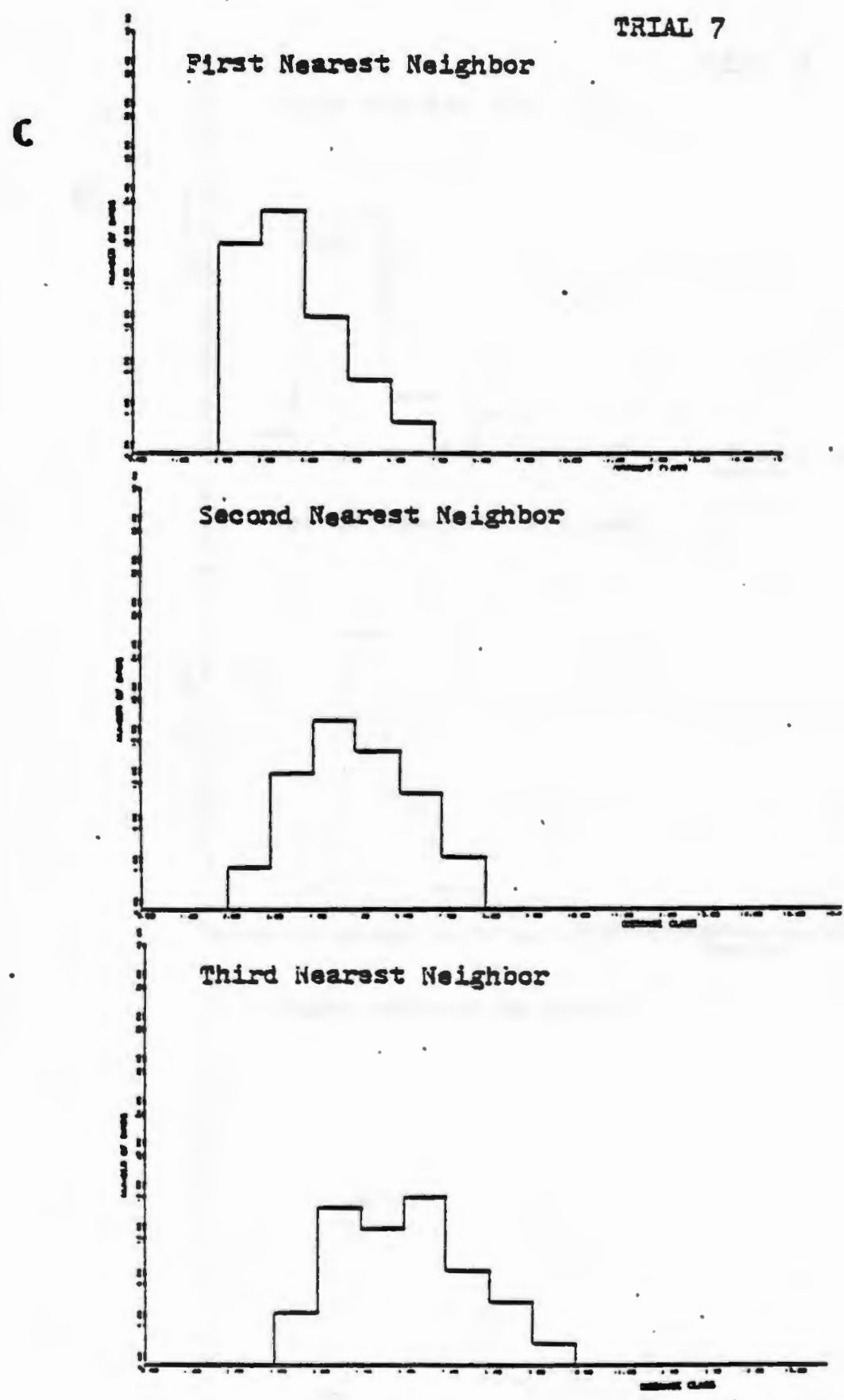


$67 d$

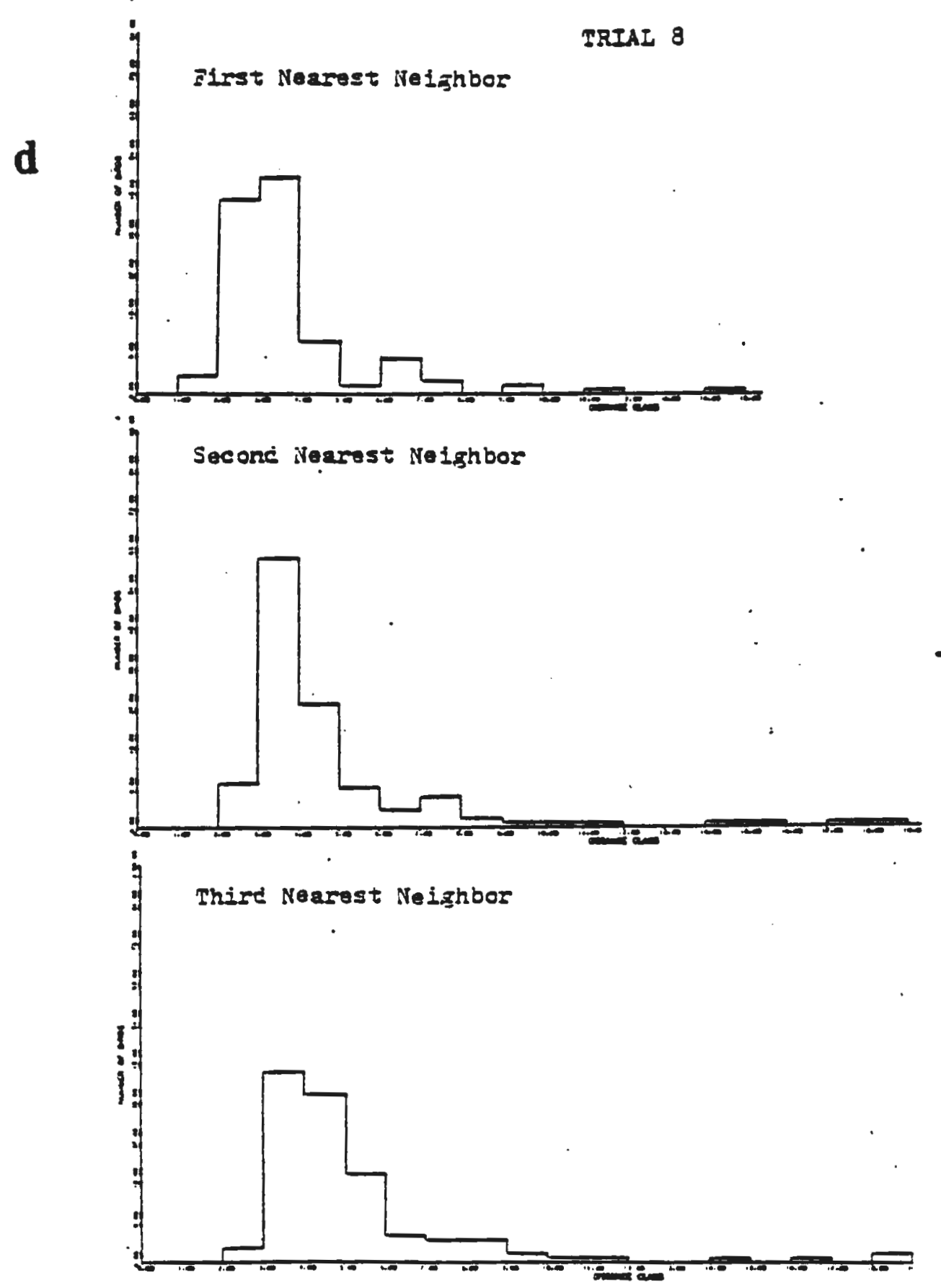




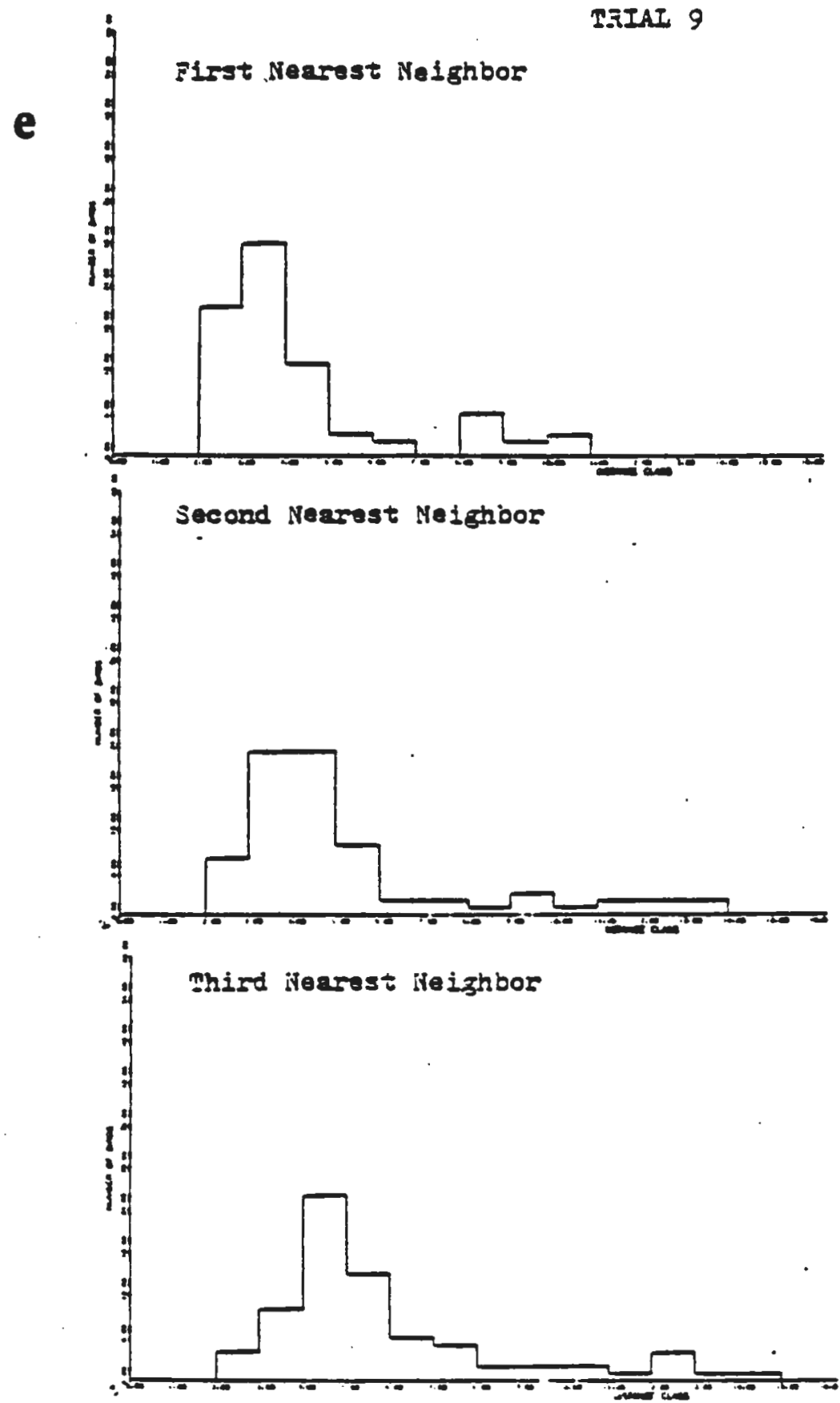


Figure 21. Differences in dominance rank of first nearest nelghbor palrs in the alrborne flocks. Each bird in the flank was analyzed in turn as the reference bird, and the difference in dominance rank of Its first nearest nelghbor was determined. This process was done for all time perfods in all trials. The possible dominance ranks of the reference bird are listed along the abscissa, with the mean difference in rank of all identified nearest nelghbors plotted on the ordinate axis. 


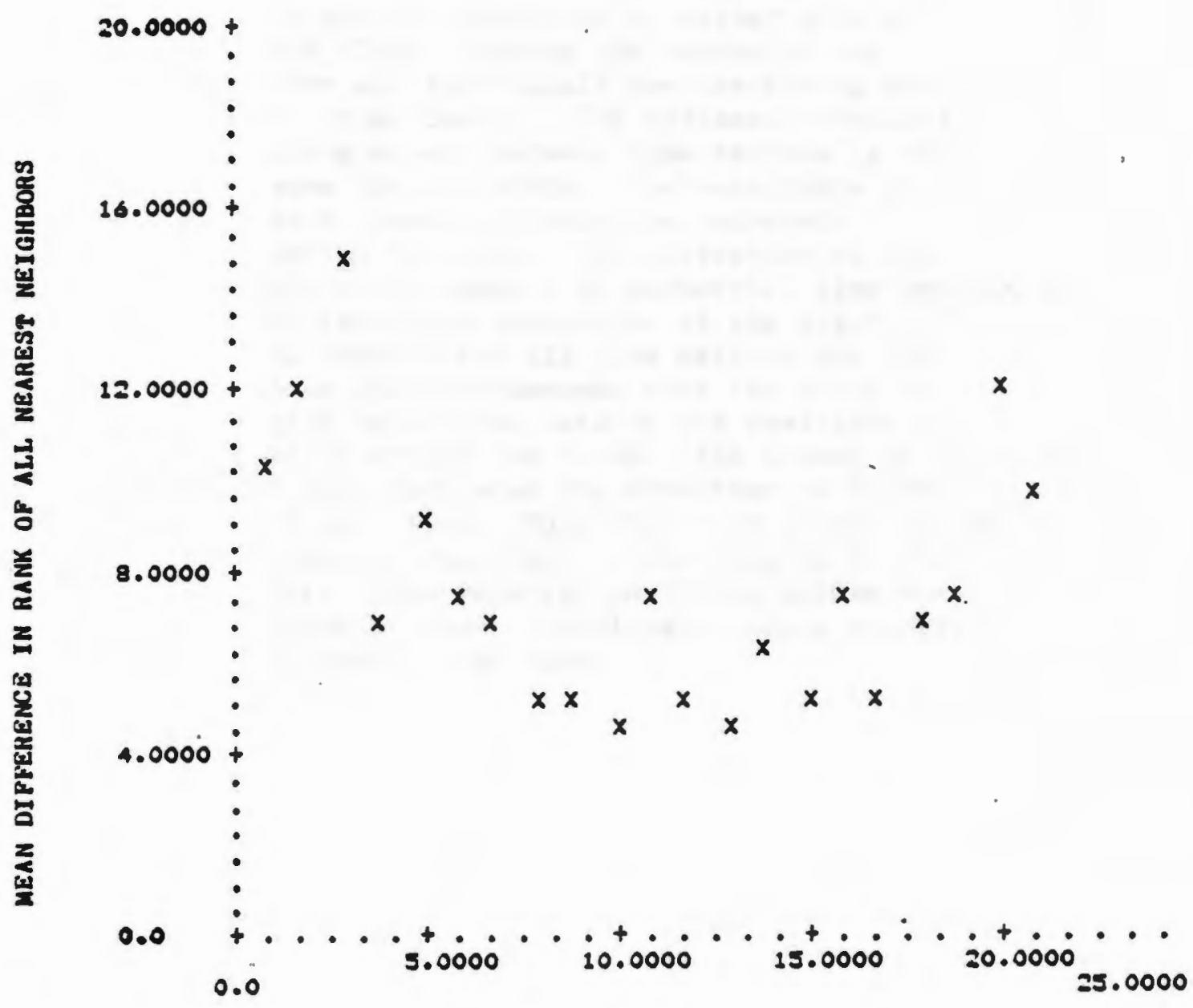

DOUINANCE RANK OF REFERENCE BIRD 
Figure 22. Flight paths of the central core of a flock ( ), with two individuals

( $\Delta$ and 0 ) travelling to efther side of the flock. During the course of the turn all individuals are describing arcs of equal radius. The distance travelled along an arc between time periods is the same for all birds. The subscripts on each symbol indicate the intervals during the turn. The alteration of open any solid symbols at sequential time periods is to facillate inspection of the figure. At each of the six time perfods the $X-Y$ axes are superimposed over the flock to give relational data on the positions of birds within the flock. The arrows on the $X$ axis indicates the direction of travel of the flock. Note that bird starts at the right of the flock, while bird is to the left. The relative positions within the flock of these individuals rotate counterclockwise over time. 


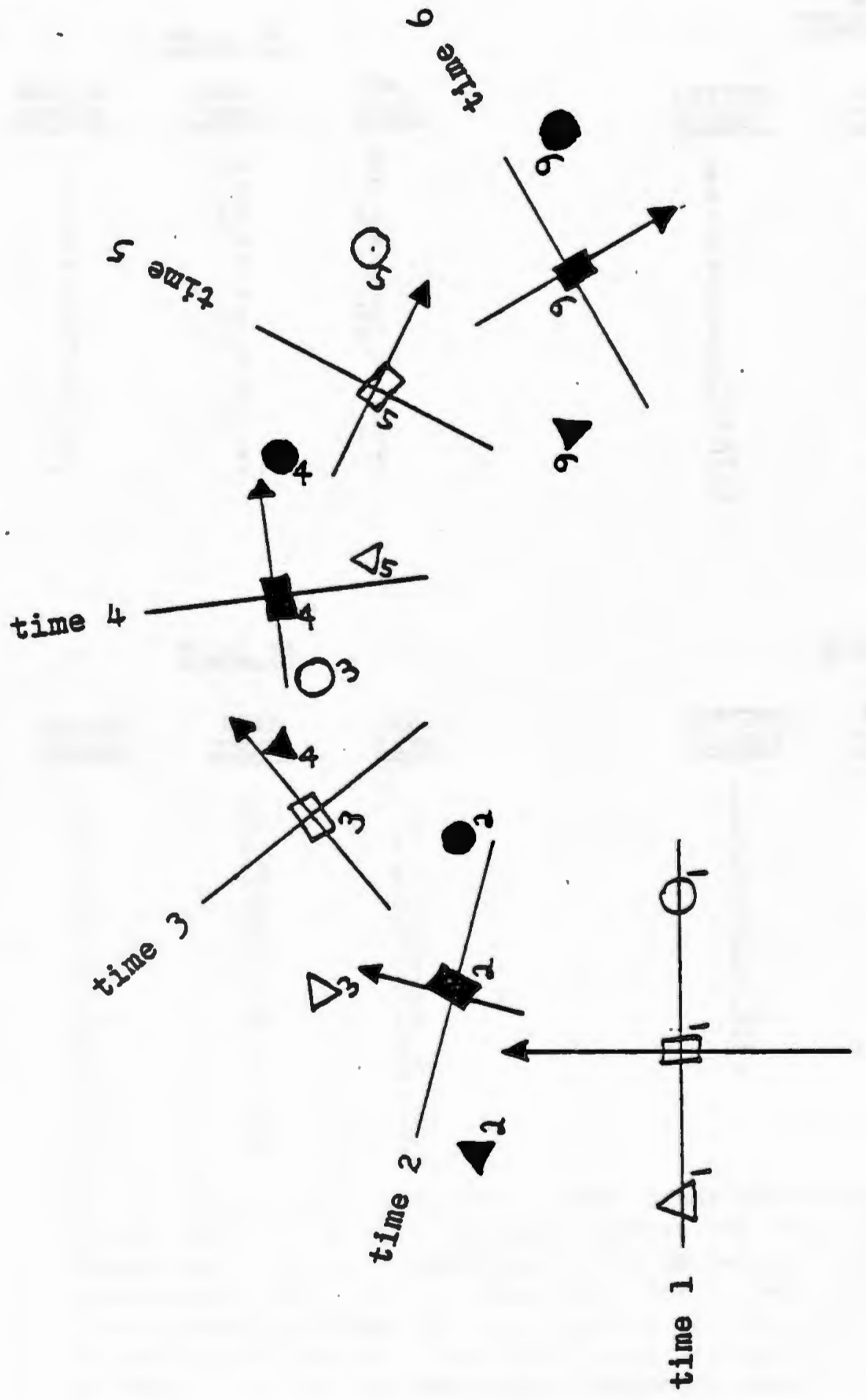


TIAT:1

IRIA工 路
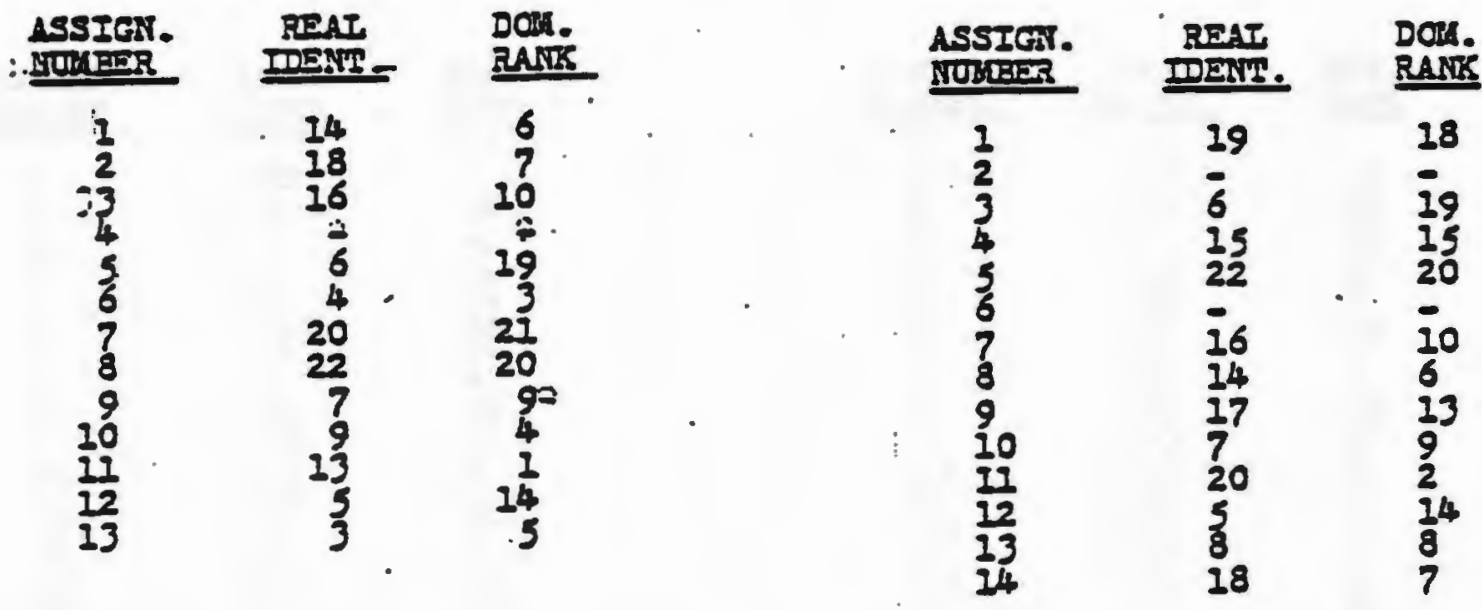

- Parar \#6

PRIA 刍?

\begin{tabular}{|c|c|}
\hline ASSIGA. & REAT \\
\hline
\end{tabular}

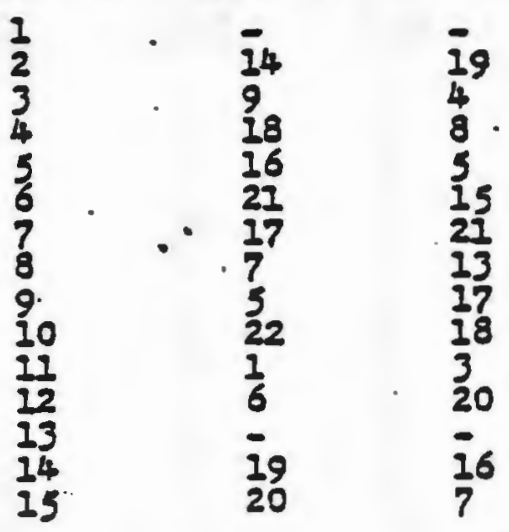

ASSIGI.

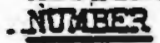

포단.

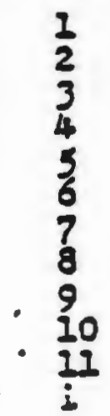

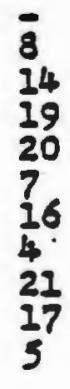

21

5
Dore.

RARE

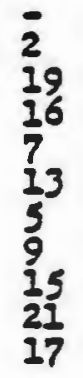

Table 1. Composition os flocks. Three types of information are listed for each trial. Assigned numbers are trial specific levels used only to distinguish birds as unique in the series of photographs for a trial. Identification numbers (ID) were given to each bird and used for the duration of the study to identify specific individuals. Each bird in an airborne flock which could be identified has the associated dominance rank of that individual listed. 
MRTAT 48

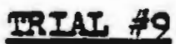

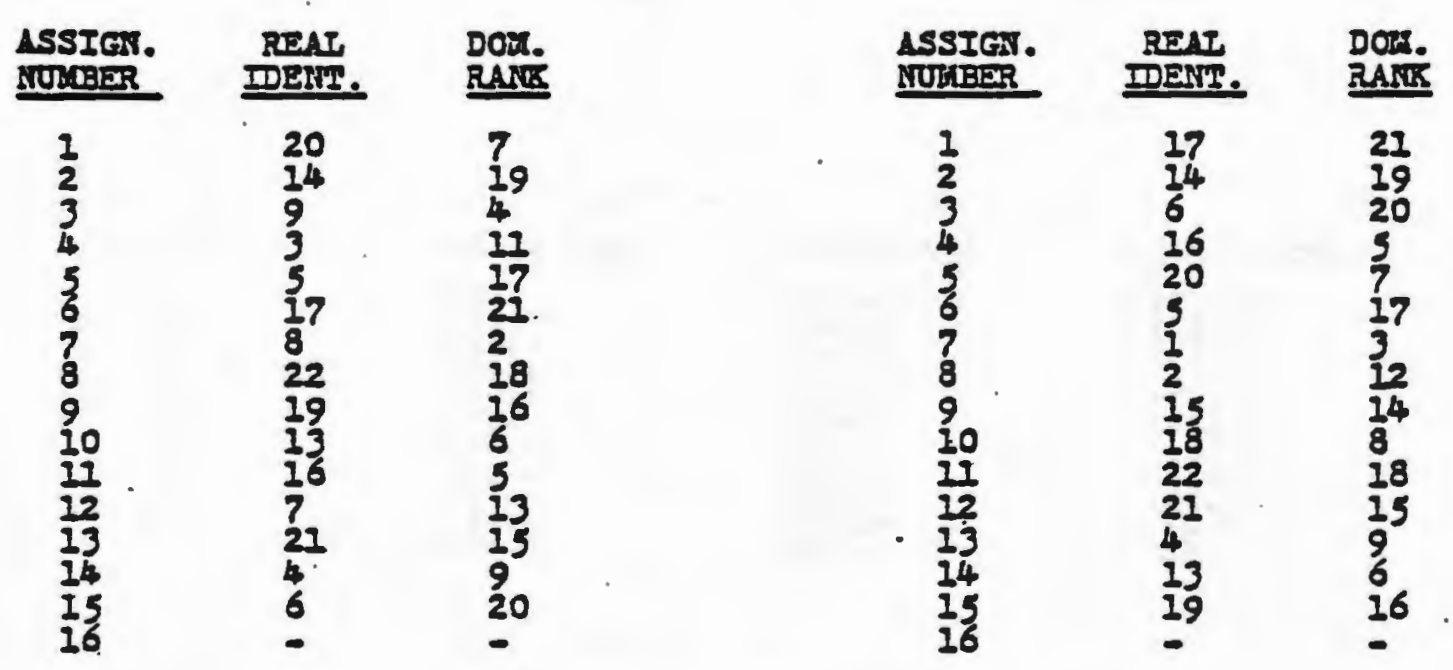

\section{IRIA工 순10}

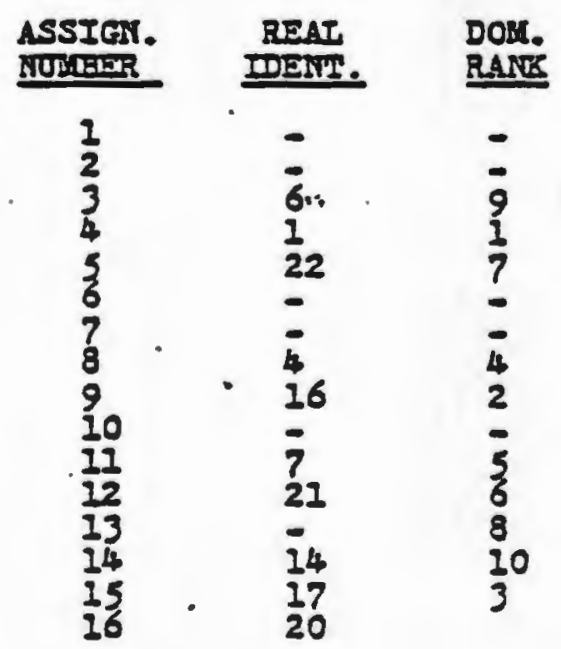


FRATE : 1

\begin{tabular}{|c|c|c|c|}
\hline 8180 & $x-4 x i s$ (cm) & $Y-4 \times I S(c=)$ & $z-4 x I S$ \\
\hline $\begin{array}{r}\frac{1}{3} \\
3 \\
4 \\
5 \\
6 \\
7 \\
8 \\
73 \\
11 \\
11\end{array}$ & 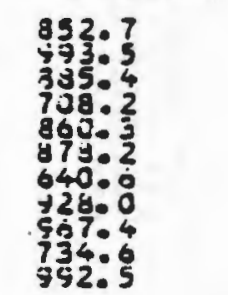 & 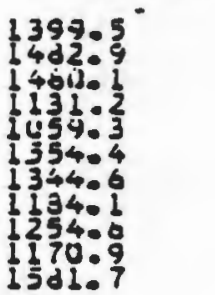 & 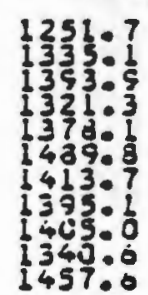 \\
\hline
\end{tabular}

\begin{tabular}{|c|c|c|c|}
\hline \multicolumn{4}{|c|}{ FR } \\
\hline 31 只0 & $x-4 x 15$ & $Y-A X i S$ & $2-4 \times 15$ \\
\hline $\begin{array}{r}2 \\
2 \\
3 \\
4 \\
5 \\
0 \\
7 \\
0 \\
9 \\
10 \\
11\end{array}$ & $\begin{array}{l}127.5 \\
1297: 3 \\
1219: 5 \\
1011.5 \\
1150: 1 \\
11050 \\
1224.5 \\
1203.9 \\
124502 \\
1050.6 \\
1312.5\end{array}$ & 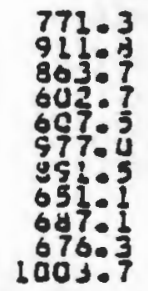 & $\begin{array}{l}1196.2 \\
1277.8 \\
1298: 3 \\
12590.5 \\
1308: 4 \\
142700 \\
131501 \\
1323.5 \\
127006 \\
125204 \\
1402.1\end{array}$ \\
\hline
\end{tabular}

FRAIAE U 3

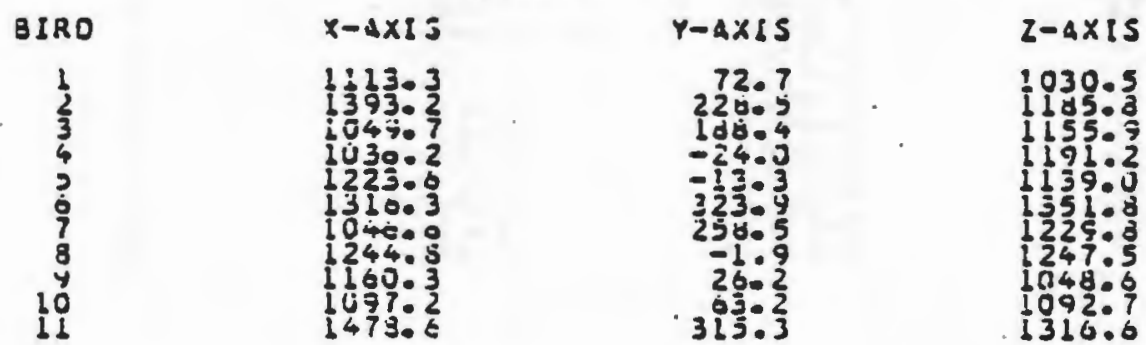

Table II. Real-space positions of birds. The displacement on the $X, Y$, and $Z$ azes of the Cartesian coordinate systems defined by the optical axes of the cameras are listed for each bird in trial seven, for each of the six points in time at which the flock was photographed. 
FindME 4

FRAME \& 5

BIRO $x-4 x<5$

FR $\triangle A E * b$

$B$ เกิU
1
$\frac{1}{2}$
3
4
5
3
7
3
5
60
11

$$
x-4 \times 15
$$

$y-4 \times 15$

Z-AXIS
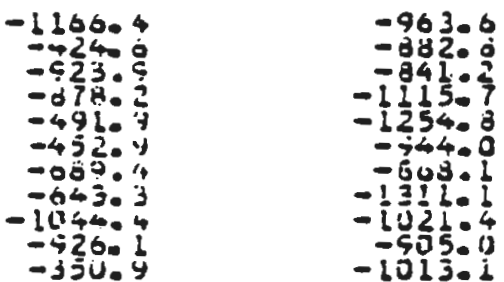

587.4 073.2 004.12 975. 683.7 408.8 620.7 8co. 0 
APPENDIX A

Descriptions of birds used in the study. The Identification number of each bird is shown to the left of each description.

BIRD

1

2

3

4

5

6

7

8

9

10

11

12

13

14

15

16

17

18

19

20

21

22

\section{DESCRIPTION}

red with white primarles and breast

red with black bars and gray belly

gray with red nape, Ilght gray primarles and tall

dark red with white primarles and tall

gray with black bars and tail, white primaries

gray with black tall

gray with black tail and primaries

red and white mottled

gray mottled, white nape

brown with white head

black with white nape and breast

black with alternating white and black prlmaries

black with white chin and belly

black with white nape and back

black with white chin, primaries; dark tail

black with white chin, primarles, light tall

white with black chin and breast

white and black mottled

white with red chin

brown with white primaries

black with white primaries; alternating white and black tall

* note with these descriptions, chin refers to the chin and throat. 
APPENDIY B

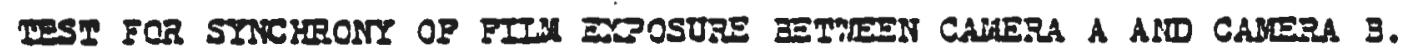

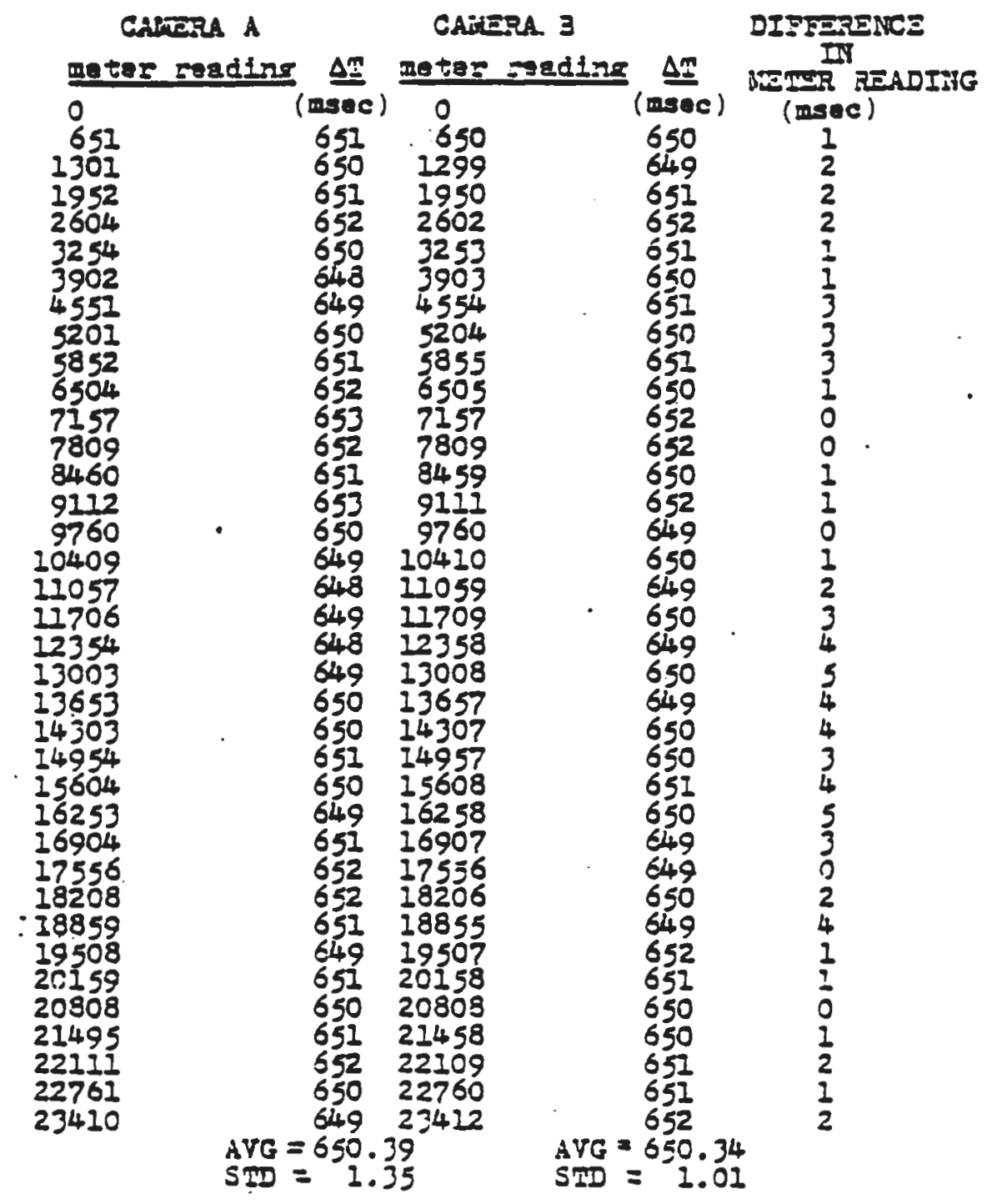




\section{A POENDIK C}

DISTANCES AND ANGULAR BETATIONSHIPS EETHEEN BIRDS IN MODEI FLCCX satarl measured distarce betreen bird gefrs..... 121.920x actonl masured angle between birds...... 30.0 degress

ERAME \#1

3IFD

P.II DISTANCE

$1-2 \quad 176.53 \mathrm{~cm}$

14 126.21em

3-2 122.3500

$34.124 .5 \mathrm{~cm}$

$5-6 \quad 112.5900$

5-8 $125.65 \mathrm{~cm}$

$7-6$ 125.18cm

$7-8 \quad 177.63 \mathrm{~cm}$

AVG 121.46

5
VAR
27.25

4.0\% $3380 R$.
FRAVIR

BIR

PAIR DISTANCE

1 -2 115.5402

$1+124.28 \mathrm{~cm}$

3-2 123.970m

$34210.34 \mathrm{~cm}$

$5-6.176 .25 \mathrm{~cm}$

5-8 $224.26 \mathrm{~cm}$

$7-6 \quad 213.95 \mathrm{~cm}$

7-3 $213.49 \mathrm{~cm}$

AVG 118.39

STD 5.48

2. $9 \%$ ERROR
BRADE F3

BIR

PAIR DISTARE

1-2 226.72cm

$14 \quad 127.93 \mathrm{~cm}$

3-2 $123.95 \mathrm{~cm}$

$5-6 \quad 127.45 \mathrm{~cm}$

5-9 $124.28 \mathrm{~cm}$

$7-6 \quad 126.11 \mathrm{~cm}$

$7-8 \quad 127.94 \mathrm{~cm}$

AVG 125.70

STD 2.30

3. IT ER?.0R
FRALE : F4

DIR

PAIR DISTANEE

1-2 $129.72 \mathrm{~cm}$

$1-115.42 \mathrm{~cm}$

3-2 122.22cm

$34 \quad 122.1200$

5-6 $128.47 \mathrm{~cm}$

$5-8 \quad 113.56 \mathrm{~cm}$

7-6 124.58c=

$7-3 \quad 124.86 \mathrm{ce}$

AVG 120.67

VAR - $4 \underline{.199}$

$1.0 \% 33302$

Fake $: 35$

\section{AIT FRAMES}

BIRD

PAIR DISTALCE

BIRD AVERACE

PATP DISTANICE STD ANGIS STD

$\begin{array}{ll}1-2 & 133.750 m \\ 1-4 & 117.35 \mathrm{~cm}\end{array}$

$\begin{array}{llll}1-2 & 124.48 \mathrm{~cm} & 7.24 & 28.3^{\circ} 2.10^{\circ}\end{array}$

$14 \quad 122.25 \mathrm{~cm} 4.95 \quad 32.71 .34$

$3-2 \quad 118.85 \mathrm{~cm} \quad 6.45 \quad 33.11 .27$

$3-4 \quad 117.47 \mathrm{~cm} 5.23 \quad 27.21 .77$

5-6 $122.2702 \quad 6.55 \quad 34.12 .21$

$\begin{array}{llll}5-8 & 123.47 \mathrm{~cm} 5.33 \quad 30.6 \quad 1.84\end{array}$

$7-6 \quad 118.39 \mathrm{~cm} 7.57 \quad 28.32 .32$

$\begin{array}{ll}5-6 & 121.87 \mathrm{~cm}\end{array}$

5-8 $129.56 \mathrm{~cm}$

7 -6 106.07 em

$7-8$ 115. 54cm

$7-8$ 119.890m 5.56

29.21 .08

AVG 219.74

STD 10.08

VAR 10I.60

1.8\% ERTOR 


\section{APPENDIX D}

Distances between birds at the six time periods (Frames) in trial seven. Mean separation distance, and the mean distance to first nearest neighbor are shown for each time period. Identification numbers of birds forming nearest neighbor pairs, and associated distances, are also listed.

FRAYE * 1

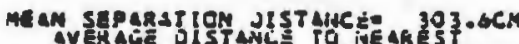

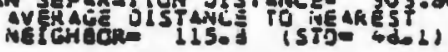

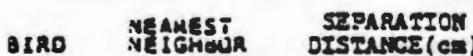<smiles>CCCOCCOCCO</smiles>

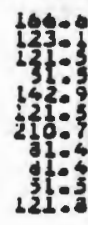

Aname $: 3$

\section{FRAME -2

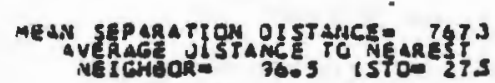

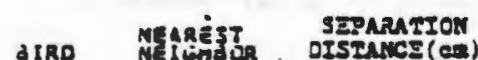

$$
\begin{array}{r}
\frac{1}{2} \\
3 \\
6 \\
5 \\
6 \\
7 \\
10 \\
10
\end{array}
$$$$
\begin{array}{r}
19 \\
7 \\
20 \\
11 \\
3 \\
3 \\
3 \\
6
\end{array}
$$$$
\text { 139.6 }
$$

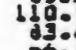$$
132 .
$$$$
76
$$

$132: 8$

PRAME

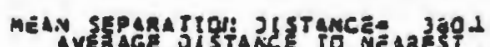

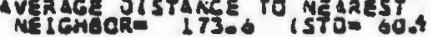

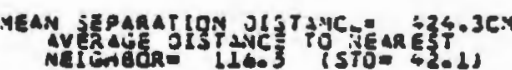

\begin{tabular}{|c|c|c|}
\hline 5880 & $\begin{array}{l}\text { NESAREST } \\
\text { NAETACR }\end{array}$ & $\begin{array}{l}\text { SEPARATIOK } \\
\text { DISTANES (CN) }\end{array}$ \\
\hline $\begin{array}{r}\frac{1}{3} \\
3 \\
5 \\
5 \\
9 \\
4 \\
10 \\
11\end{array}$ & - & 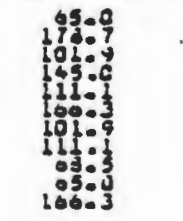 \\
\hline
\end{tabular}

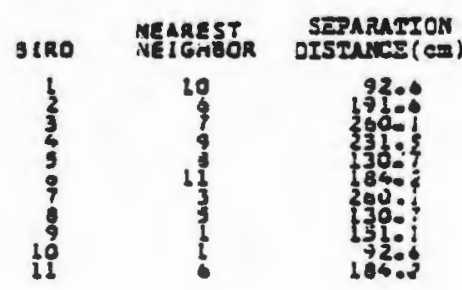


FRATE I 5

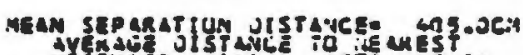

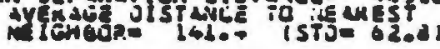

\begin{tabular}{|c|c|c|}
\hline 20 & NEITEATOR & cI \\
\hline 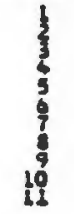 & : & 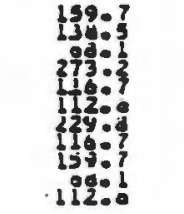 \\
\hline
\end{tabular}

PRAME -

ME AM SEPARATY COA JT ST YNCE

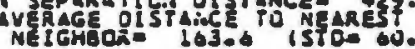

\begin{tabular}{|c|c|c|}
\hline 8120 & $\begin{array}{l}\text { MEAREST } \\
\text { NEIGNGCA }\end{array}$ & EIJUARE (E) \\
\hline 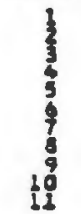 & 总 & 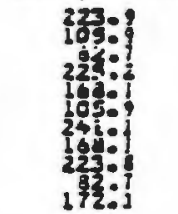 \\
\hline
\end{tabular}




\section{APPENDIX E}

Headings in the horizontal and vertical planes of the flock, and of all birds in the flock. Distance travelled and heading maintained by birds between each pair of sequential time frames in the series of photographs in trial seven are shown. The mean heading of all birds (flock heading) and assoclated standard deviation (STD) are listed. 
hORIZONTAL PLANE OISPLACEMENT

\section{$7 / 25 / 80$}

TRIAL 7

FRAME 1 TO FRAME 2

FLOCK HEADING $=300.20 \quad S T C=6.15 \mathrm{i}$.

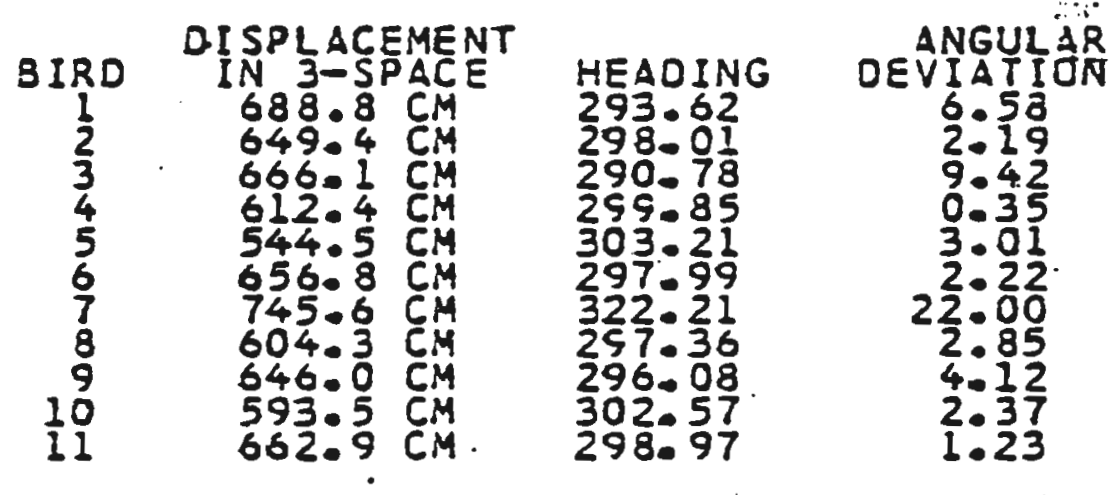

FRAME 2 TO FRAME 3

FLOCK HEADING $=271.80$ STD $=5.08$

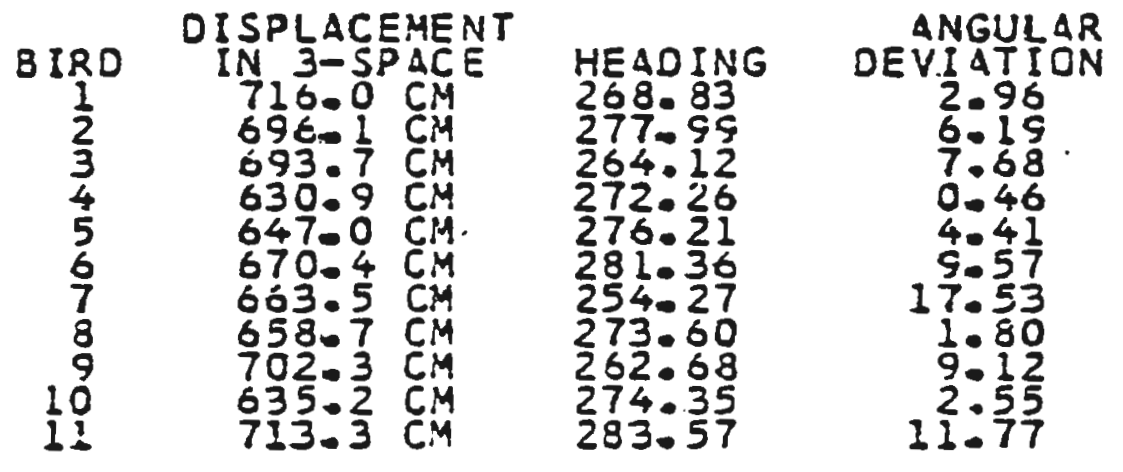


FRAME 3 TO FRAME 4

FLOCX HEAOING $=239.34$ STD $=5.22$

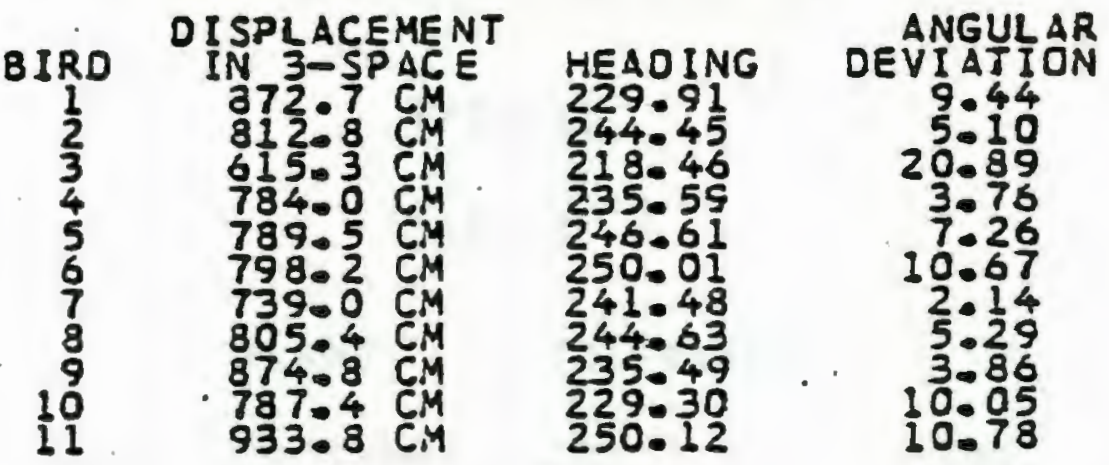

fRAME 4 TO FRAME 5

FLOCX HEADING $=209.84^{\circ}$ STD $=2.91$

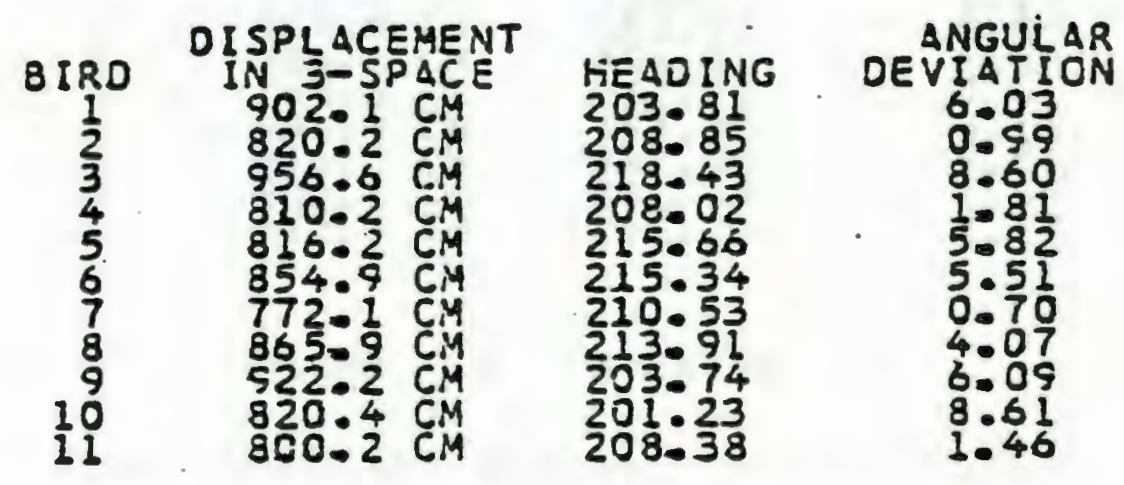

FRAME 5. TO FRAME 6

FLOCK HEADING $=185.02$. STD $=1.60$

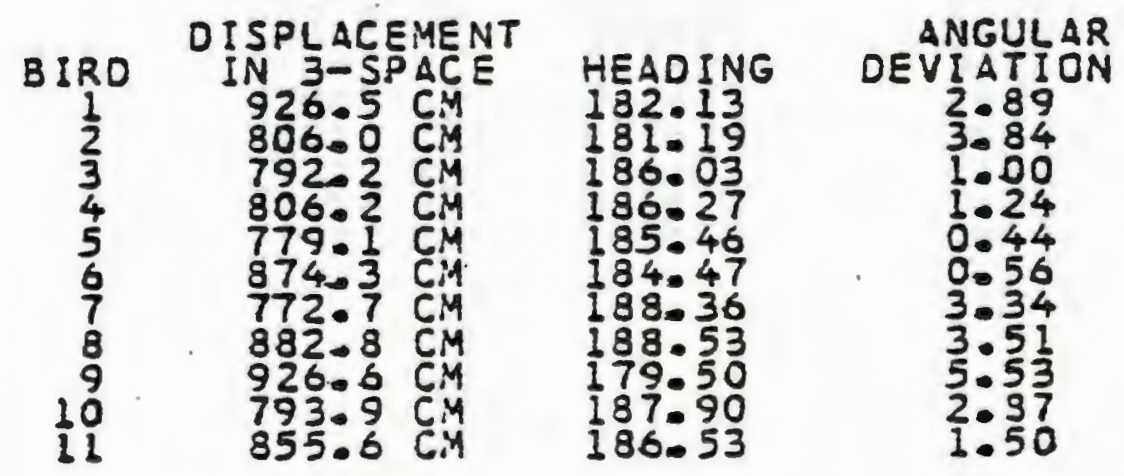


VERTICAL PLANE DISPLACEMENT

$7 / 25 / 80$

TRIAL \# 7

FRAME I TO FRAME 2

FLOCK HEADING $=353.04^{\circ}$ STD $=i .32$

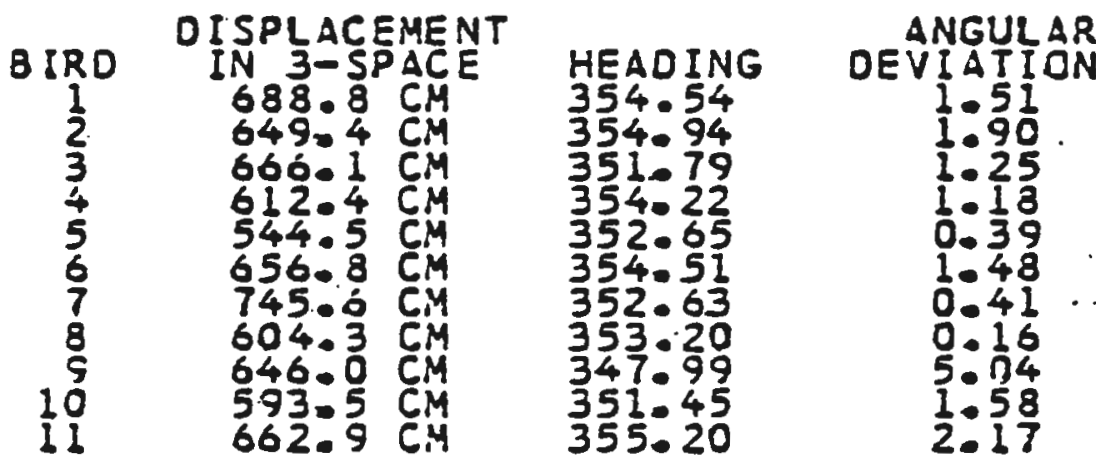

FRAME, 2. TO FRAHE 3

FLOCK HEADING $=349.64$ STD $=1.72$

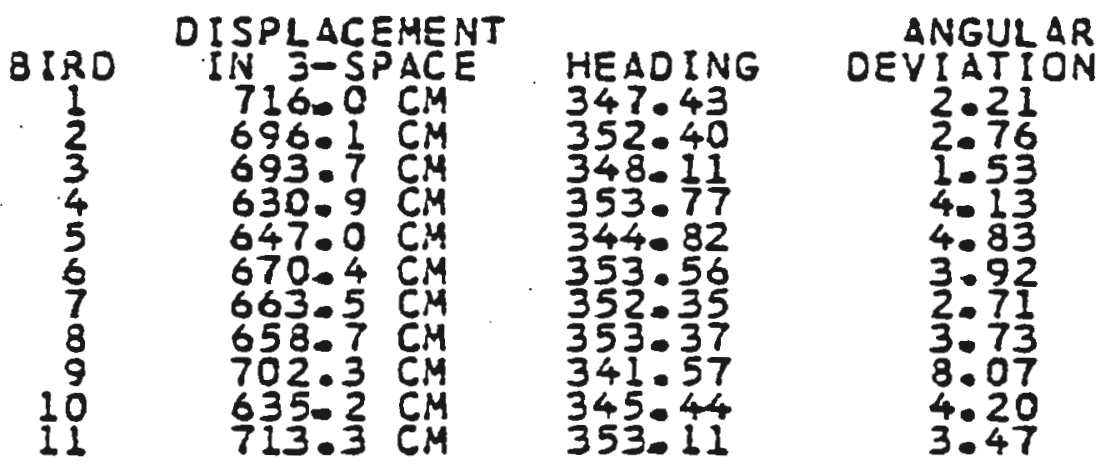


FRAME 3 TO FRAME 4

FLOCK HEADING $=346.29$ STD $=1.54$

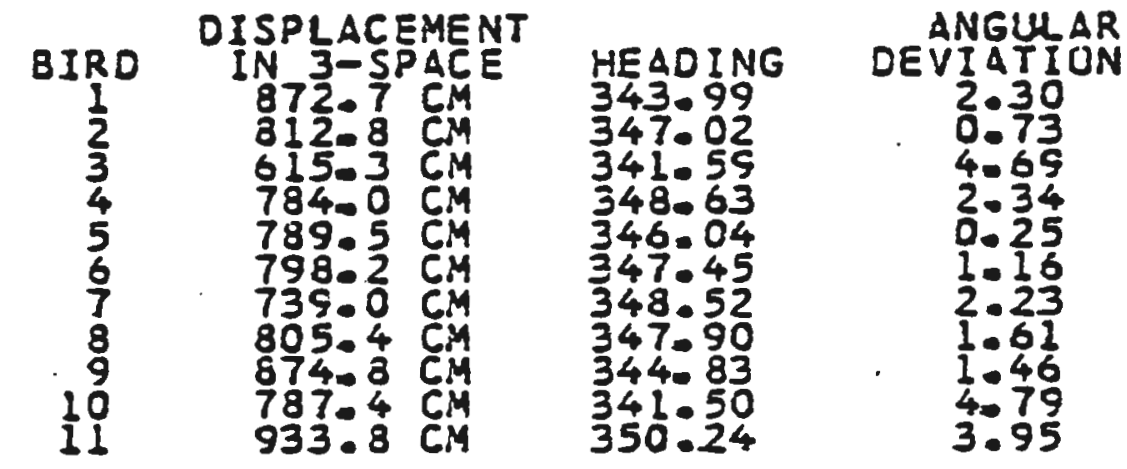

FRAME 4 TO FRAME 5

FLOCK HEAOING $=347.09$ STD= 1.72

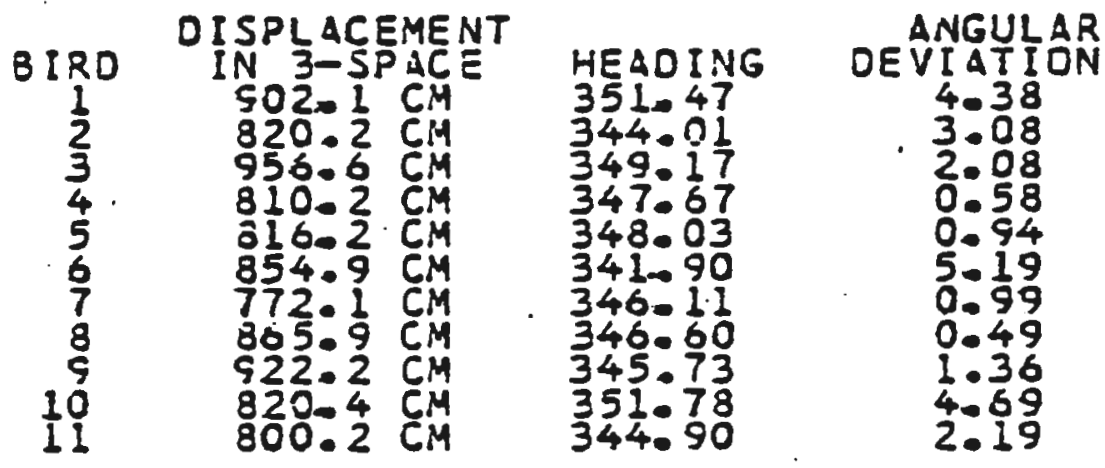

FRAME 5 TO FRAME 6

FLOCK HEADING $=349.25$ STD $=1.84$

$\begin{array}{cccc} & \text { DISPLACEMENT } & & \text { ANGULAR } \\ \text { BIRD } & \text { IN 3 S SPACEE } & \text { HEAOING } & \text { OEVIATION } \\ 1 & 926.5 C M & 355.76 & 6.51 \\ 2 & 806.0 C M & 347.15 & 2.10 \\ 3 & 792.2 C M & 352.11 & 2.86 \\ 4 & 806.2 C M & 347.14 & 2.11 \\ 5 & 779.1 C M & 349.49 & 0.21 \\ 6 & 874.3 C M & 344.54 & 4.71 \\ 7 & 772.7 C M & 346.90 & 2.35 \\ 8 & 882.8 C M & 347.29 & 1.96 \\ 9 & 926.6 C M & 348.57 & 0.68 \\ 10 & 793.9 C M & 352.41 & 3.16 \\ 11 & 855.6 C M & 349.91 & 0.66\end{array}$




\section{APPENDIX F}

Dominance matrices for the three time periods during which the flocks were photographed. Each matrix consists of data from

six 90 minutes observation sessions. The ratio of the number of wins to the number of losses that each bird had as a result of its interactions with other flock members was used to establish dominant and subordinate birds in the airborne flocks. 
JUt: 8 - JUR 21

BTR

Losses

01, $02 \quad 03 \quad 04$ 05 $06 \quad 07 \quad 080910 \quad 11 \quad 12 \quad 13 \quad 14 \quad 15161718 \quad 1920 \quad 2122$

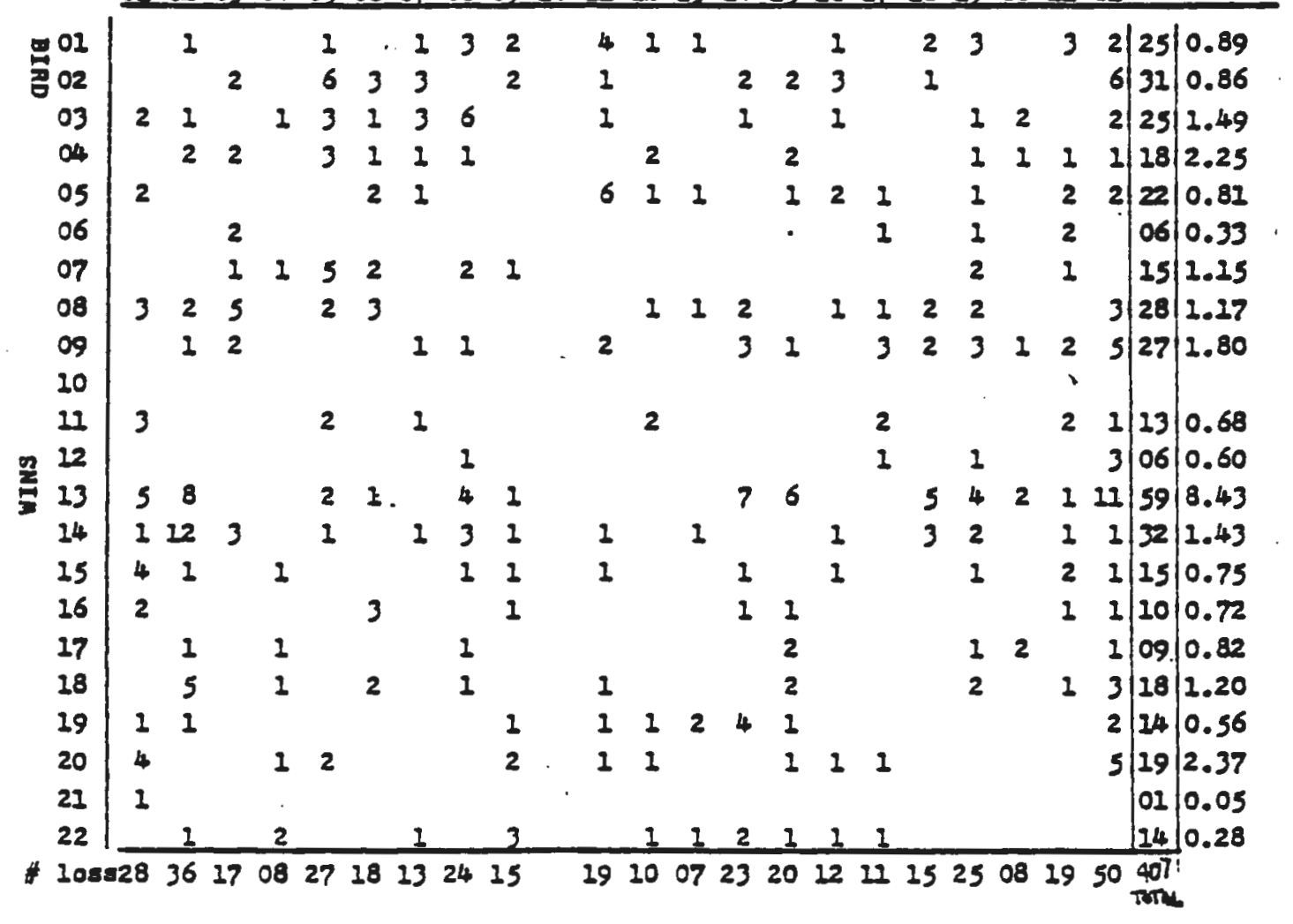


JUएक 23 - JUII 10

$\underset{3}{3}$

\begin{tabular}{|c|c|c|c|c|c|c|c|c|c|c|c|c|c|c|c|c|c|c|c|c|c|c|c|}
\hline 01 & & & 2 & 2 & 1 & & 2 & & 1 & 7 & 1 & 1 & 2 & 3 & 1 & 1 & 4 & 1 & 2 & 2 & 2 & 35 & 3.18 \\
\hline 종 02 & & & & & 1 & 1 & 1 & & 1 & 1 & & 1 & 6 & 2 & 4 & 2 & & 2 & & 1 & 3 & 26 & 0.89 \\
\hline 03 & 2 & & & 1 & & 4 & 2 & 2 & & 2 & 1 & & & 1 & & 3 & 1 & & 1 & 1 & 3 & 24 & 1.26 \\
\hline o4 & & & 1 & & & 2 & & & & 2 & 2 & & & 1 & & & 1 & & & & 1. & 09 & 0.60 \\
\hline 05 & & 1 & 1 & & & 2 & 2 & & & 2 & 1 & 3 & & 1 & & . & 2 & & & & 2 & 17. & 0.65 \\
\hline 06 & & & 4 & & & & & & & & & & & & 1 & & & 1 & & $i$ & 3. & 20 & 0.48 \\
\hline 07 & & & & & & 1 & & 2 & & & & & 1 & 2 & & 1 & & 1 & & & 1 & 09 & 0.60 \\
\hline 08 & 1 & 1 & 9 & 5 & 5 & 3 & 1 & & 1 & 9 & 4 & 1 & & & 2 & 2 & 5 & 3 & 1 & & 4 & 66 & 4.70 \\
\hline 09 & & & & & 1 & & & 1 & & 1 & & & & & 1 & & & & 1 & & 2 & or & 0.58 \\
\hline 10 & & & & & & & & & & & & & & & & & & & & & & & \\
\hline 11 & 1 & & & & 1 & 1 & & & & & 2 & & & 1 & 1 & & & & 1 & 1 & 2 & 21 & 0.32 \\
\hline 을 12 & & 1 & & & & & & & & & & & & & & & 1 & & & 2 & & 04 & 0.28 \\
\hline$=13$ & & 2 & & 1 & 8 & & & 1 & 5 & 2 & & & 2 & 6 & & & 2 & 4 & 1 & 1 & 2 & 37 & 2.47 \\
\hline$v_{4}$ & & 9 & 1 & & 2 & 1 & & & & & & & & 2 & 1 & 1 & & & & & 2 & 19 & 0.91 \\
\hline 15 & & 2 & 1 & 2 & 3 & 1 & 4 & & & & & & 2 & & & 7 & & & 1 & & 2 & 25 & 0.89 \\
\hline 16 & 1 & 2 & & & & 1 & & 1 & 3 & & 1 & & & 1 & 2 & & & 1 & 1 & 2 & 4 & 23 & 1.79 \\
\hline 17 & 3. & & & 1 & 1 & 1 & & 1 & & 1 & & & 2 & 1 & & & & 1 & & 2 & & 14 & 0.50 \\
\hline 18 & 1 & 3 & & 1 & 1 & & & & & 3 & 1 & 1 & & 2 & 2 & 2 & & & 2 & & 2 & 21 & 0.88 \\
\hline 19 & & $I$ & & & & & & 1 & & & 1 & 2 & & 1 & & 1 & & & 1 & & & 08 & 0.38 \\
\hline 20 & 1 & 7 & & 2 & 2 & 2 & 2 & 4 & 1 & 2 & $I$ & 6 & 5 & 2 & & 4 & 4 & 6 & & 2 & 2 & 55 & 4.23 \\
\hline 21 & 1 & & & & & 1 & & 1 & & & 1 & & & & & 1 & & & & & & 05 & 0.31 \\
\hline 221 & & & & & & & 1 & & & 1 & & & & 1 & & 3 & 3 & 1 & & & & 10 & 0.27 \\
\hline
\end{tabular}




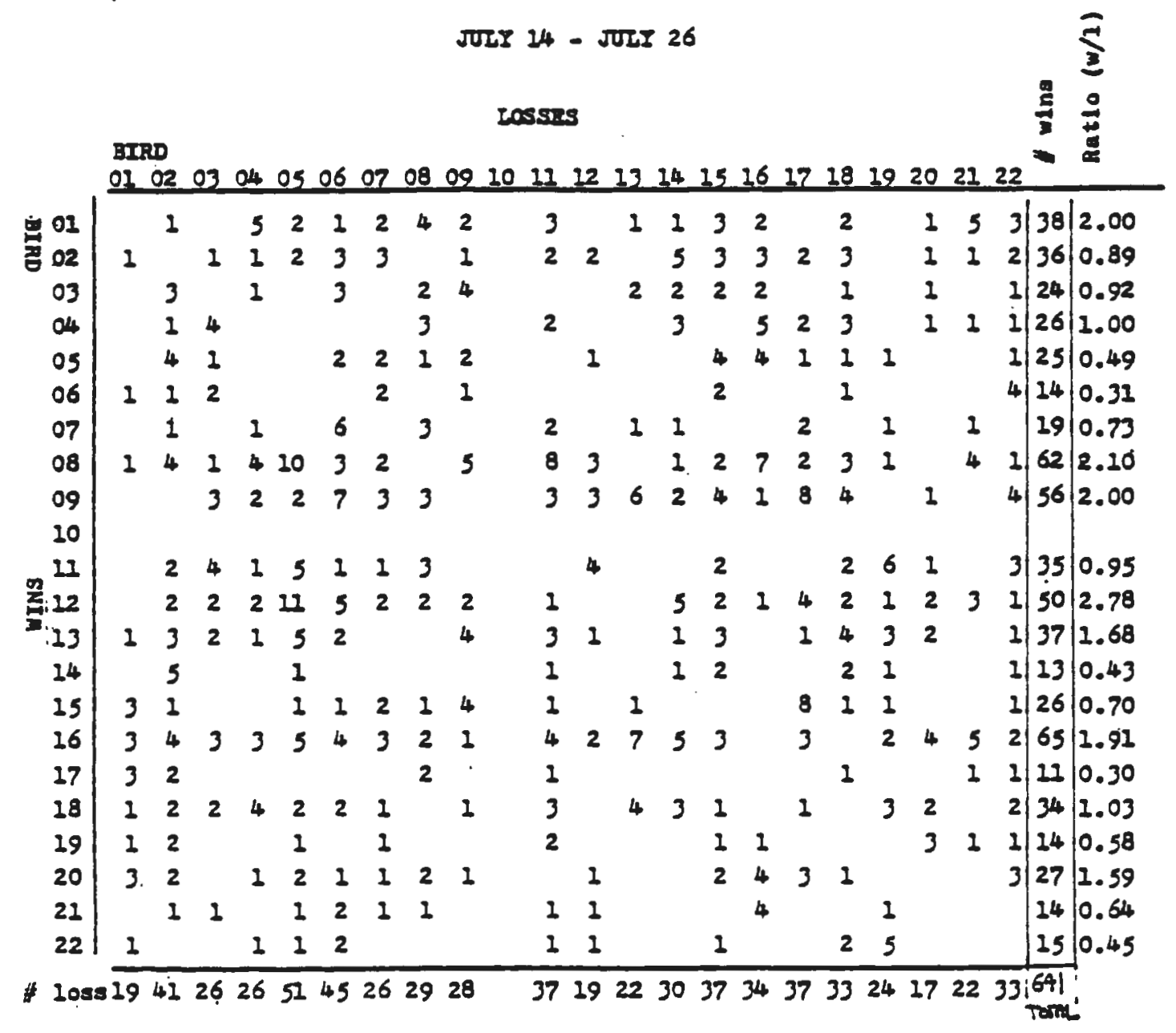

